\author{
UNIVERSIDADE DE SÃO PAULO \\ INSTITUTO DE PSICOLOGIA \\ PROGRAMA DE PÓS GRADUÇÃO EM PSICOLOGIA \\ EXPERIMENTAL
}

LUANA ZEOLLA INHAUSER

Controle por Unidades Verbais Mínimas e Extensão da Unidade Ensinada: O Efeito do Treino de Fonemas na Emergência da Leitura Recombinativa. 


\title{
Controle por Unidades Verbais Mínimas e Extensão da Unidade Ensinada: O Efeito do Treino de Fonemas na Emergência da Leitura Recombinativa. ${ }^{1}$
}

\author{
(Versão Original)
}

\begin{abstract}
Dissertação apresentada ao Instituto de Psicologia da Universidade de São Paulo como parte dos requisitos necessários à obtenção do título de Mestre em Psicologia.

Área de concentração: Análise Experimental do Comportamento.

Orientadora: Prof ${ }^{\mathrm{a}}$. Dr ${ }^{\mathrm{a}}$. Maria Martha Costa Hübner
\end{abstract}

São Paulo 2012

\footnotetext{
${ }^{1}$ Trabalho financiado pelo Conselho Nacional de Desenvolvimento Científico e Tecnológico (CNPq) sob a forma de Bolsa de Mestrado (número 134784/2010-3).
} 
AUTORIZO A REPRODUÇÃO E DIVULGAÇÃO TOTAL OU PARCIAL DESTE TRABALHO, POR QUALQUER MEIO CONVENCIONAL OU ELETRÔNICO, PARA FINS DE ESTUDO E PESQUISA, DESDE QUE CITADA A FONTE.

Catalogação na publicação

Biblioteca Dante Moreira Leite

Instituto de Psicologia da Universidade de São Paulo

Inhauser, Luana Zeolla.

Controle por unidades verbais mínimas e extensão da unidade ensinada: o efeito do treino de fonemas na emergência da leitura recombinativa / Luana Zeolla Inhauser; orientadora Maria Martha Costa Hübner. -- São Paulo, 2012.

$108 \mathrm{f}$.

Dissertação (Mestrado - Programa de Pós-Graduação em Psicologia. Área de Concentração: Psicologia Experimental) Instituto de Psicologia da Universidade de São Paulo.

1. Leitura. 2. Leitura recombinativa 3. Fonema 4. Matching to sample 5. Estímulos I. Título. 


\section{FOLHA DE APROVAÇÃO}

\section{Luana Zeolla Inhauser}

Título:

Controle por Unidades Verbais

Mínimas e Extensão da Unidade

Ensinada: O Efeito do Treino de

Fonemas na Emergência da

Leitura Recombinativa

Dissertação apresentada ao Instituto de Psicologia da Universidade de São Paulo como parte das exigências para obtenção do título de Mestre em Psicologia.

Área de Concentração: Psicologia Experimental

Aprovado em:

\section{Banca Examinadora}

Prof. Dr.

Instituição:

Assinatura:

Prof. Dr.

Instituição:

Assinatura:

Prof. Dr.

Instituição:

Assinatura:

Prof. Dr.

Instituição:

Assinatura:

Prof. Dr.

Instituição:

Assinatura: 


\section{Agradecimentos}

Muitas pessoas especiais participaram dessa jornada!!

À minha orientadora, que me abraçou, acolheu, apoiou e possibilitou inúmeros caminhos e desafios na minha vida acadêmica e profissional!! O meu muito obrigada por toda a parceria, pelas oportunidades de produção de conhecimento, pelo carinho e pela atenção, que foram fundamentais para conclusão dessa jornada!!! O meu agradecimento também pela oportunidade de compartilhar com ela momentos importantes de vida pessoal e pela convivência sempre alegre e afetiva. Carinho e admiração imensos!!!!

Ao meu marido, pelo amor, carinho, atenção, disponibilidade, paciência e principalmente pelo apoio incondicional em todos os momentos! Sua presença faz a minha vida muito mais feliz!! Te amo!!

Aos Meus pais, que tornaram possíveis todos os caminhos que me trouxeram até aqui, e que mesmo à distância compartilharam comigo todas as etapas dessa jornada!!! Amo vocês!

À minha avó Nil, por sua presença e apoio em todos os momentos da minha vida e à Nathy pela alegria e carinho sempre!

À Ariene, pela disponibilidade, parceria, ajuda, dedicação, e principalmente por todos os sorrisos, choros, alegria, horas de conversas, discussões teóricas e comemorações!! Amizade enorme!!

À Ana Luiza, pela convivência sempre acolhedora, pela alegria a cada conquista e pelo apoio nos momentos difíceis, pelas trocas de experiências pessoais e profissionais e por tornar a coleta de dados muito mais divertida!!

Ao Rafa, Robson, Dani, Larissa e Marina por todos os momentos compartilhados!!

Aos colegas do LEOV e principalmente ao Marcos, com seu imbatível senso de humor!

Aos membros da Comissão Examinadora Professor João Juliani e Professor Marcelo Benvenuti pelo tempo dispensado e valiosas contribuições.

À Professora Deisy das Graças de Souza por disponibilizar o software GEIC para a realização do presente estudo.

À Mainá Santanta e ao Leonardo Marques por todo auxílio prestado durante todo o processo de programação e utilização do GEIC na coleta de dados.

À Professora Elenice Hanna, por esclarecer as dúvidas relativas ao procedimento.

À Sônia, secretária do PSE, pela pronta ajuda em todas as situações!

À todos os professores que contribuíram para minha formação! 


\section{RESUMO}

INHAUSER, L. Z. Controle por unidades verbais mínimas e extensão da unidade ensinada: o efeito do treino de fonemas na emergência da leitura recombinativa. 2012. 108f. Dissertação (Mestrado). Instituto de Psicologia, Universidade de São Paulo, São Paulo, 2012.

A leitura é uma habilidade complexa que envolve uma rede de relações entre estímulos e entre estímulos e respostas. Para que um repertório de leitura seja considerado proficiente, o leitor deve apresentar a leitura de novas palavras, não diretamente ensinadas e formadas pela recombinação de unidades aprendidas previamente em outras relações (leitura recombinativa). Um requisito fundamental para o desenvolvimento da leitura recombinativa é, portanto, o estabelecimento de um responder diferencial sob controle das unidades menores, como por exemplo, sílabas, letras ou fonemas, componentes das palavras. O objetivo do presente trabalho foi investigar o efeito do treino direto de fonemas, combinado com um treino de palavras, sobre a emergência da leitura recombinativa de palavras inteiras. Verificou-se também se o momento de inserção do treino de fonemas no procedimento de ensino, se prévio (Condição I) ou sobreposto (Condição II) ao treino de palavras, foi uma variável relevante para a emergência da leitura recombinativa. Os participantes do estudo foram 12 estudantes universitários, com idades entre 18 e 37 anos, e que foram distribuídos igualmente entre três Condições Experimentais: a) Condição I - Treino Prévio de Fonemas; b) Condição II - Treino Sobreposto de Fonemas; c) Condição IIITreino de palavras. A Condição III foi realizada com o objetivo permitir uma comparação entre o desempenho dos participantes que foram submetidos ao treino de fonemas (Condições I e II) com o dos participantes que foram expostos somente ao treino de palavra (Condição III). Os estímulos utilizados no estudo consistiram de palavras faladas (A) e palavras escritas com um pseudoalfabeto (C), bem como de fonemas e letras do pseudoalfabeto, correspondentes a estes fonemas. Os procedimentos empregados tanto para o treino de fonemas como para o treino de palavras inteiras foram os procedimentos de MTS (relação AC) e de Nomeação Oral (relação CD). Os testes para verificar a emergência da leitura recombinativa foram os mesmos nas três Condições Experimentais e consistiram em testes parciais de leitura oral (Testes C'D') e de leitura receptiva (Testes A'C'), e em um Teste Final de Leitura Oral. Os resultados demonstraram que o treino direto de fonemas (Condições I e II) foi eficaz em estabelecer leitura recombinativa com elevados índices de acertos e pouca variabilidade intra e inter-participantes. $\mathrm{O}$ momento de inserção do treino de fonemas no procedimento de ensino foi uma variável relevante e possibilitou a observação de resultados distintos entre os participantes submetidos às Condições I e II. Os resultados sugerem que os participantes submetidos a Condição II (Sobreposto) foram os que apresentaram maior velocidade na recombinação e índices mais elevados de leitura recombinativa, enquanto os participantes submetidos a Condição I (Prévio) foram os que apresentaram menor variabilidade entre si.

Palavras-chave: leitura recombinativa, controle por unidades mínimas, fonema, matching to sample, pseudoalfabeto. 


\begin{abstract}
INHAUSER, L. Z. Minimal verbal units control and extension of the unit taught: effect of the phoneme training upon the emergence of recombinative reading. 2012. 108 f. Dissertation (Master). Instituto de Psicologia, Universidade de São Paulo, São Paulo, 2012.

Reading is a complex skill that involves a network of relationships between stimuli and between stimuli and responses. A repertoire of proficient reading is considered when the reader is able to read new words, not directly taught and composed by the recombination of units previously learned in other relationships (recombinative reading). An essential requirement for the development of recombinative reading is thus establishing a differential responding under the control of smaller units, such as syllables, phonemes or letters, components of the words. The objective of this study was to investigate the effect of direct training of phonemes, combined with a training of words, upon the emergence of recombinative reading of whole words. It was also verified the effect of the moment of insertion of phoneme training in the teaching procedure, prior (Condition I) and overlapping (Condition II) to word training. The participants were 12 college students, aged between 18 and 37 years, which were equally distributed among three Experimental Conditions: a) Condition I - Prior Phoneme Training, b) Condition II - Overlapping Phoneme Training; c) Condition III - Word Training. Condition III was conducted in order to allow a comparison between the performance of participants who were submitted to phoneme training (Condition I and II) and the performance of participants who were exposed only to word training (Condition III). The stimuli used in the study consisted of spoken pseudowords (A) and printed pseudowords (C), as well phonemes and letters form the pseudo-alphabet corresponding to these phonemes. The procedures applied for both phoneme and word training were MTS (AC relation) and Oral Naming (CD relation). Tests to verify the emergence of recombinative reading were the same in all three Experimental Conditions and consisted of partial tests of oral reading (Tests C'D') and receptive reading (Tests $\mathrm{A}^{\prime} \mathrm{C}^{\prime}$ ), as well as of a Final Test of Oral Reading. The results showed that the direct training of phonemes (Conditions I and II) was effective in establishing recombinative reading with high scores and low variability within and among participants. Regarding the moment of the insertion of phoneme training on the procedure, the conclusion is that this is an important variable and enables the observation of different results among participants submitted to Conditions I and II. The results suggest that participants undergoing Condition II (Overlapping) were those with greater recombinative speed and higher rates of recombinative reading, while participants submitted to Condition I (Prior) presented the lowest variability among themselves.
\end{abstract}

Key - Words: recombinative reading, minimal units control, phoneme, matching to sample, pseudo-alphabet. 


\section{LISTA DE TABELAS}

Tabela 1. Curso e idade dos participantes de cada Condição Experimental............... 22

Tabela 2. Palavras ensinadas e testadas em cada ciclo. ............................................. 26

Tabela 3. Estímulos de escolha incorretos (S-) utilizados com cada estímulo de

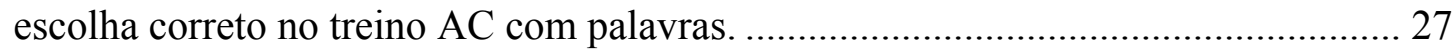

Tabela 4. Fases do Procedimento de cada Condição Experimental............................. 29

Tabela 5. Estrutura de cada bloco de treino AC e CD no Treino de Fonemas. ........... 32

Tabela 6. Número de tentativas até critério em cada subfase do treino de fonemas e número total de erros apresentados no treino de fonemas da Condição I................... 44 Tabela 7. Número de tentativas até critério em cada ciclo do treino de palavras e número total de erros apresentados no treino de palavras da Condição I. 46

Tabela 8. Erros apresentados com maior freqüência nos testes C'D' por cada participante da Condição I.

Tabela 9. Número de tentativas até critério em cada ciclo do treino de palavras e número total de erros apresentados no treino de palavras da Condição II.

Tabela 10. Número de tentativas até critério em cada subfase do treino de fonemas e número total de erros apresentados no treino de fonemas da Condição II

Tabela 11. Número de tentativas até critério em cada ciclo do treino de palavras e número total de erros apresentados no treino de palavras da Condição III. 62

Tabela 12. Erros apresentados com maior freqüência nos testes C'D' por cada participante da Condição III 66 


\section{LISTA DE FIGURAS}

Figura 1. Ilustração da disposição da sala durante as sessões experimentais

Figura 2. Ilustração de uma tentativa AC pelo GEIC 24

Figura 3. Correspondência entre as letras do pseudoalfabeto e do alfabeto romano... 26

Figura 4. Fases do procedimento da Condição Experimental I.

Figura 5. Sequência de treinos e de testes parciais a que o participante foi submetido em cada ciclo da Condição Experimental II. 40

Figura 6. Porcentagens de acerto de cada participante nos testes parciais C'D' e A'C' de cada ciclo da Condição I. 48

Figura 7. Porcentagens de acerto de cada participante nos testes parciais C'D' e A'C' de cada ciclo da Condição II. .56

Figura 8. Porcentagens de acerto de cada participante nos testes parciais C'D' e A'C' de cada ciclo da Condição III. 64 
INTRODUÇÃO.................................................................................................................

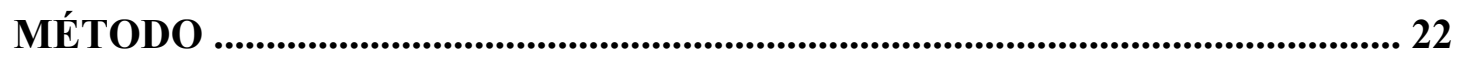

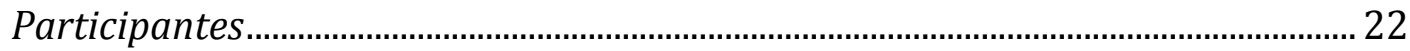

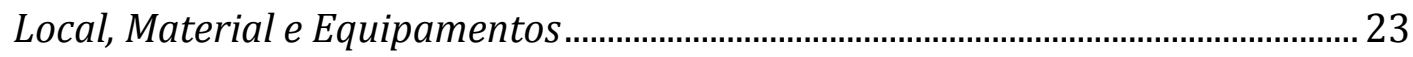

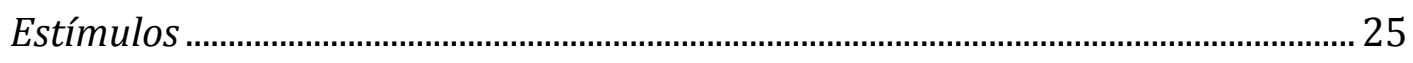

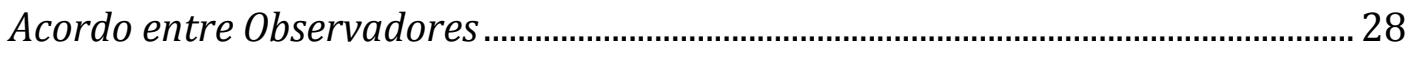

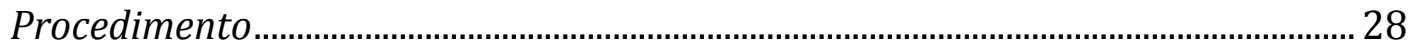

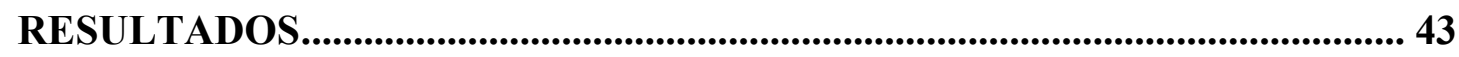

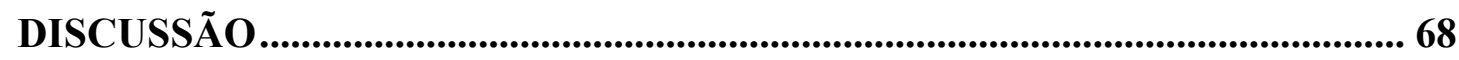

CONSIDERAÇÕES FINAIS ................................................................................ 86

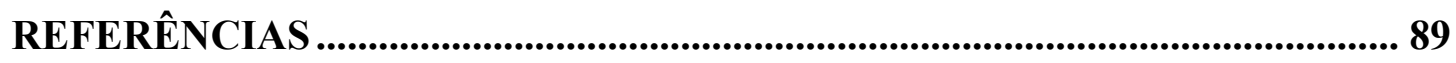

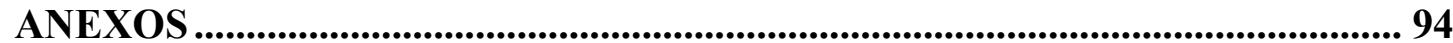


A leitura tem sido compreendida, na Análise do Comportamento, como um repertório que envolve uma rede de relações entre estímulos e entre estímulos e respostas (de Rose, 2005; Müeller, Olmi \& Saunders, 2000; Sidman, 1971). Skinner (1957) descreveu as variáveis envolvidas nos diferentes operantes verbais que compõem o repertório de leitura e diferenciou comportamento textual de leitura propriamente dita.

O comportamento textual, de acordo com Skinner (1957), pode ser definido como a emissão de respostas verbais na presença de estímulos textuais, como sentenças, palavras e letras impressas, na qual ocorre correspondência ponto a ponto entre estímulos e respostas. Pode-se dizer que o comportamento textual está ocorrendo quando, por exemplo, diante da palavra impressa SILÊNCIO o falante é capaz de emitir a resposta oral "SILÊNCIO" ou mesmo as respostas gestuais, correspondentes a essa palavra, no caso da linguagem de sinais. A leitura propriamente dita, por sua vez, ocorre quando o leitor é capaz de emitir respostas funcionais ao texto. No exemplo acima, pode-se dizer que a leitura está ocorrendo se diante da palavra SILÊNCIO, o leitor permanecer em silêncio. Assim, para que a leitura propriamente dita ocorra é necessário que a resposta do leitor esteja sob controle não só dos estímulos textuais, mas também de outros estímulos que foram relacionados aos textuais e que fornecem significado aos mesmos (Skinner, 1957).

Sidman (1971) também descreveu as relações entre estímulos e entre estímulos e respostas envolvidas no comportamento de ler e definiu três modalidades diferentes de leitura, de acordo com as relações de controle de estímulos envolvidas. A leitura oral (ou nomeação oral) pode ser entendida como a emissão de uma resposta oral sob controle de estímulos antecedentes visuais (textuais). Nesta modalidade de leitura, a compreensão do texto pode ou não estar envolvida, assemelhando-se a 
definição de Skinner (1957) de comportamento textual. A leitura com compreensão, por sua vez, pode ser equiparada a definição de leitura propriamente dita de Skinner (1957) e é demonstrada quando um leitor é capaz de relacionar um estímulo textual ao seu referente. Um exemplo da ocorrência de leitura com compreensão seria o leitor ser capaz de relacionar um cachorro ou a figura de um cachorro (chamados aqui de referente) à sua correspondente palavra impressa CACHORRO, e vice-versa. Finalmente, a leitura receptiva envolve o estabelecimento de relações entre estímulos auditivos, como por exemplo uma palavra ditada, e estímulos textuais. Neste caso, relacionar a palavra ditada "CACHORRO" à correspondente palavra impressa CACHORRO, é considerado evidência de leitura receptiva.

Cada um dos operantes envolvidos no repertório de leitura pode ser adquirido independentemente dos demais (Skinner, 1957), pois envolvem diferentes relações de controle de estímulos. No entanto, dependendo das contingências de ensino planejadas, estas diferentes relações, envolvidas na leitura, podem compartilhar estímulos que se tornam relacionados pelas contingências e passam, gradualmente, a fazer parte de uma mesma rede de relações interligadas, ou seja, de uma mesma classe de estímulos equivalentes (Sidman \& Tailby, 1982). Desta forma, a partir de um treino discriminativo, é possível que os estímulos envolvidos nas diferentes relações que compõem o repertório de leitura, se tornem substituíveis entre si no controle de respostas específicas. Isto significa que a afirmação de que um leitor é capaz de ler com compreensão envolve a descrição de uma relação de equivalência entre os estímulos que controlam as diferentes respostas envolvidas no repertório de leitura.

Os estudos iniciais sobre leitura (e.g., Sidman, 1971; Sidman \& Cresson, 1973; Sidman, Cresson \& Willson-Morris, 1974) demonstraram a emergência de um repertório de leitura com compreensão de um grupo específico de palavras, a partir do 
ensino de algumas discriminações condicionais, por meio do procedimento de Matching-to-Sample (MTS) ou emparelhamento com o modelo (Cumming \& Berryman, 1965). Nestes estudos foram ensinadas ao participante relações condicionais entre palavras ditadas (conjunto A) e figuras correspondentes (conjunto B), e relações entre as mesmas palavras ditadas (conjunto A) e palavras impressas correspondentes (conjunto C). Em seguida, foram realizados testes de equivalência entre os estímulos, os quais verificaram a emergência de relações, não diretamente treinadas, entre as figuras e palavras impressas correspondentes (relações $\mathrm{BC}^{2}$ ) e viceversa (relações CB). A emergência dessas relações significava que o participante era capaz de ler com compreensão e que palavras ditadas, palavras impressas e figuras haviam se tornado equivalentes, ou substituíveis entre si, no controle de respostas específicas.

Embora o procedimento empregado nestes estudos seja importante para o desenvolvimento da leitura com compreensão das palavras utilizadas no treino, ele não é suficiente para promover um repertório de leitura proficiente, que se estenda para além das palavras ensinadas diretamente (de Rose, de Souza, Rossito \& de Rose, 1989; Hübner-D’Oliveira, 1990).

Para que a leitura seja considerada proficiente, ela deve ser emitida diante de qualquer palavra nova da língua, não diretamente ensinada (de Rose, 2005; de Rose et al., 1989; Saunders, 2011). Isso pode ser observado, por exemplo, quando um estudante universitário, entra em contato com uma palavra desconhecida, pela primeira vez, e é capaz de emitir as respostas vocais (ou gestuais) correspondentes a essa palavra. As diferentes palavras da língua portuguesa são formadas a partir da combinação e da recombinação de unidades do reduzido conjunto de símbolos do

\footnotetext{
${ }^{2}$ Notação para relações condicionais, sendo que a primeira letra do par indica o estímulo modelo e a segunda, o estímulo de escolha.
} 
alfabeto (Hanna, Karino, Araújo \& de Souza, 2010) e o leitor proficiente deve responder diferencialmente a estas unidades para que apresente um repertório de leitura fluente.

A emissão de respostas novas a diferentes combinações ou recombinações de unidades componentes de estímulos, que estavam previamente incluídas em outras combinações de estímulos aprendidas, foi chamada na literatura de generalização recombinativa (Goldstein, 1983;1993). Na generalização recombinativa o treino é conduzido de tal maneira que os elementos que compõem os estímulos de relações previamente ensinadas são recombinados em novas configurações e continuam a exercer controle preciso sobre a respectiva resposta. Quando isso ocorre, o desempenho envolvido é denominado recombinativo, e na área de leitura esse repertório tem sido chamado de leitura recombinativa (e.g., de Souza \& de Rose, 2006; Hanna et al., 2010; Hanna et al., 2011; Matos, Hübner, Serra, Basaglia \& Avanzi, 2002; Müeller et al., 2000).

A leitura recombinativa depende, portanto, do estabelecimento de um responder diferencial às unidades mínimas, componentes das palavras como, por exemplo, sílabas, letras ou fonemas (de Rose, 2005; de Rose \& de Souza, 2006; Hanna et al., 2010; Matos et al., 2002; Müeller et al., 2000; Saunders, O’Donnell, Vaidya, Williams, 2003). Este responder diferencial sob controle das unidades menores, é que vai permitir a aquisição de um repertório que possibilita a leitura de palavras novas compostas por elementos previamente aprendidos, mas apresentados em arranjos diferentes.

Segundo Skinner (1957), o controle por unidades mínimas, ao nível da letra ou de sons isolados, pode ser desenvolvido, gradualmente, quando apenas unidades maiores são reforçadas. Desta forma, um treino envolvendo palavras inteiras, poderia 
produzir, também, um responder diferencial sob controle das unidades menores, mesmo quando estas não são diretamente ensinadas.

A extensão da unidade textual ensinada diretamente como palavras, sílabas ou fonemas tem sido alvo de algumas discussões e estudos na área de leitura (e.g., Adams, 1994; Barros, 2007; Bishop, 1964; de Rose et al., 1996; de Souza et al., 2009b; Hanna et al., 2010; Jeffrey \& Samuels, 1967; Matos et al., 2002; Matos, Avanzi \& McIlvane, 2006; Maués, 2007; Mesquita, 2007; Serejo, Hanna, de Souza e de Rose, 2007; Souza, 2009). O objetivo dos estudos da área de leitura, que empregam diferentes extensões de unidades textuais, tem sido verificar que procedimentos de ensino gerariam melhores resultados na aquisição do controle por unidades mínimas e, conseqüentemente, na leitura recombinativa

A maioria dos estudos da área tem utilizado a palavra inteira como unidade textual de ensino (e.g., de Rose et al., 1996; de Rose et al., 1989; de Rose, de Souza, Rossito \& de Rose, 1992; Hanna, Kohlsdorf, Quinteiro, Fava, de Souza \& de Rose, 2008; Hübner-D’Oliveira, 1990; Hübner-D’Oliveira \& Matos, 1993; Hübner, Gomes \& McIlvane, 2009; Matos et al., 2002; Matos, Peres, Hübner \& Malheiros, 1997; Melchiori, de Souza \& de Rose, 1992; Melchiori, de Souza \& de Rose, 2000). De forma geral, estes estudos foram conduzidos via MTS e empregaram como estímulos, conjuntos de palavras nas modalidades auditivas e visuais, respectivamente palavras ditadas (conjunto A) e palavras impressas (conjunto $\mathrm{C}$ ), e figuras (conjunto B). O procedimento destes estudos envolveu, basicamente, fases de treino das relações chamadas pré-requisito entre palavras ditadas e figuras (relação $\mathrm{AB}$ ) e entre palavras ditadas e impressas (relação AC), testes de equivalência com um conjunto específico de palavras previamente ensinadas (relações $\mathrm{BC}-\mathrm{CB}$ ), e testes de leitura de novas palavras, formadas a partir da recombinação de unidades que compunham as palavras 
de treino. Os testes de leitura das novas palavras foram compostos, comumente, por testes de leitura recombinativa com compreensão (relações $B^{\prime} C^{\prime 3}-C^{\prime} B^{\prime}$ ) e testes de leitura recombinativa oral (relações $\left.\mathrm{C}^{\prime} \mathrm{D}^{4}\right)$.

Os resultados desses estudos demonstraram que a leitura recombinativa aumentou gradativamente à medida que novas palavras foram ensinadas, indicando que o ensino de palavras inteiras produziu controle por unidades mínimas, a depender do número de palavras empregadas no treino (e.g., de Rose et al., 1996; de Rose et al., 1989; Hanna et al., 2008; Hübner - D’Oliveira, 1990; Hübner-D’Oliveira \& Matos, 1993; Hübner et al., 2009; Melchiori et al., 1992). A variável importante para o desenvolvimento da leitura recombinativa foi o treino de múltiplos exemplares juntamente com a variação sistemática das sílabas que compõe as palavras ensinadas, ou seja, a apresentação da mesma sílaba em diferentes posições, a depender da palavra, ao longo do treino (e.g., Hanna et al., 2008; Hanna et al., 2011; HübnerD’Oliveira, 1993; Hübner et al., 2009; Matos et al., 2002; Matos et al., 1997; Müeller et al., 2000).

No entanto, apesar da quantidade de palavras empregadas no treino e da recombinação das mesmas sílabas em diferentes posições nas palavras se constituírem em variáveis relevantes para aquisição do controle por unidades mínimas, os resultados dos estudos apresentaram muita variabilidade entre o desempenho dos participantes, sendo que alguns participantes não foram capazes de ler palavras novas, mesmo depois de terem sido submetidos a um treino direto de mais de 30 (de Rose et al., 1989) ou 50 palavras (de Rose et al., 1996). Essa variabilidade entre os participantes sugere que o controle por unidades mínimas pode se desenvolver a partir

\footnotetext{
${ }^{3}$ A notação '(linha) indica um estímulo novo derivado.

${ }^{4}$ A letra D indicada como a segunda letra do par na notação das relações condicionais, refere- se à resposta de nomeação do participante em relação ao estímulo indicado na primeira letra do par. Neste caso, refere-se a nomeação de uma palavra impressa (conjunto C').
} 
do ensino de palavras inteiras, conforme proposto por Skinner (1957), mas que esta não é uma condição para assegurar leitura recombinativa estável e sistemática (Hanna et al., 2010). Isso ocorre possivelmente, porque o ensino de palavras inteiras deixa ao acaso o reconhecimento das correspondências entre os elementos sonoros e textuais que compõem as palavras (Sidman, 1994), que é fundamental para a aquisição do controle por unidades mínimas e, consequentemente, para a leitura recombinativa.

Por esta razão, muitos dos estudos que utilizaram a palavra inteira como unidade textual ensinada adicionaram, ao procedimento padrão de ensino, procedimentos especiais, que pudessem favorecer o desenvolvimento de um responder diferencial sob controle das unidades menores, componentes das palavras. Os procedimentos especiais foram empregados em diferentes fases do treino e envolveram manipulações dos elementos sonoros e/ou dos elementos textuais componentes das palavras. As manipulações experimentais dos elementos sonoros envolveram a oralização fluente ou escandida (sílaba a sílaba) das palavras de treino (e.g, Matos, Hübner \& Peres, 1999; Matos et al., 2002; Matos et al., 1997). Já as manipulações dos elementos textuais, envolveram o treino de cópia por construção de resposta, que foi realizado com oralização (e.g., de Rose, et al., 1996; Matos et al., 2002; Matos et al., 1997; Melchiori et al., 2000) ou sem oralização das palavras ensinadas (e.g., Matos et al., 1999; Matos et al., 2002; Matos et al., 1997). No treino de cópia por construção de resposta, o procedimento utilizado foi o de Constructed Response MTS (CRMTS), no qual a resposta de escolha de acordo com o modelo é uma resposta construída (Mackay \& Sidman, 1984). Neste procedimento, também chamado em alguns estudos de Anagrama (e.g., Gomes et al. 2007; Matos et al., 2002; Matos et al., 1997), a tarefa do participante é diante de uma palavra ditada ou impressa, apresentada como modelo, selecionar, entre as unidades verbais disponíveis 
(sílabas ou letras), aquelas que compõem a palavra e posicioná-las na sequência correspondente ao modelo.

No estudo realizado por de Rose et al. (1996), crianças com idades entre sete e dez anos e história de fracasso em leitura, aprenderam a ler 51 palavras de treino. As palavras utilizadas no estudo foram palavras da língua portuguesa, formadas por duas ou três sílabas, no formato de consoante + vogal $(\mathrm{CV})$, como por exemplo, BOLO e TOMATE. As palavras de treino foram ensinadas através do estabelecimento de relações entre palavras ditadas e palavras impressas (relação AC). Para o ensino destas relações foi utilizado o procedimento de Exclusão (Dixon, 1977; McIlvane \& Stoddard, 1981). Foram realizados dois experimentos, sendo que em um deles foi adicionada a tarefa de cópia por construção de palavras (Experimento 1) e no outro não (Experimento 2).

Os resultados mostraram que os participantes que foram submetidos ao treino com adição do procedimento de cópia por construção de palavras apresentaram desempenho superior em leitura recombinativa do que os participantes que foram submetidos ao mesmo treino, porém sem o procedimento de cópia. Esses resultados foram posteriormente replicados, por Melchiori et al. (2000), com diferentes populações. A adição do procedimento de cópia por construção cria uma condição na qual o participante deve responder diferencialmente tanto a cada elemento impresso que compõe a palavra como à sequência na qual estes elementos devem ser encadeados para a formação da palavra inteira, o que parece favorecer o desenvolvimento da leitura recombinativa. Porém, em ambos os estudos, ainda foram verificados desempenhos muito variáveis entre os participantes.

Uma possível explicação para isso é o fato de que além do responder diferencial aos componentes das unidades textuais impressas, o participante precisa 
estabelecer as relações entre a sequência de sons emitidos em uma palavra e suas unidades impressas correspondentes, para que possa adquirir o controle por unidades mínimas e a leitura de qualquer palavra da língua não diretamente treinada. Desta forma, de Rose et al. (1996) consideram que a inclusão de novas etapas de treino, com o ensino explícito da correspondência entre unidades textuais e sons, poderia produzir resultados com menor variabilidade entre os participantes.

Matos et al. (2002) realizaram oito estudos com 66 crianças, em idades entre três e cinco anos, para investigar os efeitos dos procedimentos especiais na aquisição do controle por unidades mínimas e leitura recombinativa. Os conjuntos de estímulos empregados no estudo foram palavras da língua portuguesa nas modalidades auditiva (A) e impressa (C), e as figuras correspondentes a estas palavras (B). Os procedimentos especiais envolveram: oralização fluente e escandida, após teste de equivalência; oralização fluente e escandida durante a aquisição de relações prérequisitos (treino das relações $\mathrm{AB}$ e $\mathrm{AC}$ ); e anagrama sem oralização, com oralização fluente e com oralização escandida, após os testes de relações de equivalência.

Os resultados indicaram que tanto a utilização dos procedimentos especiais quanto o momento de inserção desses procedimentos no treino foram variáveis relevantes para a emergência de leitura recombinativa. Os participantes submetidos ao procedimento de anagrama com oralização escandida, realizado após testes de equivalência, foram os que apresentaram os maiores índices de leitura recombinativa. De acordo com Matos et al. (2002), apesar de a palavra ser a unidade ensinada diretamente, o procedimento de anagrama com oralização escandida pareceu propiciar a discriminação da sílaba como uma unidade funcional independente da palavra na qual ela foi aprendida. Esse procedimento envolveu manipulações tanto dos 
elementos sonoros como dos elementos textuais das palavras e pareceu favorecer o estabelecimento do controle por unidades mínimas.

Em conjunto, os resultados dos estudos de de Rose et al. (1996), Melchiori et al. (2000) e Matos et al. (2002) parecem indicar que a leitura recombinativa ocorreu, com mais freqüência, após treinos que apresentavam as unidades menores separadamente, embora sempre no contexto de palavras inteiras (e.g., CRMTS ou anagrama). Desta forma, os procedimentos adicionais de cópia e cópia com oralização escandida das palavras ensinadas parecem ter produzido um treino que permitiu aos participantes responder diferencialmente aos componentes das palavras (sílabas ou letras) e apresentar leitura recombinativa.

No entanto, a variabilidade, novamente encontrada entre os desempenhos dos participantes, sugere que o treino indireto das unidades menores pode ser efetivo, mas não suficiente para o desenvolvimento de leitura recombinativa de forma sistemática entre os todos os participantes.

Diante dos resultados obtidos, outra possibilidade a ser investigada seria, o efeito do treino direto de unidades menores do que a palavra na emergência da leitura recombinativa. $\mathrm{O}$ treino direto de unidades menores teria como objetivo estabelecer as relações entre grafemas e fonemas necessárias ao estabelecimento do controle por unidades mínimas e, consequentemente, favorecer o desenvolvimento da leitura recombinativa.

Serejo et al. (2007) realizaram um estudo com palavras dissílabas, e acrescentaram, ao ensino de palavras inteiras, um treino silábico. O objetivo do estudo foi investigar o efeito de um treino composto pelo ensino direto de palavras e de sílabas (componentes das palavras) no desenvolvimento da leitura recombinativa. Os participantes do estudo foram nove crianças pré-escolares, com idades entre cinco e 
sete anos. Seis participantes foram submetidos as fases de ensino e testes de novas relações (Grupo Experimental) e três expostos apenas aos testes (Grupo Controle). Os conjuntos de estímulos empregados constituíram-se de palavras ditadas (conjunto A), palavras impressas (conjunto C) e figuras (conjunto B) correspondentes a estas palavras. As palavras foram formadas a partir de sílabas e letras da língua portuguesa. Metade das palavras utilizadas no estudo foram palavras com significado, como por exemplo FIGO. A outra metade foi composta por palavras inventadas, que seguiam as mesmas normas gramaticais da língua portuguesa, mas não possuíam significado no idioma português, como por exemplo LAFI.

O procedimento empregado por Serejo et al., (2007) foi composto por duas fases experimentais, nas quais foram utilizados conjuntos diferentes de estímulos. $\mathrm{Na}$ Fase 1 as palavras empregadas eram dissílabas, formadas por combinações do tipo consoante + vogal (e.g., LAGO), e na Fase 2 as palavras utilizadas eram formadas pela dificuldade da língua vogal + letra $\mathrm{R}+$ consoante (e.g., PORTA). Em uma das fases, um treino de sílabas (consoante + vogal, CV) foi adicionado ao treino de palavras inteiras. No treino silábico, as relações entre as unidades sonoras (A) e textuais (C) foram explicitamente ensinadas por meio do procedimento de MTS. Todos os participantes do Grupo Experimental foram submetidos às duas fases do procedimento. A ordem de exposição ao treino adicional de sílabas foi controlada entre os participantes, sendo que três foram expostos ao treino adicional na Fase 1 e três na Fase 2 .

Os resultados do estudo indicaram que os escores finais de leitura recombinativa oral foram maiores nas fases em que os participantes foram submetidos ao treino silábico, do que quando os participantes foram expostos somente ao treino de palavras. Além disso, de um modo geral, todos os participantes do Grupo 
Experimental apresentaram algum nível de leitura recombinativa, o que segundo Serejo et al. (2007) demonstra que um treino combinado de palavras e sílabas foi eficaz para facilitar o desenvolvimento de leitura recombinativa.

No entanto, ainda pode-se observar variabilidade entre o desempenho dos participantes e diferenças entre os escores finais de leitura das palavras de treino e de recombinação. Uma possível justificativa para isso poderia ser, segundo Serejo et al. (2007), o fato de que as palavras de recombinação foram formadas pelas letras/fonemas da palavras de treino, o que exigia do participante a mudança do controle elementar da menor unidade diretamente treinada (sílaba) para a menor unidade textual empregada nas palavras de recombinação (letra/fonema).

De Souza et al. (2009b) também investigaram o efeito de um treino explícito de unidades menores do que a palavra no desenvolvimento da leitura recombinativa. Para isso, adicionaram ao treino de palavras inteiras, um treino direto das relações entre sílabas ditadas e sílabas impressas (relação AC) e um treino de construção de palavras. Os participantes do estudo foram 12 crianças, com idades entre oito e 12 anos, com história de fracasso na aquisição da leitura. Os estímulos utilizados no estudo foram palavras e sílabas ditadas (A), palavras, sílabas e letras impressas (C) e figuras (B). As palavras, tanto de treino como de teste, foram palavras comuns da língua portuguesa, formadas por duas ou três sílabas, no formado consoante + vogal (e.g., PATO). As palavras de teste foram formadas a partir da recombinação das sílabas das palavras de treino. Foram empregados os procedimentos de MTS padrão e de CRMTS. O procedimento do estudo foi composto por 17 unidades de ensino e 11 unidades de teste. Para o ensino das relações entre as palavras ditadas e impressas (e das sílabas ditadas e impressas) foi empregado o procedimento de Exclusão (Dixon, 1977; McIlvane \& Stoddard, 1981). Em cada unidade de ensino três palavras 
diferentes foram ensinadas, por meio de uma sequência específica de tarefas que se repetiu ao longo do treino. Esta sequência de tarefas incluiu o treino de palavras inteiras e o treino das sílabas componentes das palavras. Após a aquisição das relações entre palavras ditadas e impressas (relação AC), o treino de unidades menores (sílabas) era iniciado. Os blocos de tentativas programados para ensinar diretamente as sílabas constituíram-se em um treino bastante extenso e foram compostos por diversos tipos de tentativas: tentativas de relações entre palavras ditadas e figuras (relação AB); tentativas de CRMTS com modelo impresso; tentativas de CRMTS com modelo ditado; e, finalmente, tentativas de ensino de relações entre sílabas ditadas e sílabas impressas (relação AC). Toda a sequência de treino de palavras inteiras e de sílabas se repetia a cada unidade, até que o ensino das 51 palavras de treino fosse finalizado.

Os resultados de interesse para o presente estudo referem-se ao desempenho dos participantes nos testes de leitura oral das palavras novas, formadas pela recombinação de unidades das palavras previamente ensinadas. Os dados demonstraram que os participantes apresentaram altos índices de leitura recombinativa e pouca variabilidade entre o desempenho dos participantes. Esses resultados foram substancialmente melhores do que os obtidos em estudos anteriores que utilizaram procedimentos semelhantes, mas não realizaram o treino explícito das unidades menores (e.g., de Rose et al., 1996).

Outro dado relevante do estudo realizado por de Souza et al. (2009b) refere-se ao fato de que as palavras de teste foram formadas pela recombinação das sílabas das palavras de treino, e não pela recombinação das letras componentes das palavras ensinadas. Assim, se as palavras ensinadas fossem, por exemplo, MALA e PATO, as palavras de recombinação poderiam ser MATO e MAPA, mas não LATA. Para que a 
segunda sílaba da palavra LATA fosse formada seria necessária uma recombinação intra-silábica, a partir das letras componentes das sílabas MA e TO, e a leitura de palavras novas compostas por este tipo de recombinação não foi investigada no estudo. Desta forma, é possível afirmar que o procedimento utilizado por de Souza et al. (2009b) treinou diretamente as unidades menores específicas (sílabas) que foram apresentadas nas novas palavras. Esses dados parecem sugerir que o treino direto da unidade de recombinação, ou seja, da menor unidade sonora e textual empregada na recombinação das palavras ensinadas, pode favorecer o desenvolvimento da leitura recombinativa.

De forma geral, os procedimentos empregados por Serejo et al. (2007) e de Souza et al. (2009b) foram efetivos para o estabelecimento das relações entre unidades sonoras e textuais silábicas e favoreceram a aquisição do controle por unidades mínimas. No entanto, o procedimento utilizado por de Souza et al. (2009b), que foi o que produziu desempenhos mais sistemáticos entre os participantes, utilizou um treino muito extenso para possibilitar a abstração da sílaba e a obtenção de resultados positivos no desenvolvimento de leitura recombinativa. A desvantagem da utilização de procedimentos longos de ensino é que estes podem produzir comportamentos de fuga e esquiva, por parte das crianças, os quais muitas vezes são acompanhados de quedas no desempenho (Hanna, Benvenuti \& Melo, 2010).

Por esta razão e diante dos dados obtidos por Serejo et al. (2007) e de Souza et al. (2009b), dois questionamentos parecem pertinentes e de certo modo interrelacionados. O primeiro refere-se a possibilidade de se obter controle por unidades mínimas e leitura recombinativa por meio de um procedimento menos extenso. O segundo está relacionado com a investigação do efeito de um ensino direto, não somente de unidades menores, mas sim das unidades específicas que serão 
apresentadas nas palavras de recombinação. Se o ensino direto das unidades específicas apresentadas nas novas palavras for suficiente para produzir um responder diferencial a estas unidades, quando apresentadas em palavras inteiras, é possível que procedimentos de ensino menos extensos permitam o desenvolvimento de leitura recombinativa. Estudos realizados anteriormente em um contexto diferente de experimentação (e.g., Bishop, 1964; Jeffrey \& Samuels, 1967) já sugeriram que o ensino explícito da menor unidade sonora e textual empregada nas palavras de recombinação favorece o desenvolvimento da leitura recombinativa.

O estudo realizado por Bishop (1964) teve como objetivo comparar o efeito de um treino de letras e de um treino de palavras inteiras no desenvolvimento de leitura recombinativa. Participaram do estudo 60 universitários, que foram divididos em três grupos: um submetido a um treino do som das letras, outro submetido a um treino de palavras e um grupo controle. Os estímulos utilizados foram letras e palavras impressas, formadas a partir de caracteres árabes. Foram utilizadas 12 letras árabes que tinham correspondência um a um entre a unidade textual e a sonora (grafemafonema). O conjunto de letras foi formado por oito consoantes e quatro vogais e estas letras foram combinadas para formar dois conjuntos de oito palavras dissílabas (do tipo $\mathrm{CVCV}$ ). Um dos conjuntos de palavras foi empregado no treino (somente para o Grupo Palavra) e o outro foi utilizado para avaliar o desenvolvimento da leitura de palavras novas. O procedimento do estudo foi dividido em três fases, sendo que a Fase1 e a Fase 3 foram iguais para todos os grupos, e se constituíram em um procedimento para familiarizar os participantes com os estímulos (Fase 1), e no teste para a emergência da leitura de palavras novas (Fase 3). A Fase 2 constituiu-se do treino e foi diferente para cada um dos grupos. O Grupo Letras foi submetido ao um treino direto de unidades menores que a palavra e aprendeu o som correspondente a 
cada letra árabe. O Grupo Palavras foi submetido a um treino de palavras inteiras e o Grupo Controle, foi submetido a uma tarefa não relacionada ao experimento. Foram realizados testes para avaliar a leitura recombinativa oral das oito palavras novas. Os resultados demonstraram que tanto os participantes do Grupo Letras como os participantes do Grupo Palavras apresentaram a leitura de palavras novas, o que não ocorreu com os participantes do Grupo Controle. No entanto, o Grupo Letras apresentou desempenho superior, quando comparado ao Grupo Palavras, na leitura recombinativa e necessitou de um menor número de tentativas para aquisição de um desempenho com $100 \%$ de acertos na leitura das palavras novas.

Jeffrey e Samuels (1967) consideraram que os resultados superiores, obtidos por Bishop (1964), dos grupos experimentais em relação ao grupo controle e do Grupo Letras em relação ao Grupo Sílabas, poderiam ter relação com a experiência prévia de participantes adultos de que palavras são constituídas por sílabas e letras, e com aspectos dos estímulos não controlados no estudo. Desta forma, Jeffrey e Samuels (1967) realizaram uma replicação sistemática do estudo de Bishop (1964), tendo como participantes 60 crianças pré-escolares. Os estímulos empregados foram seis grafemas inventados que tinham correspondência um a um com seis fonemas da língua inglesa. Os seis grafemas, compostos por três consoantes e três vogais, foram combinados para formar um conjunto de oito palavras monossilábicas (CV). Quatro palavras foram utilizadas no treino (Grupo Palavra) e as outras quatro no teste de leitura recombinativa. Os resultados replicaram os dados obtidos por Bishop (1964), sugerindo que o grupo submetido ao treino do som das letras apresentou desempenho superior na leitura de palavras novas em relação ao grupo exposto ao treino de palavras. Porém, Jeffrey e Samuels (1967) consideraram que os resultados superiores obtidos pelo Grupo Letras foram diretamente influenciados por uma fase incluída no 
procedimento, que ensinava as crianças que as palavras monossilábicas empregadas no estudo eram compostas por dois fonemas. Os autores levantaram ainda, a hipótese de que o treino isolado dos fonemas, isto é, sem a apresentação dos mesmos em uma unidade maior, como a palavra, não seria suficiente para produzir a leitura das novas palavras.

Um aspecto importante que pode ser observado no estudo de Jeffrey e Samuels (1967) foi a tentativa de controlar tanto a história prévia dos participantes em relação aos estímulos como a forma de composição e apresentação destes estímulos no estudo, através da utilização de unidades de ensino inventadas. O uso de palavras da língua pode envolver diferentes histórias pré-experimentais dos participantes com os estímulos (Hanna, et al., 2010), e em estudos realizados com crianças escolares, pode ainda ser difícil distinguir entre os efeitos das variáveis experimentais e da instrução escolar (Hanna et al., 2010; Hanna et al., 2008).

Com o objetivo de controlar a influência dessas variáveis, alguns estudos que investigam a aquisição do controle por unidades mínimas e a leitura recombinativa têm utilizado um pseudoalfabeto, que caracteriza um sistema lingüístico em miniatura (SLM) e simula a aprendizagem de leitura em uma nova língua (e.g., Albuquerque, 2001; Hanna et al., 2010; Hanna et al., 2008; Hanna et al., 2011; Quinteiro, 2003). Um sistema lingüístico em miniatura pode ser definido como um conjunto de símbolos, desenvolvidos para fins experimentais, que variam ao longo de uma ou mais dimensões (e.g., forma, tamanho, posição), e um conjunto de respostas específicas requeridas na presença de tais símbolos (Foss, 1968). A utilização de um pseudoalfabeto para o ensino da leitura permite, não somente controlar a história com os estímulos experimentais, como também manipular a composição dos estímulos no que se refere, por exemplo, ao número de sílabas e letras utilizadas, forma de 
recombinação das unidades do pseudoalfabeto, e tamanho das palavras empregadas (Hanna et al., 2010; Hanna, et al, 2008; Hanna et al., 2011).

Hanna et al. (2010), considerando as vantagens da utilização do pseudoalfabeto, utilizou um SLM com o objetivo de verificar o efeito do treino direto de diferentes extensões de unidades menores que as palavras (letras e sílabas) no desenvolvimento de leitura recombinativa (Experimento 2). Os participantes foram oito estudantes universitários, com idades entre 19 e 22 anos. Quatro participantes foram submetidos ao treino direto de sílabas (Grupo Sílabas) e os outros quatro participantes foram submetidos ao treino direto de letras (Grupo Letras). Os estímulos auditivos empregados no estudo foram nomes de letras, sílabas e palavras faladas (A). Os estímulos visuais foram todos formados a partir do pseudoalfabeto e consistiram de letras, sílabas e palavras escritas com o pseudoalfabeto (C). As letras do pseudoalfabeto foram criadas a partir do alfabeto grego e tinham correspondência unívocas com letras e fonemas do alfabeto português. As palavras de treino foram dissílabas, no formato consoante + vogal $(\mathrm{CV})$, e as palavras de teste foram formadas pela recombinação das letras das palavras de treino.

O procedimento utilizado por Hanna et al. (2010) consistiu, de forma geral, de um treino prévio das unidades menores (letras ou sílabas) seguido por um treino de palavras inteiras. No treino prévio das unidades menores, os participantes do Grupo Sílaba aprenderam a relacionar sílabas ditadas a sílabas impressas correspondentes (relação $\mathrm{AC}$ ) e a nomear sílabas (relação $\mathrm{CD}$ ), enquanto os participantes do Grupo Letras aprenderam a relacionar o nomes das letras ditadas a letras impressas correspondentes (relação AC) e a nomear letras (relação CD). Após os treinos das unidades menores (letras ou sílabas), os participantes de ambos os grupos foram submetidos ao treino de palavras inteiras. Esse treino foi realizado por meio de 
procedimentos de MTS e de nomeação oral e cada participante aprendeu a relacionar as palavras ditadas a suas unidades impressas correspondentes (relação AC) e a nomear as palavras (relação CD).

A leitura recombinativa foi avaliada por meio de testes parciais de leitura oral (Testes $C^{\prime} D$ ) e de leitura receptiva (Testes $A^{\prime} C^{\prime}$ ), que ocorreram no decorrer do procedimento, e por meio de um Teste Final de Leitura Oral, que avaliou a leitura de todas as palavras empregadas no estudo.

De forma geral, os resultados de todos os testes demonstraram que os participantes submetidos ao treino de letras (Grupo Letras) apresentaram maiores índices de acerto e menor variabilidade no desempenho, do que os participantes submetidos ao treino de sílabas (Grupo Sílabas). O melhor desempenho dos participantes do Grupo Letras pode ser explicado pelo fato de que as palavras de teste foram formadas pela recombinação das letras das palavras de treino. Assim, para estes participantes a leitura de palavras novas dependia da recombinação das unidades que haviam sido diretamente ensinadas (letras), enquanto que para o Grupo Sílabas a leitura das palavras novas dependia ainda da mudança do controle das unidades aprendidas previamente (sílabas), para unidades ainda menores componentes da palavras de teste (letras).

Os resultados do Experimento 2 do estudo de Hanna et al. (2010) indicaram portanto, que o treino prévio de letras, seguido por um treino de palavras, foi suficiente para o estabelecimento de leitura recombinativa consistente e sistemática entre os participantes e que a extensão da menor unidade ensinada diretamente (letra ou sílaba) foi uma variável relevante na emergência da leitura recombinativa.

Desta forma, se a extensão da unidade textual ensinada diretamente é uma variável importante e se o ensino direto da menor unidade empregada nas palavras de 
recombinação produz leitura recombinativa com altos índices de acerto e pouca variabilidade entre os participantes (de Souza et al., 2009b; Hanna et al., 2010) uma pergunta que parece pertinente refere-se a que resultados seriam obtidos caso o som de cada letra (fonema), e não o nome, fosse diretamente ensinado.

O som de cada letra, ou seja, o fonema, se constitui na menor unidade da língua portuguesa e, portanto, o ensino explícito das relações entre letras e sons possivelmente favoreceriam a aquisição do controle por unidades mínimas e a emergência da leitura recombinativa. Além disso, quando o som de cada letra é ensinado, a topografia de resposta estabelecida na presença da maioria das letras individualmente é semelhante à estabelecida na presença dessas mesmas letras, quando apresentadas em palavras inteiras. Por exemplo, o som da letra $\mathrm{N}$ ensinado isoladamente é muito semelhante ao som da letra $\mathrm{N}$ na palavra NAVIO. Isso poderia se constituir em uma vantagem em relação ao ensino do nome da letra, pois quando o nome da letra é ensinado não existe correspondência entre a topografia de resposta emitida na presença da letra $\mathrm{N}$ isoladamente (por exemplo "ene" na presença de $\mathrm{N}$ ) e da topografia emitida presença da letra $\mathrm{N}$, quando apresentada em uma palavra inteira.

A realização de estudos que tenham como objetivo verificar o efeito do ensino do fonema na emergência da leitura recombinativa, possibilitariam ainda uma ampliação da análise do efeito das diferentes extensões de unidades diretamente ensinadas na emergência da leitura recombinativa.

Diante disso, o objetivo do presente trabalho foi investigar o efeito de um treino explícito de fonemas, combinado com um treino de palavras, na emergência da leitura recombinativa de palavras inteiras, constituídas a partir de um pseudoalfabeto. Verificou-se ainda se o momento de inserção do treino de fonemas no procedimento 
de ensino, se prévio (Condição I) ou sobreposto (Condição II) ao ensino de palavras se constitui uma variável relevante para a leitura recombinativa. Para tanto, foram realizadas três condições experimentais. As condições I e II investigaram o efeito do treino de fonemas, combinado com o treino de palavras, na emergência da leitura recombinativa. A Condição III investigou o efeito do treino somente de palavras inteiras na leitura recombinativa, com o objetivo de permitir uma comparação intraestudo entre os desempenhos dos participantes submetidos ao treino de fonemas e palavras (Condições I e II) com os desempenhos dos participantes submetidos somente ao treino de palavras inteiras (Condição III). 


\section{MÉTODO}

\section{Participantes}

Participaram da pesquisa 12 estudantes universitários, com idades entre 18 e 37 anos. Os 12 participantes foram distribuídos em três condições experimentais (Tabela 1). O critério para a distribuição dos participantes entre as três condições foi de que houvesse apenas um participante oriundo da faculdade de psicologia por condição. A distribuição dos demais participantes foi feita de forma aleatória.

Tabela 1. Curso e idade dos participantes de cada Condição Experimental.

\begin{tabular}{cccc}
\hline Condição Experimental & Participantes & Curso & Idade \\
\hline \hline Treino Prévio de Fonemas & P1 & Fisioterapia & 23 \\
& P3 & Psicologia & 20 \\
& P4 & Pedagogia & 37 \\
Treino Sobreposto de & P6 & Encias Atuariais & 24 \\
Fonemasia de Produção & Psicologia & 25 \\
& P7 & Quimica & 23 \\
& P8 & Jornalismo & 18 \\
& & & \\
Treino de Palavras & P9 & Psicologia & 30 \\
& P10 & Engenharia Civil & 23 \\
& P1 & Ciências Sociais & 23 \\
& & Quimica & 22 \\
\hline
\end{tabular}

Os participantes foram informados sobre a frequência e a duração estimada das sessões experimentais e que o estudo se tratava de uma investigação sobre comportamento simbólico. Além disso, foi entregue aos participantes o Termo de Consentimento Livre e Esclarecido (Anexo A), o qual foi devidamente preenchido e 
devolvido ao experimentador. Ao final da coleta de dados os participantes receberam informações detalhadas sobre o objetivo da pesquisa. Este projeto foi submetido ao Comitê de Ética em Pesquisa com Seres Humanos do Instituto de Psicologia da USP.

\section{Local, Material e Equipamentos}

As sessões experimentais foram conduzidas na sala do Laboratório de Estudos de Operantes Verbais (LEOV) da Universidade de São Paulo. Sobre uma das mesas foi colocado um computador, caixas de som e um mouse, que foram utilizados para a coleta de dados. Um gravador portátil usado para gravar as respostas orais do participante também foi colocado sobre a mesa. Em todas as sessões experimentais estiveram presentes o experimentador e um observador, devidamente treinado para analisar e registrar as respostas orais do participante. O participante sentava-se em frente à tela do computador. $\mathrm{O}$ experimentador permanecia à esquerda do participante, um pouco atrás, com o teclado utilizado para o registro e consequênciação das respostas orais. O observador ficava à direita do participante, também um pouco atrás, registrando as respostas orais em um protocolo de registro (Figura 1).

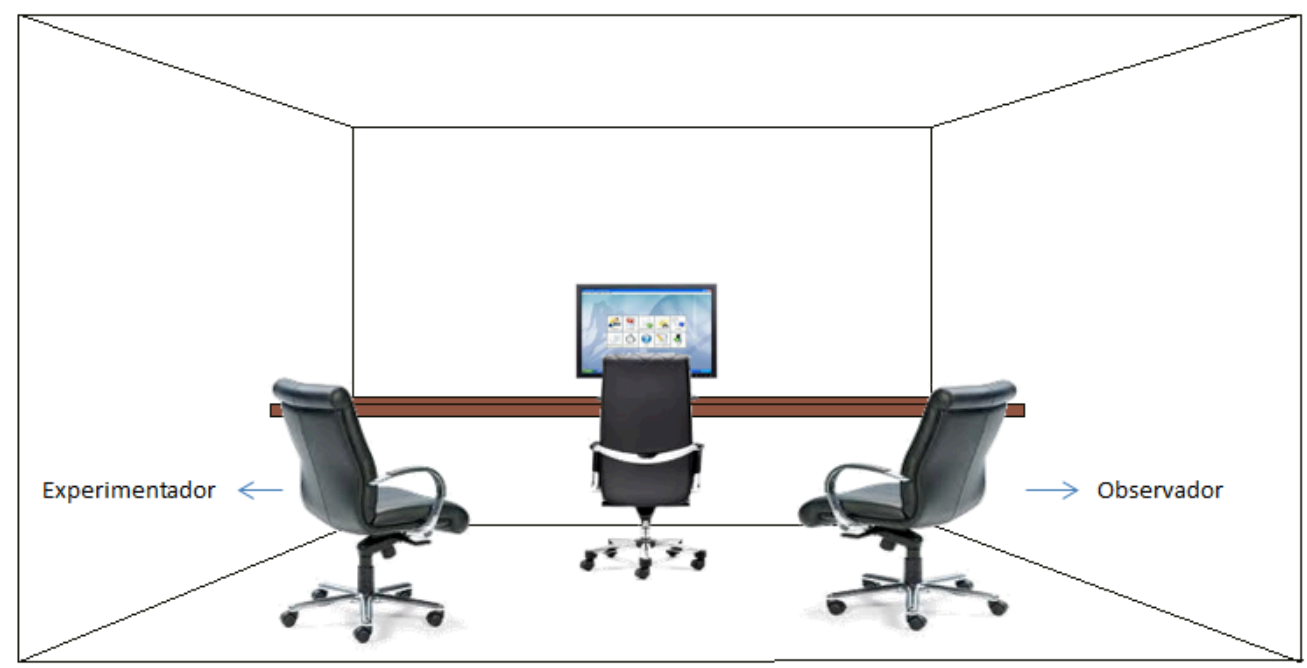

Figura 1. Ilustração da disposição da sala durante as sessões experimentais 
Para a apresentação das tarefas experimentais e o registro de dados foi utilizado o software GEIC (Capobianco, Orlando, Marques, Teixeira, de Souza \& de Rose, 2011). O programa exibe no monitor de vídeo as configurações de estímulos programadas para cada fase do procedimento. Nas tentativas que envolvem MTS, o estímulo modelo é apresentado simultaneamente aos estímulos de escolha. A janela superior central da tela é designada para o estímulo modelo e os estímulos de escolha são randomizados entre as três janelas disponíveis na parte inferior da tela. Como no presente estudo o estímulo modelo foi auditivo, a janela superior central da tela não foi utilizada e os estímulos de escolha foram apresentados de forma randômica nas três janelas disponíveis na parte inferior da tela do computador (Figura 2).

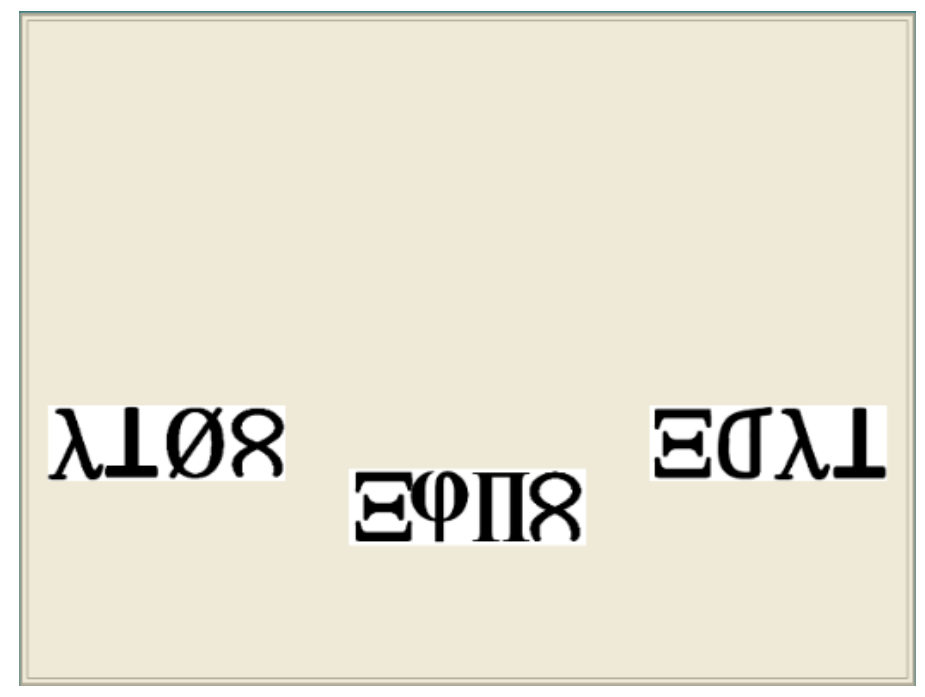

Figura 2. Ilustração de uma tentativa AC pelo GEIC.

A emissão da resposta de clicar com o mouse sobre o estímulo de escolha correto foi seguida no treino por um som, composto por uma sequência de duas notas musicais, emitido pelo computador (conseqüência de acerto). Não existiram consequências programadas para as respostas incorretas nas tentativas de MTS (Tentativas AC). As respostas incorretas foram seguidas por um IET de 1,5 segundos 
e pela apresentação da próxima tentativa. Nas tentativas que requeriam a nomeação oral (Tentativas CD), somente um estímulo foi apresentado na janela superior central da tela. A correta nomeação do estímulo, foi seguida, no treino, pela mesma consequência de acerto, empregada nas tentativas de MTS. Respostas incorretas de nomeação oral foram também seguidas por um IET de 1,5 segundos e pela apresentação da próxima tentativa.

O software GEIC registra automaticamente as respostas de seleção, nas tentativas de MTS. O registro das respostas de nomeação oral foi feito pelo experimentador nas teclas Shift + Alt + F5 (acerto) e Shift + Alt + F6 (erro) do teclado do computador, e pelo observador em protocolos que incluíram a listagem sequêncial de tentativas que requeriam a nomeação oral. Em tentativas nas quais um participante apresentou mais de uma resposta oral na presença de um mesmo estímulo impresso, ambas foram registradas, mas apenas a primeira resposta foi considerada para consequência e análise.

\section{Estímulos}

Os estímulos consistiram de palavras faladas (A) e palavras escritas com um pseudoalfabeto (C), bem como de fonemas e letras do pseudoalfabeto, correspondentes a estes fonemas. Os estímulos textuais e as palavras faladas foram os mesmos empregados no Experimento 2 de Hanna et al. (2010). As palavras foram dissílabas (consoante + vogal + consoante + vogal ou CVCV) e constituídas por quatro fonemas. As letras do pseudoalfabeto (Figura 3) foram criadas a partir do alfabeto grego e mantém uma correspondência um a um com os fonemas /a/, / / /, /i/, /o/, /b/, /f/, /1/, e /n/. 


\begin{tabular}{|cc|}
\hline Alfabeto Romano & Pseudoalfabeto \\
N & $\Xi$ \\
B & $\Pi$ \\
F & $\lambda$ \\
L & $\emptyset$ \\
A & $\perp$ \\
E & $\sigma$ \\
I & $\varphi$ \\
O & $\&$ \\
\hline
\end{tabular}

Figura 3. Correspondência entre as letras do pseudoalfabeto e do alfabeto romano

As sílabas utilizadas na formação das palavras de treino foram as sílabas do pseudoalfabeto correspondentes a NI, BO, LE e FA. Cada sílaba foi apresentada tanto no início quanto no final das palavras, ao longo do treino. Foram utilizadas 12 palavras diferentes no treino e 14 palavras novas nos testes (Tabela 2). As palavras novas utilizadas nos testes foram compostas por pelo menos uma sílaba não diretamente treinada, formada pela recombinação das letras das palavras de treino e foram indicadas como pertencentes aos conjuntos $A^{\prime}$ e $C^{\prime}$. Todas as vogais foram pronunciadas de forma aberta e as palavras foram pronunciadas como oxítonas.

Tabela 2. Palavras ensinadas e testadas em cada ciclo.

\begin{tabular}{c|cc|cccc}
\hline Ciclo & \multicolumn{2}{|c|}{ Palavras de Treino } & \multicolumn{4}{|c}{ Palavras de Teste } \\
\hline 1 & nibo & fale & lofi & nibe & falo & bena \\
\hline 2 & bofa & leni & nale & bofi & falo & bena \\
\hline 3 & lebo & fani & nofa & leba & falo & bena \\
\hline 4 & boni & lefa & lefi & bona & falo & bena \\
\hline 5 & fabo & nile & nilo & fabe & falo & bena \\
\hline 6 & bole & nifa & febi & lano & falo & bena \\
\hline
\end{tabular}


Nenhuma das palavras de treino, que foram designadas arbitrariamente como corretas (com função de $\mathrm{S}+$ ) nas tentativas de MTS, tem significado na língua portuguesa. Os estímulos de escolha incorretos foram palavras dissílabas que possuíam apenas uma letra em comum com o estímulo de escolha correto (diferenças múltiplas), e localizada na mesma posição em ambos os estímulos, correto e incorreto (Tabela 3). Esta configuração dos estímulos de escolha incorretos previne o controle por apenas uma das letras localizada em uma determinada posição (Hanna et al., 2011)

Tabela 3. Estímulos de escolha incorretos (S-) utilizados com cada estímulo de escolha correto no treino AC com palavras. A letra em destaque nos estímulos de escolha incorretos é igual à letra correspondente no escolha correto.

\begin{tabular}{|c|c|c|c|c|c|}
\hline Ciclos & $\mathbf{S}+$ & S- & S- & S- & S- \\
\hline 1 & $\begin{array}{c}\text { nibo } \\
\text { fale }\end{array}$ & $\begin{array}{l}\text { nefa } \\
\text { fibo }\end{array}$ & $\begin{array}{c}\text { lifa } \\
\text { nabo }\end{array}$ & $\begin{array}{l}\text { fabe } \\
\text { boli }\end{array}$ & $\begin{array}{r}\text { falo } \\
\text { bone }\end{array}$ \\
\hline 2 & $\begin{array}{c}\text { bofa } \\
\text { leni }\end{array}$ & $\begin{array}{l}\text { bile } \\
\text { labo }\end{array}$ & $\begin{array}{l}\text { nole } \\
\text { febo }\end{array}$ & $\begin{array}{c}\text { lefi } \\
\text { bona }\end{array}$ & $\begin{array}{l}\text { lena } \\
\text { bofi }\end{array}$ \\
\hline 3 & $\begin{array}{l}\text { lebo } \\
\text { fani }\end{array}$ & $\begin{array}{l}\text { lani } \\
\text { fole }\end{array}$ & $\begin{array}{l}\text { feni } \\
\text { bale }\end{array}$ & $\begin{array}{l}\text { niba } \\
\text { leno }\end{array}$ & $\begin{array}{l}\text { nifo } \\
\text { lebi }\end{array}$ \\
\hline 4 & $\begin{array}{c}\text { boni } \\
\text { lefa }\end{array}$ & $\begin{array}{l}\text { befa } \\
\text { loni }\end{array}$ & $\begin{array}{l}\text { lofa } \\
\text { beni }\end{array}$ & $\begin{array}{l}\text { fane } \\
\text { nifo }\end{array}$ & $\begin{array}{l}\text { fali } \\
\text { niba }\end{array}$ \\
\hline 5 & $\begin{array}{c}\text { fabo } \\
\text { nile } \\
\end{array}$ & $\begin{array}{l}\text { file } \\
\text { nofa }\end{array}$ & $\begin{array}{l}\text { nale } \\
\text { bifa }\end{array}$ & $\begin{array}{l}\text { lebi } \\
\text { falo }\end{array}$ & $\begin{array}{l}\text { leno } \\
\text { fabe }\end{array}$ \\
\hline 6 & $\begin{array}{l}\text { bole } \\
\text { nifa }\end{array}$ & $\begin{array}{l}\text { bani } \\
\text { nebo }\end{array}$ & $\begin{array}{l}\text { foni } \\
\text { libo }\end{array}$ & $\begin{array}{l}\text { nila } \\
\text { bofe }\end{array}$ & $\begin{array}{l}\text { nife } \\
\text { Bola }\end{array}$ \\
\hline
\end{tabular}

Nos testes de leitura recombinativa receptiva (Testes A'C') os estímulos de escolha incorretos foram palavras dissílabas que possuíam apenas uma letra diferente do estímulo de escolha correto (diferenças críticas), exigindo que o participante 
estivesse sob controle de cada uma das unidades que compõem a palavra para emitir uma resposta correta (Anexo B).

\section{Acordo entre Observadores}

Foi calculado o índice de acordo entre os registros das respostas orais realizados pelo observador e pelo experimentador em todas as sessões de treino e teste do experimento. $\mathrm{O}$ índice de acordo entre os registros foi calculado dividindo-se o número de acordos pelo número total de registros de leitura oral realizados na sessão (acordos + desacordos) e multiplicado por 100. O índice de acordo foi calculado para 2021 respostas orais e foi de $98,02 \%$.

Nas tentativas em que foram observados desacordos entre os registros do observador e do experimentador, uma terceira pessoa escutou a gravação e efetuou o registro. Para fins de análise, foi considerada a resposta registrada da mesma maneira duas vezes.

\section{Procedimento}

Foram empregadas no estudo três condições experimentais, chamadas de: a) Condição Experimental I - Treino Prévio de Fonemas; b) Condição Experimental II Treino Sobreposto de Fonemas e c) Condição Experimental III - Treino de Palavras. Os 12 participantes foram divididos entre as três condições, sendo quatro o número de participantes submetidos a cada uma. A Tabela 4 mostra as fases que compõem o procedimento de cada uma das três condições experimentais. 
Tabela 4. Fases do Procedimento de cada Condição Experimental.

\begin{tabular}{|c|c|c|c|}
\hline $\begin{array}{c}\text { Fases do } \\
\text { Procedimento }\end{array}$ & $\begin{array}{c}\text { Condição I - } \\
\text { Treino Prévio de } \\
\text { Fonemas } \\
\end{array}$ & $\begin{array}{c}\text { Condição II - } \\
\text { Treino Sobreposto } \\
\text { de Fonemas }\end{array}$ & $\begin{array}{l}\text { Condição III - } \\
\text { Treino de Palavras }\end{array}$ \\
\hline $\begin{array}{c}\text { Treino AC/CD de } \\
\text { Fonemas }\end{array}$ & $\sqrt{ }$ & - & - \\
\hline $\begin{array}{l}\text { Teste Inicial de } \\
\text { Leitura Oral de } \\
\text { Palavras }\end{array}$ & $\sqrt{ }$ & - & - \\
\hline $\begin{array}{c}\text { Ciclos de Treino } \\
\text { AC/CD e Testes } \\
\text { Parcias } \\
\text { C'D'/A'C'de } \\
\text { Palavras }\end{array}$ & $\sqrt{ }$ & $\begin{array}{c}\sqrt{ } \\
+ \text { Treino AC/CD } \\
\text { de Fonemas }\end{array}$ & $\sqrt{ }$ \\
\hline $\begin{array}{l}\text { Teste Final de } \\
\text { Leitura Oral de } \\
\text { Palavras }\end{array}$ & $\sqrt{ }$ & $\sqrt{ }$ & $\sqrt{ }$ \\
\hline
\end{tabular}

Em cada uma das condições experimentais foram ensinadas ao participante relações entre unidades sonoras e textuais, por meio dos procedimentos de emparelhamento com o modelo (Treino AC) e de nomeação oral (Treino CD). O emparelhamento com o modelo entre as unidades sonoras (A) e textuais (C) foi ensinado gradualmente, de forma que o número de estímulos de escolha apresentados aumentou, progressivamente, ao longo do treino. Na primeira tentativa, somente o estímulo de escolha correto (S+) foi apresentado e, gradualmente, no decorrer das tentativas, dois outros estímulos de escolha foram inseridos. O número máximo de estímulos de escolha apresentados por tentativa foi de três estímulos (um correto e dois incorretos). A posição dos estímulos de escolha foi randomizada a cada tentativa. No treino de MTS (AC), a seleção do estímulo de escolha designado como correto foi seguida por consequências de acerto, como sons emitidos pelo computador. Não havia consequências programadas para as respostas incorretas. 
No treino de nomeação oral (CD), as tentativas foram iniciadas com a apresentação de um estímulo impresso na parte superior central da tela. A tarefa do participante consistiu em: 1) nomear os estímulos apresentados na tela, quando o estímulo era uma palavra; ou 2) emitir o som correspondente ao estímulo impresso (fonema), quando o estímulo era uma letra. Respostas corretas foram seguidas de consequências de acerto. Não havia consequências programadas para as respostas incorretas.

Fases de Procedimento

A seguir serão descritas detalhadamente, para cada Condição Experimental, as fases do procedimento com seus respectivos parâmetros experimentais e instruções.

\section{Condição Experimental I}

\section{Treino Prévio de Fonemas}

O procedimento da Condição Experimental I consistiu em uma replicação sistemática do Experimento 2 de Hanna et al. (2010) e apresentou a seguinte sequência de fases: 1) Treino AC/CD de Fonemas; 2) Teste Inicial de Leitura Oral de Palavras; 3) Ciclos de Treino AC/CD e Testes Parciais C'D'5/A'C' de Palavras e 4) Teste Final de Leitura Oral de Palavras (Figura 4).

\footnotetext{
${ }^{5}$ A notação linha (') na letra D foi empregada para indicar a resposta de nomeação esperada, que é neste caso referente ao estímulo C'. No entanto, o participante pode emitir qualquer outra resposta diferente da esperada.
} 


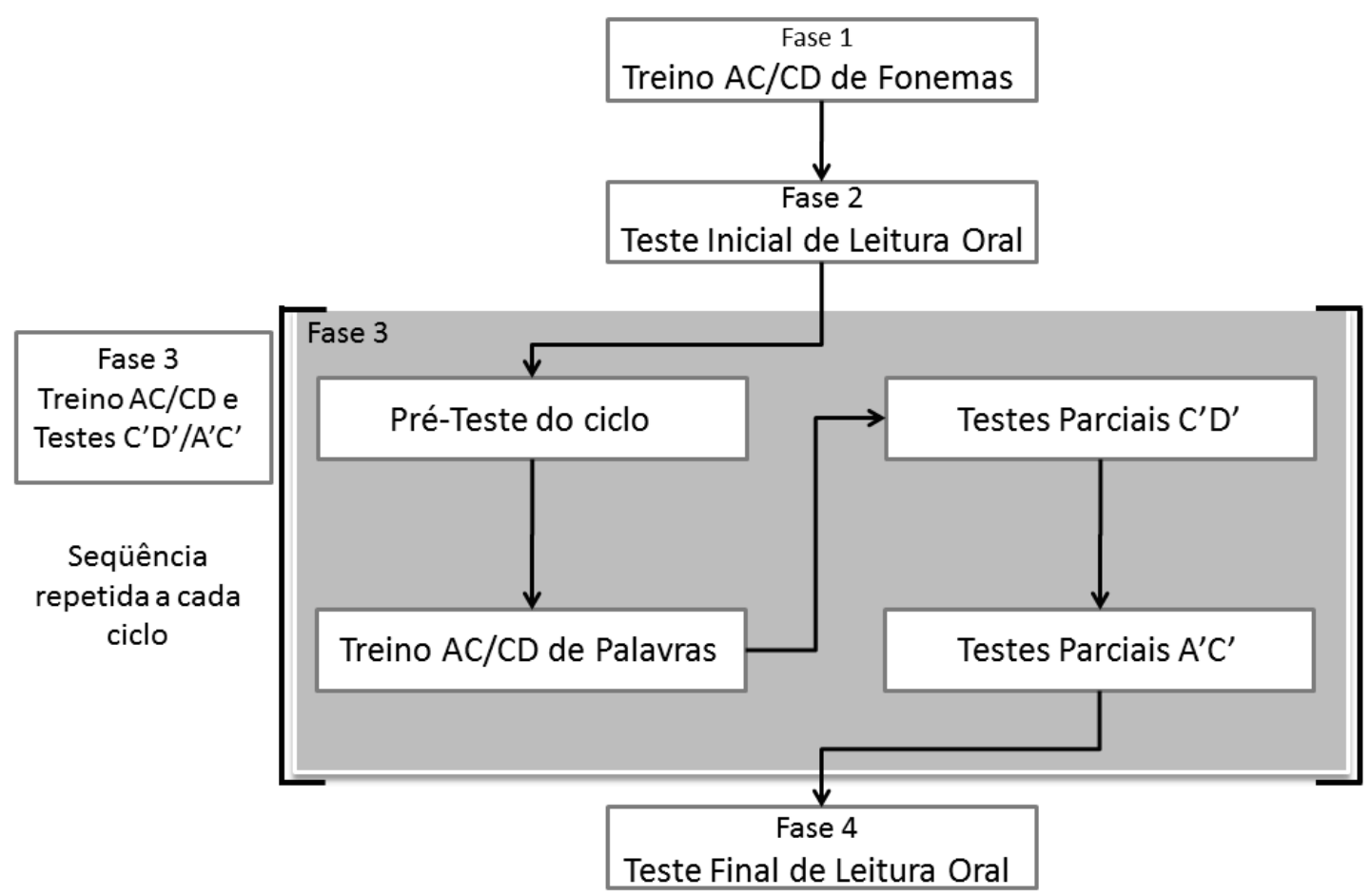

Figura 4. Fases do procedimento da Condição Experimental I.

Os Ciclo de Treino AC/CD e Testes Parciais C'D'/A'C' de palavras foram constituídos por uma sequência específica de tarefas (em cinza no diagrama da Figura 4). Essa sequência de tarefas se repetiu em cada um dos seis ciclos de treino e testes parciais com palavras, que foram realizados em cada uma das três condições experimentais.

\section{Fase 1 - Treino AC/CD de Fonemas}

O objetivo desta fase foi ensinar ao participante as relações entre as letras do pseudoalfabeto e os sons correspondentes a cada uma dessas letras. O participante aprendeu a, diante do fonema oralmente apresentado pelo computador, selecionar a unidade textual escrita com pseudoalfabeto, correspondente a este fonema (relação AC), e a diante da unidade textual escrita com pseudoalfabeto, emitir o som correspondente a este fonema (relação CD). O treino de fonemas foi composto por 
cinco subfases. Cada uma das quatro primeiras subfases ensinou ao participante dois fonemas. O treino dessas subfases foi composto por blocos de tentativas de ensino individual de cada fonema e por blocos de tentativas que empregaram os dois fonemas ensinados na subfase (Tabela 5).

Tabela 5. Estrutura de cada bloco de treino AC e CD no Treino de Fonemas.

\begin{tabular}{cccccc}
\hline Bloco & $\begin{array}{c}\text { Tipo de } \\
\text { Tentativa }\end{array}$ & $\begin{array}{c}\text { Número de } \\
\text { Tentativas }\end{array}$ & Modelo & S+ & $\begin{array}{c}\text { Número de } \\
\text { Estímulos de } \\
\text { Escolha }\end{array}$ \\
\hline \hline 1 & $\mathrm{AC}$ & 1 & $\mathrm{~A} 1^{6}$ & $\mathrm{C} 1$ & 1 \\
2 & $\mathrm{AC}$ & 2 & $\mathrm{~A} 1$ & $\mathrm{C} 1$ & 2 \\
3 & $\mathrm{AC}$ & 3 & $\mathrm{~A} 1$ & $\mathrm{C} 1$ & 3 \\
4 & $\mathrm{CD}$ & 2 & $\mathrm{C} 1$ & - & - \\
5 & $\mathrm{AC}$ & 1 & $\mathrm{~A} 2^{7}$ & $\mathrm{C} 2$ & 1 \\
6 & $\mathrm{AC}$ & 2 & $\mathrm{~A} 2$ & $\mathrm{C} 2$ & 2 \\
7 & $\mathrm{AC}$ & 4 & $\mathrm{~A} 1 ; \mathrm{A} 2$ & $\mathrm{C} 1 ; \mathrm{C} 2$ & 2 \\
8 & $\mathrm{AC}$ & 6 & $\mathrm{~A} 1 ; \mathrm{A} 2$ & $\mathrm{C} 1 ; \mathrm{C} 2$ & 3 \\
9 & $\mathrm{CD}$ & 2 & $\mathrm{C} 2$ & - & - \\
10 & $\mathrm{AC}$ & 6 & $\mathrm{~A} 1 ; \mathrm{A} 2$ & $\mathrm{C} 1 ; \mathrm{C} 2$ & 3 \\
11 & $\mathrm{CD}$ & 4 & $\mathrm{C} 1 ; \mathrm{C} 2$ & - & - \\
\hline
\end{tabular}

O treino do primeiro fonema foi iniciado com a apresentação de um estímulo modelo auditivo e de um estímulo de escolha impresso na parte inferior central da tela. A tarefa do participante foi, diante do estímulo auditivo (fonema), selecionar um dos estímulos de escolha disponíveis na parte inferior da tela. $\mathrm{O}$ experimentador apresentou a seguinte instrução: "Escute atentamente o som emitido pelo computador e, então, escolha um dos quadrados apresentados na parte inferior da tela. Aparecerão um, dois ou três quadrados na parte inferior da tela de cada vez. Se você acertar, o computador apresentará sons de acerto."

\footnotetext{
${ }^{6}$ As notações A1 e C1 referem-se, respectivamente, ao primeiro fonema ensinado em cada subfase (A1) e sua correspondente unidade impressa (C1).

${ }^{7}$ As notações A2 e C2 referem-se, respectivamente, ao segundo fonema ensinado em cada subfase (A2) e sua correspondente unidade impressa (C2).
} 
O critério de aprendizagem da relação AC para o primeiro fonema, individualmente, foi de $100 \%$ de acertos em um bloco de três tentativas, com três estímulos de escolha (Bloco 3).

Após a aquisição do critério no ensino da relação $\mathrm{AC}$, o treino $\mathrm{CD}$, para o primeiro fonema ensinado na subfase, foi iniciado (Bloco 4). O estímulo impresso correspondente ao primeiro fonema, foi apresentado na parte superior central da tela, e o experimentador fez a seguinte pergunta: "Qual é o som desse símbolo?". As respostas corretas foram seguidas de sons de acerto apresentados pelo computador. A emissão de respostas incorretas de nomeação oral determinava o retorno do treino para o Bloco 3. O retorno para o Bloco 3 poderia ocorrer até duas vezes, sem que outro procedimento de correção fosse incluído. Após a segunda repetição do Bloco 3, as respostas incorretas de nomeação oral foram seguidas pela emissão da resposta correta pelo experimentador e pelo retorno ao Bloco 3. O critério de aprendizagem da relação CD para o primeiro fonema foi de $100 \%$ de acertos em um bloco de duas tentativas.

A aquisição dos critérios de aprendizagem nos treinos $\mathrm{AC}$ e $\mathrm{CD}$ para o primeiro fonema ensinado na subfase, determinava o encerramento do treino individual do primeiro fonema e o início do treino do segundo fonema. O treino da relação AC para o segundo fonema foi realizado, individualmente, nos Blocos 5 e 6 , da mesma forma e de acordo com os mesmo critérios que o primeiro.

Em seguida, foram realizados dois blocos compostos por tentativas $\mathrm{AC}$, nas quais os dois fonemas, treinados na subfase, foram apresentados como estímulos modelo, alternando-se de forma assistemática. A instrução foi a mesma apresentada para o treino das relações $\mathrm{AC}$ de cada fonema, individualmente, e o critério de aprendizagem foi de $100 \%$ de acertos em um bloco de quatro tentativas, com dois 
estímulos de escolha (Bloco 7) e, posteriormente, em um bloco de seis tentativas, com três estímulos de escolha (Bloco 8).

Um bloco de treino de duas tentativas de nomeação oral (CD) do segundo fonema (Bloco 9) foi, então, realizado da mesma forma e de acordo com os mesmos critérios utilizados no treino $\mathrm{CD}$ para o primeiro fonema. A emissão de respostas incorretas de nomeação oral no Bloco 9 determinava o retorno do treino para o Bloco 8. Assim como no treino CD para o primeiro fonema, o retorno para o Bloco 8 poderia ocorrer até duas vezes, sem que outro procedimento de correção fosse incluído. Após a segunda repetição do Bloco 8, as respostas incorretas de nomeação oral foram seguidas pela emissão da resposta correta pelo experimentador e pelo retorno ao Bloco 8.

O treino da subfase foi finalizado por dois blocos, sendo um bloco de treino $\mathrm{AC}$ e outro $\mathrm{CD}$, que utilizaram os dois fonemas ensinados na subfase. $\mathrm{O}$ bloco AC foi composto por seis tentativas, nas quais os dois fonemas treinados na subfase foram apresentados como estímulos modelo, alternando-se de forma assistemática (Bloco 10). A instrução foi a mesma apresentada para o treino das relações $\mathrm{AC}$ dos fonemas individualmente, e o critério de aprendizagem foi de 100\% de acertos.

No bloco final CD, os dois fonemas ensinados na subfase foram apresentados um a um, de forma intercalada, na parte superior central da tela (Bloco 11). A instrução foi a mesma apresentada no treino CD dos fonemas, individualmente, e o critério de aprendizagem foi de $100 \%$ de acertos em um bloco de quatro tentativas. Respostas incorretas de nomeação oral dos fonemas neste bloco, determinavam o retorno do treino para o Bloco 10. 
Na Subfase 1 foram ensinados os fonemas /n/ e /i/, na Subfase 2 os fonemas /b/ e /o/, na Subfase 3 os fonemas /f/ e /a/ e na Subfase 4 os fonemas /1/ e /e/. Em todas essas subfases o ensino dos fonemas seguiu a sequência descrita.

Após a finalização do treino das quatro primeiras subfases, o participante foi submetido a Subfase 5, chamada de treino misto. Esta subfase empregou os oito fonemas ensinados nas subfases anteriores e foi composta por três blocos, dois blocos de treino AC e um CD. Cada um desses blocos foi composto por oito tentativas e o critério de aprendizagem foi de 100\% de acertos. Respostas incorretas em blocos AC implicavam na repetição do bloco. No bloco $\mathrm{CD}$, a emissão de respostas incorretas determinava o retorno do treino para o bloco anterior de treino AC.

\section{Fase 2 - Teste Inicial de Leitura Oral}

O objetivo desta fase foi avaliar o efeito do treino isolado de fonemas na leitura oral de palavras impressas com pseudoalfabeto. Foi realizado um teste de nomeação ou leitura oral de 26 palavras impressas, sendo que 12 destas palavras foram utilizadas no treino e 14 nos testes, nas fases subsequentes do experimento.

Em cada tentativa de teste uma palavra escrita com pseudoalfabeto foi apresentada na parte superior central da tela. O experimentador forneceu a seguinte instrução: "Nomeie o que foi apresentado na tela".

Esta fase foi composta por 26 tentativas, sendo uma com cada palavra. Não havia consequências programadas para as respostas do participante. As respostas corretas ou incorretas foram seguidas da apresentação da próxima tentativa. 


\section{Fase 3 - Ciclos de Treino AC/CD e Testes Parciais C'D'/ A'C' de palavras}

Os objetivos desta fase foram ensinar ao participante as relações entre palavras faladas e palavras impressas com pseudoalfabeto e verificar a leitura de palavras novas, formadas pela recombinação das letras das palavras de treino (palavras de recombinação ou de teste).

Para cada conjunto de palavras, o treino e os testes parciais ocorreram em uma sequência específica de tarefas, que se constitui em um ciclo (em cinza no diagrama da Figura 4). Foram realizados seis ciclos de treino e testes parciais com pseudopalavras. Em cada ciclo foi realizado o treino das relações entre palavras ditadas e palavras impressas com pseudoalfabeto (relações AC) e da leitura oral de palavras escritas com pseudoalfabeto (relações CD). Duas palavras diferentes foram ensinadas a cada ciclo, totalizando 12 palavras de treino. Cada ciclo foi finalizado com testes parciais para verificar a leitura oral (Teste C'D') de quatro palavras de recombinação e a leitura receptiva (Teste $A^{\prime} C^{\prime}$ ) destas mesmas quatro palavras. As palavras de recombinação FALO e BENA foram apresentadas nos testes parciais de todos os ciclos, sendo chamadas de palavras "constantes" de teste. As outras duas palavras de recombinação foram diferentes e completamente novas a cada ciclo, totalizando 14 palavras de teste.

A seguir serão descritos o conjunto de tarefas apresentadas em cada ciclo:

\section{1) Pré-Teste de Leitura Oral}

Cada ciclo foi iniciado com um pré-teste de leitura oral das duas palavras que seriam ensinadas no ciclo. Cada palavra foi apresentada individualmente e o experimentador forneceu a seguinte instrução: "Nomeie o que foi apresentado na tela". 
O erro de pelo menos uma das duas palavras do ciclo, determinava o início do treino $\mathrm{AC} / \mathrm{CD}$ com palavras. Caso o participante acertasse as duas palavras no PréTeste, somente os Blocos 10 e 11 do treino AC/CD com palavras eram conduzidos.

\section{2) Treino $A C / C D$ com palavras}

O Treino AC/CD com palavras foi realizado de maneira idêntica ao Treino $\mathrm{AC} / \mathrm{CD}$ de Fonemas (Fase 1). A diferença foi de que no Treino AC/CD com palavras foram ensinadas duas palavras por ciclo, em seis ciclos, totalizando 12 palavras de treino. As duas palavras foram ensinadas em cada ciclo por meio de um treino composto por blocos de tentativas de ensino individual de cada palavra, e por blocos de tentativas que empregaram as duas palavras ensinadas no ciclo. A estrutura do treino $\mathrm{AC} / \mathrm{CD}$ de cada ciclo seguiu, para o ensino de palavras, a mesma sequência de blocos descrita na Tabela 5 .

A aquisição do critério de aprendizagem nos blocos finais de treino AC (Bloco 10) e CD (Bloco 11) de palavras determinaram o encerramento do treino AC/CD para as duas palavras do ciclo.

\section{3) Teste Parciais $C^{\prime} D^{\prime} / A^{\prime} C^{\prime}$}

Os testes parciais foram realizados com o objetivo de avaliar a emergência da leitura de novas palavras. Foram avaliadas a leitura oral (Teste C'D') e a leitura receptiva (Teste $A^{\prime} C^{\prime}$ ) de quatro palavras por ciclo. As mesmas quatro palavras foram avaliadas em ambos os testes e foram compostas por duas palavras "constantes" e duas palavras novas a cada ciclo. As palavras constantes foram FALO e BENA e estiveram presentes nos testes parciais de todos os ciclos. O participante foi primeiramente submetido ao teste de leitura oral (C'D') das quatro palavras de 
recombinação, que foi composto por oito tentativas, sendo duas com cada palavra. Em seguida, o participante foi submetido ao teste de leitura receptiva (A'C') que foi constituído por oito tentativas de MTS auditivo-visual, sendo duas com cada palavra de teste. Três estímulos de escolha foram apresentados em todas as tentativas de teste A'C'. As palavras de recombinação foram apresentadas em duas sequências distintas tanto no teste de leitura oral (Anexo C) como no teste de leitura receptiva (Anexo B).

\section{Fase 4 - Teste Final de Leitura Oral}

O objetivo desta fase foi avaliar a leitura oral das 26 palavras (12 de treino e 14 de teste) empregadas no experimento.

Em cada tentativa de teste uma palavra escrita com pseudoalfabeto foi apresentada na parte superior central da tela. $\mathrm{O}$ experimentador forneceu a seguinte instrução: "Nomeie o que foi apresentado na tela".

Esta fase foi composta por 26 tentativas, sendo uma com cada palavra. Não havia consequências programadas para as respostas do participante. As respostas corretas ou incorretas foram seguidas da apresentação da próxima tentativa. 


\section{Condição Experimental II}

\section{Treino Sobreposto de Fonemas}

O procedimento da Condição Experimental II empregou de forma sobreposta, isto é na mesma fase, os ciclos de treino e testes parciais de palavras e o treino de fonemas. A sequência de fases dessa condição experimental foi: 1) Ciclos de Treino AC/CD e de Testes Parciais C'D'/A'C' de palavras com Treino Sobreposto de Fonemas e 2) Teste Final de Leitura Oral de Palavras.

\section{Fase 1 - Ciclos de Treino AC/CD e de Testes Parciais C'D'/ A'C' de palavras com Treino Sobreposto de Fonemas}

Os objetivos desta fase foram: 1) ensinar ao participante as relações entre palavras faladas e palavras impressas com pseudoalfabeto, e verificar a leitura recombinativa de palavras novas (testes parciais pré-sobreposição) e, em seguida, 2) ensinar ao participante as relações entre as letras do pseudoalfabeto e os sons correspondentes a cada uma dessas letras, e verificar o efeito dessa aprendizagem na leitura das mesmas palavras de recombinação testadas anteriormente (testes parciais pós-sobreposição).

Desta forma, nesta fase, os ciclos de treino $\mathrm{AC} / \mathrm{CD}$ e testes parciais C'D'/A'C' de palavras ocorreram juntamente com a inserção de subfases de treino de fonemas. A inserção ou não das subfases de treino de fonemas dependeu do desempenho do participante nos testes parciais de leitura recombinativa de cada ciclo. Os testes parciais que ocorreram antes da inserção da subfase do treino de fonemas foram chamados de pré-sobreposição e os testes parciais que foram repetidos após a inserção do treino de fonemas foram chamados de pós-sobreposição. A Figura 5 mostra a sequência de treinos e testes parciais a que o participante foi submetido em cada ciclo. 


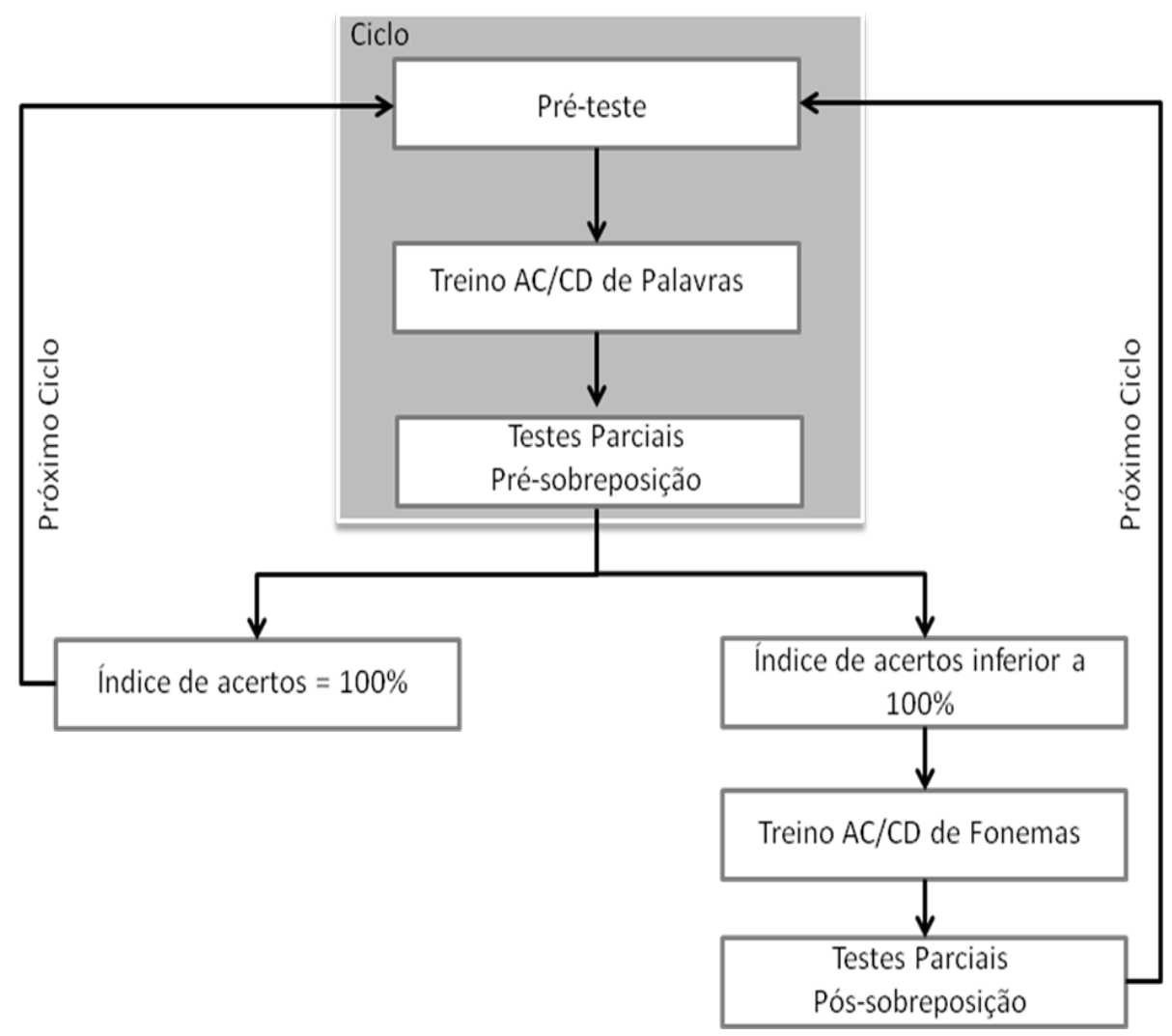

Figura 5. Sequência de treinos e de testes parciais a que o participante foi submetido em cada ciclo da Condição Experimental II.

O participante foi submetido, em cada ciclo, ao treino $\mathrm{AC} / \mathrm{CD}$ de palavras seguido pelos testes parciais pré-sobreposição de leitura recombinativa (Testes C'D'e $\left.\mathrm{A}^{\prime} \mathrm{C}^{\prime}\right)$. O desempenho do participante nesses testes parciais serviu como critério para determinar o próximo passo do procedimento. Quando o participante apresentou índice de acertos igual a 100\% nos testes parciais pré-sobreposição C'D' e A'C', o ciclo foi finalizado e o participante direcionado para o próximo ciclo de treino e testes parciais de palavras. Quando o desempenho nos testes parciais pré-sobreposição foi inferior a $100 \%$ de acertos, seja nos testes C'D'ou A'C', o participante foi submetido a uma subfase de treino $\mathrm{AC} / \mathrm{CD}$ de fonemas. Cada subfase de treino de fonemas ensinou ao participante dois fonemas. Após a aquisição do critério de aprendizagem na subfase de treino de fonemas, o participante foi submetido aos testes parciais pós- 
sobreposição (C'D'e A'C') do ciclo, que avaliaram a leitura recombinativa das mesmas quatro palavras apresentadas nos testes pré-sobreposição.

Os testes parciais pós-sobreposição, quando realizados, se constituíam na última tarefa do ciclo. Desta forma, após a realização dos testes parciais póssobreposição, independentemente do desempenho do participante nestes testes, o ciclo era finalizado e o participante direcionado para o próximo ciclo de treino e testes parciais com palavras (ver Figura 5).

O procedimento do treino $\mathrm{AC} / \mathrm{CD}$ empregado para o ensino das duas palavras de cada ciclo foi idêntico ao empregados na Fase 3 da Condição Experimental I.

O treino de fonemas ocorreu de forma que a Subfase 1 (fonemas $/ \mathrm{n} / \mathrm{e} / \mathrm{i} /$ ) foi inserida após o Ciclo 1, a Subfase 2 (fonemas /b/ e /o/) após o Ciclo 2, a Subfase 3 (fonemas /f/ e /a/) após o Ciclo 3 e Subfase 4 (fonemas /1/ e /ع/) após o Ciclo 4 . O procedimento de treino utilizado nas subfases de Treino AC/CD de Fonemas foi idêntico ao empregado na Fase 1 da Condição Experimental I.

\section{Fase 2 - Teste Final de Leitura Oral}

O objetivo desta fase foi avaliar a leitura oral das 26 palavras (12 de treino e 14 de teste) empregadas no experimento. O procedimento empregado nesta fase foi idêntico ao do Teste Final de Leitura Oral (Fase 4) da Condição Experimental I. 


\section{Condição Experimental III}

Treino de Palavras

O procedimento da Condição Experimental 1II foi composto por duas fases: 1) Ciclos de Treino AC/CD e Testes Parciais C'D'/A'C' de palavras e 2) Teste Final de Leitura Oral de Palavras

\section{Fase 1 - Ciclos de Treino AC/CD e Testes Parciais C'D'/A'C' com palavras}

Os objetivos desta fase foram ensinar ao participante as relações entre palavras faladas e palavras impressas com pseudoalfabeto, e verificar a leitura de palavras novas, formadas pela recombinação das letras das palavras de treino (palavras de recombinação ou de teste). O procedimento empregado nesta fase foi idêntico ao da Fase 3 da Condição Experimental I.

\section{Fase 2 - Teste Final de Leitura Oral}

O objetivo desta fase foi avaliar a leitura oral das 26 palavras (12 de treino e 14 de teste) empregadas no experimento. O procedimento empregado nesta fase foi idêntico ao do Teste Final de Leitura Oral (Fase 4) da Condição Experimental I. 


\section{RESULTADOS}

Serão apresentados a seguir os resultados referentes a cada Condição Experimental. Nos treinos, a análise dos resultados foi realizada considerando o número de tentativas a que o participante foi submetido e o número total de erros que cada participante apresentou, tanto no treino de fonemas quanto no treino de palavras. Nos testes, foram analisadas a porcentagem de acertos apresentada por cada participante nos testes de leitura recombinativa e os erros apresentados nos testes C'D'. A análise dos erros dos participantes nos testes $A^{\prime} C^{\prime}$ não será apresentada, para nenhuma Condição Experimental, pois não foi possível identificar um padrão específico de erros.

\section{Condição Experimental I}

\section{Treino Prévio de Fonemas}

Foram expostos a essa condição experimental quatro participantes: P1, P2, P3 e P4. Os participantes concluíram todas as fases previstas no procedimento. As sessões experimentais foram realizadas de duas a cinco vezes por semana, com duração media de 20 minutos para todos os participantes do estudo, em todas as Condições Experimentais.

\section{Fase 1 - Treino AC/CD de Fonemas}

A Tabela 6 apresenta o número de tentativas realizadas até a aquisição do critério de aprendizagem para cada participante, em cada uma das subfases, e o número total de erros que cada participante apresentou no treino de fonemas. Cada uma das quatro primeiras subfases ensinou ao participante dois fonemas. A Subfase 5, 
chamada de treino misto, empregou os oito fonemas ensinados nas subfases anteriores. O número mínimo de tentativas programadas para cada uma das cinco subfases do treino de fonemas é apresentado na tabela como referência para a análise do número de tentativas a que cada participante foi submetido.

Tabela 6. Número de tentativas até critério em cada subfase do treino de fonemas e número total de erros apresentados no treino de fonemas da Condição I.

\begin{tabular}{|c|c|c|c|c|c|}
\hline \multirow{2}{*}{ Subfases } & \multirow{2}{*}{$\begin{array}{c}\text { Mínimo } \\
\text { Programado }\end{array}$} & \multicolumn{4}{|c|}{ Participantes } \\
\hline & & $\mathrm{P} 1$ & $\mathrm{P} 2$ & $\mathrm{P} 3$ & $\mathrm{P} 4$ \\
\hline 1 Fonemas /n/ - /i/ & 33 & 49 & 33 & 38 & 70 \\
\hline 2 Fonemas $/ \mathrm{b} /-/ \mathrm{o} /$ & 33 & 33 & 33 & 33 & 49 \\
\hline 3 Fonemas /f/ - /a/ & 33 & 33 & 53 & 33 & 33 \\
\hline 4 Fonemas $/ 1 /-/ \varepsilon /$ & 33 & 53 & 73 & 48 & 43 \\
\hline 5 Treino Misto & 24 & 48 & 64 & 48 & 56 \\
\hline Tentativas (Total) & 156 & 216 & 256 & 200 & 251 \\
\hline No. Total de Erros & & 17 & 29 & 11 & 22 \\
\hline
\end{tabular}

Todos os participantes necessitaram de um número maior do que o total de tentativas programadas para a fase, que foi 156 . Os resultados demonstraram que as Subfases 1 e 4, as quais ensinaram os fonemas $/ \mathrm{n} /-\mathrm{i} / \mathrm{e} / 1 /-/ \varepsilon /$, foram as que os participantes precisaram do maior número de tentativas extras para atingir o critério de aprendizagem. No treino $\mathrm{AC} / \mathrm{CD}$ de fonemas, respostas incorretas em tentativas $\mathrm{CD}$, implicavam no retorno do treino para o bloco anterior $\mathrm{AC}$ seguido pela reapresentação do bloco $\mathrm{CD}$. Esse retorno poderia ocorrer até no máximo duas vezes, sem que outro procedimento de correção fosse incluído. Nas Subfases 1 e 4 foi necessária a aplicação de um procedimento adicional de correção após o treino de nomeação oral (CD) envolvendo os fonemas /n/ (Subfase 1) e /1/ (Subfase 4). Após o 
segundo retorno ao bloco anterior de treino $\mathrm{AC}$, as respostas incorretas em tentativas CD foram seguidas pela emissão da resposta correta pelo experimentador e pelo retorno ao bloco anterior $\mathrm{AC}$. Dois dos quatro participantes (P1 e P4) foram submetidos ao procedimento adicional de correção na Subfase 1 e todos os participantes foram submetidos ao procedimento adicional de correção na Subfase 4.

Na Subfase 5, o número de tentativas necessárias para a atingir o critério de aprendizagem também foi superior ao programado para todos os participantes.

No Treino $\mathrm{AC} / \mathrm{CD}$ de fonemas como um todo o número de erros foi maior em tentativas $\mathrm{CD}$ do que AC para todos os participantes. Nas quatro subfases iniciais do treino de fonemas, $\mathrm{P} 2$ e P3 acertaram todas as tentativas $\mathrm{AC}$ e os erros apresentados por esses participantes ocorreram somente em tentativas CD. P1 e P4 apresentaram erros tanto em tentativas $\mathrm{AC}$ como $\mathrm{CD}$ na Subfase 1, mas nas demais subfase os erros concentraram-se exclusivamente em tentativas CD.

\section{Fase 2 - Teste Inicial de Leitura Oral (C'D')}

No Teste Inicial de Leitura Oral foram apresentadas as 26 palavras empregadas no experimento. Nenhum participante leu corretamente as palavras apresentadas. No entanto, P2, P3 e P4 soletraram corretamente, fonema a fonema, todas as palavras. P1 apresentou um único erro, soletrando corretamente 25 das 26 palavras. O erro apresentado por P1 consistiu na emissão incorreta de apenas um dos quatro fonemas que compõem a palavra.

\section{Fase 3 - Ciclos de Treino AC/CD e de Testes Parciais C'D'/ A'C' de palavras}

Nesta fase os Treinos AC/CD e os Testes Parciais C'D'/A'C' de palavras ocorreram de forma intercalada ao longo dos ciclos. No entanto, os resultados 
referentes aos treinos e aos testes parciais serão apresentados separadamente para facilitar a análise. A ordem de apresentação dos resultados será: Treino AC/CD de palavras e Testes Parciais C'D'/A'C' de leitura recombinativa.

\section{Treino AC/CD de palavras}

A Tabela 7 apresenta o número de tentativas realizadas até a aquisição do critério de aprendizagem para cada participante em cada ciclo, e o número total de erros que cada participante apresentou no treino de palavras. O número mínimo de tentativas programadas para cada ciclo é apresentado como referência para a análise do número de tentativas a que cada participante foi submetido.

Tabela 7. Número de tentativas até critério em cada ciclo do treino de palavras e número total de erros apresentados no treino de palavras da Condição I.

\begin{tabular}{cccccc}
\hline Ciclos & $\begin{array}{c}\text { Mínimo } \\
\text { Programado }\end{array}$ & Participantes & \\
& & P1 & P2 & P3 & P4 \\
\hline \hline 1 & 33 & 33 & 33 & 49 & 48 \\
2 & 33 & 33 & 33 & 10 & 10 \\
3 & 33 & 10 & 10 & 33 & 10 \\
4 & 33 & 33 & 10 & 10 & 10 \\
5 & 33 & 10 & 10 & 10 & 10 \\
6 & 33 & 33 & 10 & 10 & 10 \\
& & & & & \\
Tentativas (Total) & 198 & 152 & 106 & 122 & 98 \\
No. Total de Erros & & 0 & 0 & 2 & 2 \\
\hline
\end{tabular}

Todos os participantes terminaram a fase com um número de tentativas inferior ao programado. O total de tentativas programadas para a fase foi de 198 e o número total de tentativas a que os participantes foram submetidos variou entre 98 (P4) e 152 (P1). Isso foi possível porque, no treino $\mathrm{AC} / \mathrm{CD}$ de palavras, das três 
condições experimentais, o acerto no Pré-Teste das duas palavras que seriam ensinadas no ciclo implicavam na redução de blocos de treino. Assim, quando o participante acertava as duas palavras no Pré-Teste do ciclo era exposto somente aos Blocos 10 e 11 do treino de palavras e o número de tentativas do ciclo diminuía de 33 para 10.

De forma geral, os resultados demonstraram que o procedimento empregado no treino possibilitou a aquisição do critério de aprendizagem com a emissão de um número muito reduzido de erros. Somente dois dos quatro participantes (P3 e P4) apresentaram erros nas tentativas de treino. Os erros apresentados por P3 e P4 concentraram-se exclusivamente no ciclo 1. P3 apresentou um erro em uma tentativa $\mathrm{AC}$ e outro em uma tentativa CD. P4 apresentou os dois erros em tentativas CD.

\section{Testes Parciais de Leitura Recombinativa C'D' e A'C'}

Os resultados dos testes parciais de leitura recombinativa são apresentados na Figura 6. Os gráficos à esquerda mostram os resultados referentes aos testes de leitura recombinativa oral (Testes C'D') e os gráficos à direta os resultados dos testes de leitura recombinativa receptiva (Testes $\left.\mathrm{A}^{\prime} \mathrm{C}^{\prime}\right)$. $\mathrm{O}$ eixo das ordenadas mostra a porcentagem de acertos nos testes parciais C'D' e A'C' de cada participante, e o eixo das abscissas mostra cada um dos ciclos a que o participante foi submetido. 

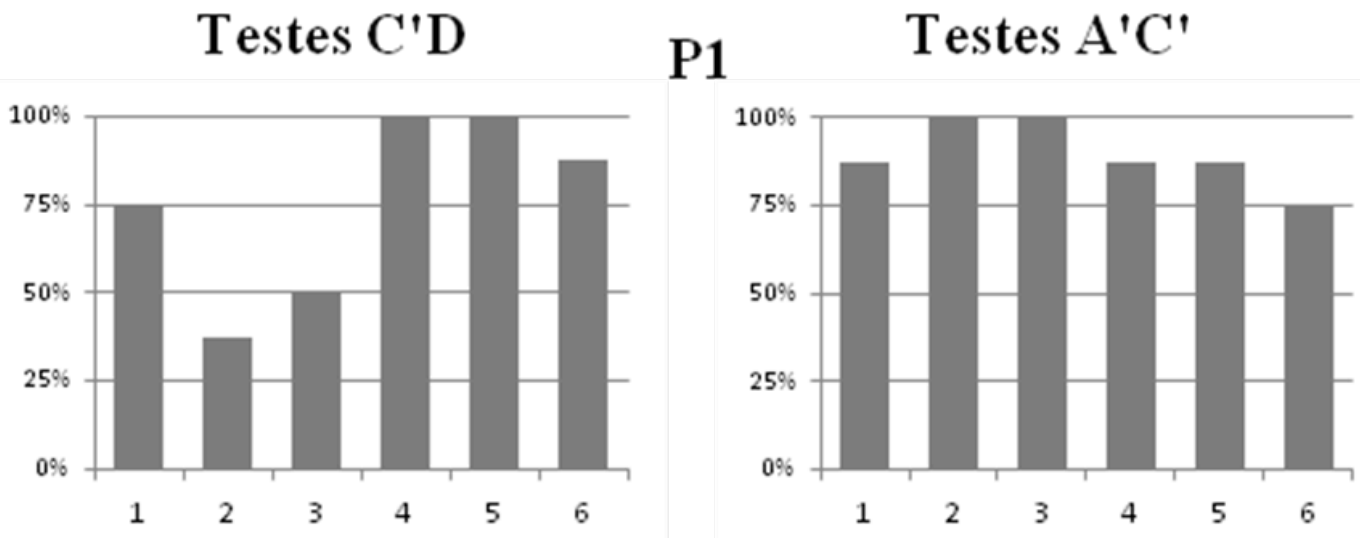

P2
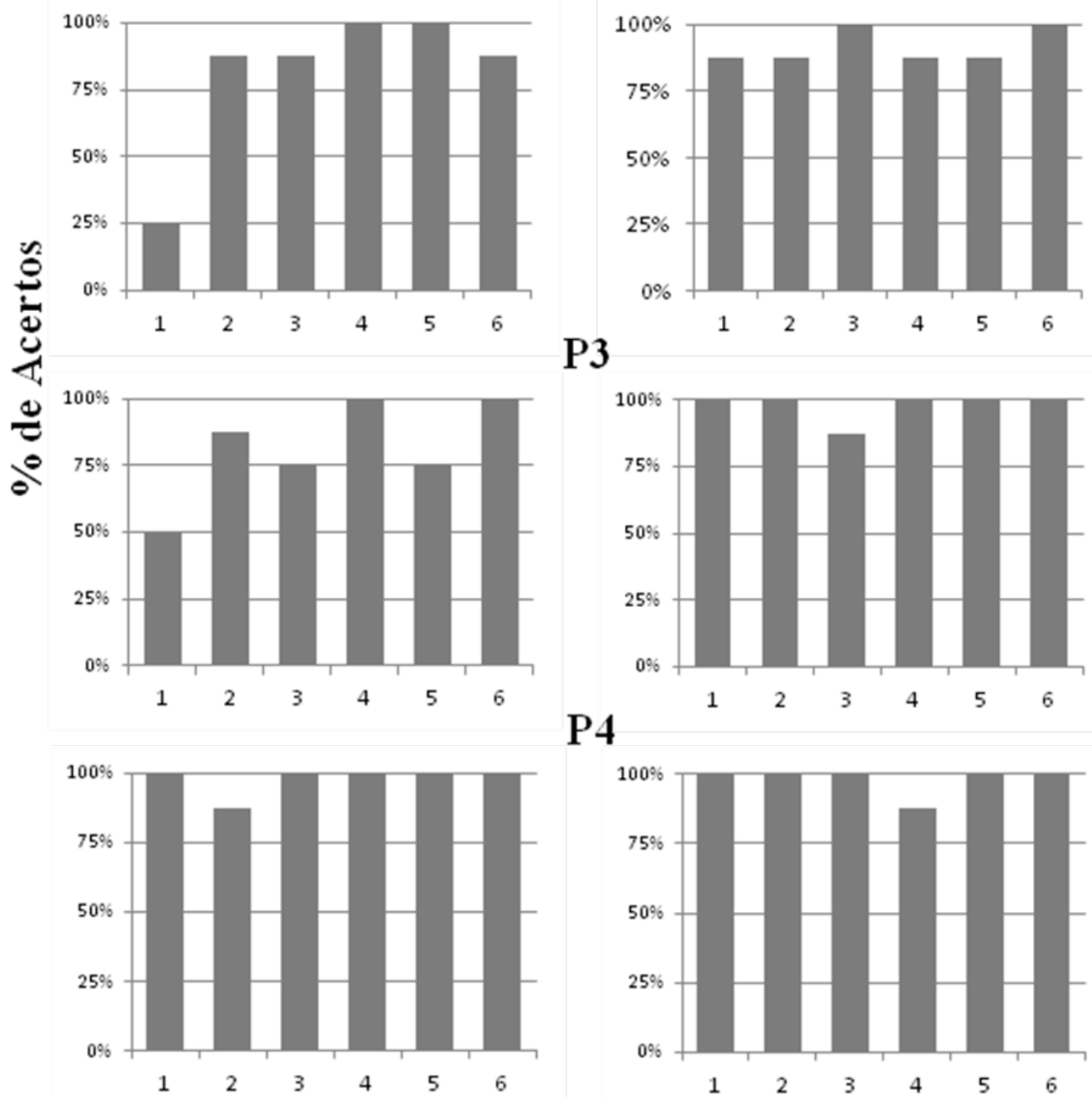

\section{Ciclos}

Figura 6. Porcentagens de acerto de cada participante nos testes parciais C'D' e A'C' de cada ciclo da Condição I. 
Nos testes parciais C'D' todos os participantes apresentaram índices de acerto iguais ou superiores a $25 \%$ já no primeiro ciclo. A partir do Ciclo 3 nenhum participante apresentou resultados inferiores a 50\%. Os índices de acerto dos Ciclos 4 a 6 permaneceram entre 75 e 100\% para todos os participantes. P4 foi o participante que apresentou o melhor desempenho atingindo $100 \%$ de acertos em cinco dos seis ciclos de testes parciais.

Os resultados dos testes parciais $\mathrm{A}^{\prime} \mathrm{C}^{\prime}$ demonstraram pouca variabilidade entre os ciclos e entre participantes, permanecendo com índices de acerto entre 75 e $100 \%$ para todos os participantes em todos os ciclos. Dois dos quatro participantes (P3 e P4) apresentaram índices de $100 \%$ de acertos em cinco dos seis ciclos de testes parciais. Ambos os participantes erraram somente uma tentativa de teste, P3 no Ciclo 3 e P4 no Ciclo 4. P2 apresentou $100 \%$ de acertos em dois dos seis ciclos de testes parciais e $87,5 \%$ de acertos nos quatro ciclos restantes, o que representa o erro de uma tentativa em cada um desses ciclos. P1 também obteve resultados de $100 \%$ de acertos em dois ciclos. Nos quatro ciclos restantes os índices de acertos de P1 foram de 87,5\% em três ciclos e de $75 \%$ em um ciclo.

Analisando a Figura 6, foram observados índices maiores de acertos e menor variabilidade entre os participantes nos testes parciais $A^{\prime} C^{\prime}$ do que nos testes parciais C'D'.

Será apresentada a seguir a análise dos principais erros apresentados pelos participantes nos testes C'D'. A análise dos erros dos participantes nos testes $\mathrm{A}^{\prime} \mathrm{C}^{\prime}$ não será apresentada, para nenhuma Condição Experimental, pois não foi possível identificar um padrão específico de erros. Nos testes A'C', cada palavra de teste foi apresentada duas vezes. Os estímulos de escolha incorretos foram diferentes a cada apresentação da palavra e possuíam diferenças críticas (apenas uma letra) em relação 
ao estímulo de escolha correto, o que dificultou a verificação de um padrão de erros intra ou inter participantes.

\section{Análise de erros nos testes C'D'}

A Tabela 8 apresenta os erros (trocas entre fonemas) apresentados com maior frequência nos testes C'D' por cada participante.

Tabela 8. Erros apresentados com maior frequência nos testes C'D' por cada participante da Condição I.

\begin{tabular}{lcccc}
\hline \multicolumn{1}{c}{$\begin{array}{c}\text { Erros } \\
\text { Troca entre Fonemas }\end{array}$} & \multicolumn{4}{c}{ Participantes } \\
\hline \hline$/ \mathrm{P} / \mathrm{e} / \mathrm{o} /$ & $\mathrm{P} 2$ & $\mathrm{P} 3$ & $\mathrm{P} 4$ \\
\hline $\mathrm{n} / \mathrm{e} / \mathrm{m} /$ & 1 & 4 & 1 & 0 \\
$/ \mathrm{l} / \mathrm{e} / \mathrm{n} /$ & 9 & 0 & 4 & 0 \\
$/ \mathrm{b} / \mathrm{e} / \mathrm{l} /$ & 3 & 2 & 0 & 0 \\
$/ \mathrm{n} / \mathrm{e} / \mathrm{b} /$ & 0 & 1 & 3 & 0 \\
\hline
\end{tabular}

Todos os participantes apresentaram maior número de erros nos testes C'D' dos Ciclos 1 a 3. Dos erros apresentados por P1, P2 e P3, seis referiram-se a trocas entre os fonemas $/ \varepsilon /$ e $/ \mathrm{o} /$. Todas as trocas entre os fonemas $/ \varepsilon / \mathrm{e} / \mathrm{o} /$ que foram observadas na Condição I ocorreram quando diante de uma palavra de teste o participante disse o nome de uma palavra de treino. Por exemplo, diante da palavra de teste NIBE, o participante leu NIBO ou diante da palavra de teste FALO o participante leu FALE. Isso também foi observado para P3, quando esse participante apresentou trocas entre os fonemas $/ 1 / \mathrm{e} / \mathrm{b} /$. Neste caso, diante da palavra de teste NILO P3 leu NIBO, e diante da palavra de teste FABE o participante leu FALE. P1 e P3 foram os únicos participantes que apresentaram trocas entre os fonemas $/ \mathrm{n} / \mathrm{e} / \mathrm{m} /$ 
nos testes parciais. Essas trocas somaram 13 erros e foram verificadas quando por exemplo, diante da palavra de teste BENA, o participante leu BEMA ou diante da palavra NOFA, o participante leu MOFA. P4 apresentou um único erro que consistiu na troca dos fonemas $/ \mathrm{n} / \mathrm{e} / \mathrm{b} /$ em uma palavra de teste do Ciclo 2 .

\section{Fase 4 - Teste Final de Leitura Oral (C'D')}

No Teste Final de Leitura Oral todos os participantes apresentaram leitura recombinativa. P1, P2 e P3 apresentaram índices de acertos de 96,15\%, o que significa o erro de apenas uma palavra dentre as 26 apresentadas. P4 errou a leitura de duas palavras e apresentou índice de acertos de 92,30\%. Para todos os participantes o erro de leitura consistiu na emissão incorreta de apenas um dos quatro fonemas que compõem as palavras. As palavras lidas incorretamente por P1 e P3 foram palavras de treino e por P2 e P4 palavras de teste. 


\section{Condição Experimental II}

\section{Treino Sobreposto de Fonemas}

Foram expostos a essa condição experimental quatro participantes: P5, P6, P7 e P8. Os quatro participantes concluíram todas as fases previstas no procedimento.

\section{Fase 1 - Ciclos de Treino AC/CD e de Testes Parciais C'D'/ A'C' de palavras com Treino Sobreposto de Fonemas}

Nesta fase, os ciclos de treino $\mathrm{AC} / \mathrm{CD}$ e testes parciais $\mathrm{C}^{\prime} \mathrm{D}^{\prime} / \mathrm{A}^{\prime} \mathrm{C}^{\prime}$ de palavras ocorreram juntamente com a inserção de subfases de treino de fonemas. O treino de fonemas ocorreu de maneira sobreposta ao treino de palavras, a depender do desempenho do participante nos testes parciais de leitura recombinativa de cada ciclo. Desta forma, o participante foi submetido, em cada ciclo, ao treino $\mathrm{AC} / \mathrm{CD}$ de palavras seguido pelos testes parciais C'D' e $A^{\prime} C^{\prime}$ de leitura recombinativa. Um desempenho inferior a $100 \%$ de acertos nos testes parciais do ciclo implicava na inserção de uma subfase de treino de fonemas e na reapresentação do testes parciais do ciclo ( ver Figura 5).

Apesar de os ciclos de Treinos AC/CD e Testes Parciais C'D'/A'C' de palavras terem ocorrido de forma intercalada com o Treino AC/CD de fonemas, os resultados de cada treino (palavras e fonemas) e dos testes parciais serão apresentados separadamente. A ordem de apresentação dos resultados será: Treino AC/CD de palavras; Treino $\mathrm{AC} / \mathrm{CD}$ de fonemas e Testes Parciais C'D'/A'C' de leitura recombinativa. 


\section{Treino AC/CD de palavras}

A Tabela 9 apresenta o número de tentativas realizadas até a aquisição do critério de aprendizagem para cada participante em cada ciclo, e o número total de erros que cada participante apresentou no treino de palavras. O número mínimo de tentativas programadas para cada ciclo é apresentado como referência para a análise do número de tentativas a que cada participante foi submetido.

Tabela 9. Número de tentativas até critério em cada ciclo do treino de palavras e número total de erros apresentados no treino de palavras da Condição II.

\begin{tabular}{cccccc}
\hline Ciclos & $\begin{array}{c}\text { Mínimo } \\
\text { Programado }\end{array}$ & Participantes & P5 & P6 & P7 \\
\hline \hline 1 & 33 & 33 & 55 & 46 & 33 \\
2 & 33 & 43 & 43 & 33 & 33 \\
3 & 33 & 10 & 10 & 10 & 33 \\
4 & 33 & 10 & 35 & 10 & 39 \\
5 & 33 & 10 & 10 & 10 & 53 \\
6 & 33 & 10 & 10 & 10 & 33 \\
& & & & & \\
Tentativas (Total) & 198 & 116 & 163 & 119 & 224 \\
No. Total de Erros & & 4 & 12 & 5 & 4 \\
\hline
\end{tabular}

Três dos quatro participantes (P5, P6 e P7) terminaram a fase com um número de tentativas inferior ao programado. P8 foi submetido a 224 tentativas e foi o participante que necessitou do maior número de tentativas para concluir o treino. Apesar de ter apresentado um número reduzido de erros, P8 foi o único participante que não acertou a leitura de palavras no Pré-Teste de nenhum ciclo e, portanto, foi submetido em todos os ciclos às 33 tentativas de treino inicialmente programadas.

De maneira geral, os resultados demonstraram que procedimento empregado no treino possibilitou a aquisição do critério de aprendizagem com a emissão de um 
número reduzido de erros. Os erros apresentados por P5 ocorreram exclusivamente em tentativas CD. Os demais participantes (P6, P7 e P8) apresentaram erros tanto tentativas $\mathrm{AC}$ como $\mathrm{CD}$.

\section{Treino AC/CD de fonemas}

O treino $\mathrm{AC} / \mathrm{CD}$ de fonemas foi constituído por quatro subfases e ocorreu de forma sobreposta aos ciclos de treino e testes parciais de palavras. A Tabela 10 apresenta o número de tentativas realizadas até a aquisição do critério de aprendizagem para cada participante, em cada uma das subfases, e o número total de erros que cada participante apresentou no treino de fonemas. O número mínimo de tentativas programadas para cada uma das quatro subfases é apresentado como referência para a análise do número de tentativas a que cada participante foi submetido.

Tabela 10. Número de tentativas até critério em cada subfase do treino de fonemas e número total de erros apresentados no treino de fonemas da Condição II.

\begin{tabular}{cccccc}
\hline Subfases & $\begin{array}{c}\text { Mínimo } \\
\text { Programado }\end{array}$ & P5 & P6 & P7 & P8 \\
\hline \hline Fonemas $/ \mathrm{n} /-/ \mathrm{i} /$ & 33 & 33 & 33 & 33 & 33 \\
2 Fonemas $/ \mathrm{b} /-$ /o/ & 33 & 33 & 33 & 33 & 33 \\
3 Fonemas /f/ - /a/ & 33 & - & - & - & 33 \\
4 Fonemas /1/ - / $/ 1$ & 33 & - & - & - & 33 \\
& 132 & 66 & 66 & 66 & 132 \\
Tentativas (Total) & & 0 & 0 & 0 & 0 \\
No. Total de Erros & & & & & \\
\hline
\end{tabular}

O número total de tentativas a que cada participante foi submetido nas quatro subfases do treino de fonemas variou entre 66 e 132. Todos os participantes 
concluíram as subfases do treino de fonemas com o número mínimo de tentativas programadas. $\mathrm{P} 8$ foi o único participante submetido às quatro subfases do treino de fonemas. Os participantes P5, P6 e P7 foram submetidos somente as Subfases 1 e 2. A inserção das subfases do treino de fonemas dependia de um desempenho inferior a $100 \%$ de acertos nos testes parciais de leitura recombinativa do ciclo. P5, P6 e P7 apresentaram $100 \%$ de acertos em todas as tentativas dos testes parciais de leitura recombinativa a partir do Ciclo 3, e portanto, não foram expostos as Subfases 3 e 4 do treino de fonemas.

\section{Testes Parciais de Leitura Recombinativa: C'D' e A'C'}

Os resultados dos testes parciais de leitura recombinativa são apresentados na Figura 7. Os gráficos à esquerda mostram os resultados referentes aos testes de leitura recombinativa oral (Testes C'D') e os gráficos à direta os resultados dos testes de leitura recombinativa receptiva (Testes $\left.\mathrm{A}^{\prime} \mathrm{C}^{\prime}\right)$. $\mathrm{O}$ eixo das ordenadas mostra a porcentagem de acertos nos testes parciais $C^{\prime} D^{\prime}$ e $A^{\prime} C^{\prime}$ de cada participante. Nos ciclos em que foram introduzidos o treino de fonemas, os resultados dos testes parciais pós-sobreposição do treino de fonemas são apresentados nas barras pretas. $\mathrm{O}$ eixo das abscissas mostra cada um dos ciclos a que o participante foi submetido. 

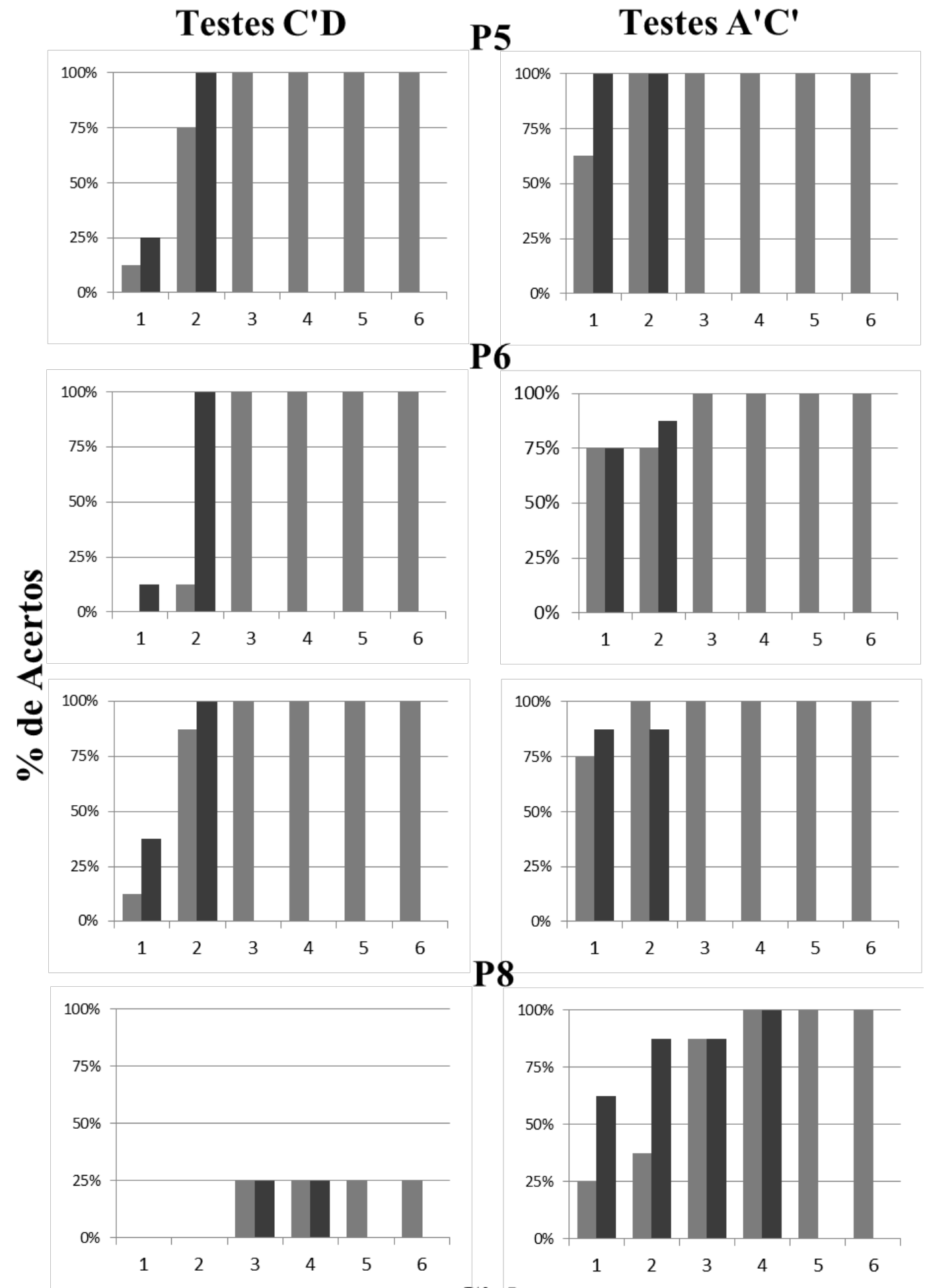

Ciclos

Figura 7. Porcentagens de acerto de cada participante nos testes parciais C'D' e A'C' de cada ciclo da Condição II. 
Nos testes C'D' a porcentagem de acerto nos testes parciais pós-sobreposição do treino de fonemas foi superior à porcentagem de acerto nos testes présobreposição, para três dos quatro participantes (P5, P6 e P7). Esses participantes apresentaram índice de $100 \%$ de acertos a partir do teste parcial pós-sobreposição do Ciclo 2 e mantiveram esse índice em todos os testes parciais C'D' dos Ciclos 3 a 6. Para P8 não foram observadas diferenças entre os resultados dos testes parciais C'D' pré e pós sobreposição do treino de fonemas. P8 apresentou índice de acertos igual a 25\% nos testes parciais C'D', a partir do Ciclo 3. Em todos esses testes uma única palavra foi lida corretamente por $\mathrm{P} 8 \mathrm{e}$, portanto, os resultados indicaram que o participante não apresentou leitura recombinativa oral das palavras de teste.

Nos testes A'C' a porcentagem de acertos nos testes parciais pós-sobreposição do treino de fonemas foi igual ou superior à porcentagem de acerto nos testes présobreposição, para todos os participantes em todos os ciclos. A única exceção observada foi P7 que apresentou no Ciclo 2 índice de acertos inferior nos testes parciais pós-sobreposição $(87,5 \%)$, quando comparado ao índice de acertos nos testes pré-sobreposição (100\%). De maneira geral, P5 foi o participante que apresentou melhor desempenho nos testes $\mathrm{A}^{\prime} \mathrm{C}^{\prime}$ com índices de $100 \%$ de acertos em todos os testes a partir do Ciclo 2. P6 e P7 apresentaram 100\% de acertos em quatro dos seis ciclos de testes parciais. Os resultados de P8 mostraram tendência crescente a partir do Ciclo 1, atingindo $100 \%$ de acertos nos testes parciais $A^{\prime} C^{\prime}$ no Ciclo 4 . Em contraste com os resultados apresentados por P8 nos testes C'D', os resultados dos testes parciais $A^{\prime} C^{\prime}$ são indicativos de emergência de leitura recombinativa receptiva das palavras de teste, para esse participante. 
Analisando a Figura 7, foram observados índices maiores de acertos e menor variabilidade entre os participantes nos testes parciais $\mathrm{A}^{\prime} \mathrm{C}^{\prime}$ do que nos testes parciais C'D'.

\section{Análise de erros nos testes C'D'}

A análise dos erros apresentados nos testes C'D' foi realizada por participante comparando os resultados obtidos nos testes parciais pré e pós treino de fonemas.

Os erros apresentados por P5 nos testes parciais pré-sobreposição do Ciclo 1 envolveram oito trocas diferentes entre dois fonemas. Das oito, duas envolviam o fonema $/ \mathrm{n} /$. Após a inserção do treino dos fonemas $/ \mathrm{n} / \mathrm{e} / \mathrm{i} /$, o participante foi submetido aos testes parciais pós-sobreposição do Ciclo 1 e nenhum erro envolvendo os fonemas treinados foi apresentado. No Ciclo 2, os erros apresentados por P5 nos testes parciais pré-sobreposição consistiram somente em trocas entre os fonemas $/ \varepsilon /$ e /o/. O participante foi submetido ao treino dos fonemas /b/ e /o/ e apresentou índice de $100 \%$ de acertos nos testes parciais pós-sobreposição do Ciclo 2.

P6 apresentou nos testes parciais pré-sobreposição do Ciclo 1 dois tipos de erros: dizer "Não sei" diante de seis das oito palavras de teste e trocas entre os fonemas $/ \varepsilon /$ e /o/. Nos testes parciais que ocorreram após a inserção do treino dos fonemas $/ \mathrm{n} / \mathrm{e} / \mathrm{i} /$, P6 apresentou três tipos diferentes de erro. O primeiro consistiu em dizer "Não sei" diante de três das oito palavras de teste, o segundo em acertar a primeira sílaba da palavra ("NI.. as outras duas eu não lembro") e o terceiro em trocas entre dois fonemas. Nos testes pós-sobreposição do Ciclo 1 não foram observadas trocas envolvendo o fonema $/ \mathrm{n} /$, mas foi observada uma troca envolvendo o fonema /i/. Nesta ocasião, diante da palavra NIBE, a primeira resposta emitida pelo participante foi NABE (considerada para análise), mas em seguida P6 se corrigiu e 
disse NIBE. Nos testes parciais pré-sobreposição do Ciclo 2, os erros apresentados por P6 envolveram predominantemente trocas entre os fonemas $/ \varepsilon / \mathrm{e} / \mathrm{o} / \mathrm{e}$ entre os fonemas /b/ e /1/. Após a inserção do treino dos fonemas /b/ e /o/ P6 apresentou índice de $100 \%$ de acertos nos testes parciais pós-sobreposição.

P7 apresentou nos testes parciais pré-sobreposição do Ciclo 1 dois tipos de erros: dizer "NIBO com FALE" diante de duas das oito palavras de teste, e quatro trocas entre dois fonemas diferentes. Após a inserção do treino dos fonemas /n/ e /i/, P7 foi submetido aos testes pós-sobreposição e não apresentou erro algum envolvendo o fonema /i/, mas apresentou dois erros envolvendo o fonema /n/. Esses erros consistiram na troca entre os fonemas $/ \mathrm{m} / \mathrm{e} / \mathrm{n} /$, os quais não haviam ocorrido nos testes parciais pré-sobreposição. Nos testes parciais pré-sobreposição do Ciclo 2, P7 apresentou um único erro que envolveu a troca entre os fonemas $/ \mathrm{b} / \mathrm{e} / \mathrm{n} /$. Após a inserção do treino dos fonemas /b/ e /o/ P7 apresentou índice de 100\% de acertos nos testes parciais pós-sobreposição.

Os erros apresentados por P8 em todos os testes parciais C'D' consistiram basicamente em dizer "Não sei" diante das palavras de teste e nomear aleatoriamente os palavras apresentadas (e.g., ODI, ILOG). Isto ocorreu tanto nos testes parciais pré quanto pós-sobreposição do treino de fonemas.

\section{Fase 2 - Teste Final de Leitura Oral (C'D')}

No Teste Final, três dos quatro participantes (P5, P6 e P7) apresentaram leitura recombinativa oral. P6 leu corretamente todas as palavras apresentadas. P5 e P7 apresentaram índices de acertos de 96,15\%, o que significa o erro de apenas uma palavra dentre as 26 apresentadas. Para estes dois participantes (P5 e P7) o erro de leitura apresentado consistiu na emissão incorreta de apenas um dos quatro fonemas 
que compõem as palavras. A palavra lida incorretamente por P5 foi uma palavra de treino e por P7 uma palavra de teste. P8 apresentou índice de acertos de 7,69\% e leu corretamente somente duas das 26 palavras. Esse resultado indica que o participante não apresentou repertório de leitura recombinativa oral. Umas das palavras lida corretamente por P8 foi uma palavra de treino e a outra foi uma das palavras constantes de teste. 


\section{Condição Experimental III}

\section{Treino de Palavras}

Foram expostos a essa condição experimental quatro participantes: P9, P10, P11 e P12. Os quatro participantes concluíram todas as fases previstas no procedimento.

\section{Fase 1- Ciclos de Treino AC/CD e de Testes Parciais C'D'/ A'C' de palavras}

Nesta fase os Treinos AC/CD e os Testes Parciais C'D'/A'C' de palavras ocorreram de forma intercalada ao longo dos ciclos. No entanto, os resultados referentes aos treinos e aos testes parciais serão apresentados separadamente para facilitar a análise. A ordem de apresentação dos resultados será: Treino AC/CD de palavras e Testes Parciais C'D'/A'C' de leitura recombinativa.

\section{Treino AC/CD de palavras}

A Tabela 11 apresenta o número de tentativas realizadas até a aquisição do critério de aprendizagem para cada participante, em cada ciclo, e o número total de erros que cada participante apresentou no treino de palavras. O número mínimo de tentativas programadas para cada ciclo é apresentado como referência para a análise do número de tentativas a que cada participante foi submetido. 
Tabela 11. Número de tentativas até critério em cada ciclo do treino de palavras e número total de erros apresentados no treino de palavras da Condição III.

\begin{tabular}{cccccc}
\hline Ciclos & $\begin{array}{c}\text { Mínimo } \\
\text { Programado }\end{array}$ & \multicolumn{4}{c}{ Participantes } \\
\hline \hline 1 & 33 & 33 & 35 & 46 & 51 \\
2 & 33 & 43 & 33 & 51 & 51 \\
3 & 33 & 33 & 33 & 33 & 39 \\
4 & 33 & 33 & 10 & 33 & 49 \\
5 & 33 & 10 & 10 & 33 & 37 \\
6 & 33 & 10 & 10 & 33 & 10 \\
& & & & & \\
Tentativas (Total) & 198 & 162 & 131 & 229 & 237 \\
No. Total de Erros & & 4 & 2 & 11 & 18 \\
\hline
\end{tabular}

Dois dos quatro participantes (P9 e P10) terminaram a fase com um número de tentativas inferior ao programado para a fase. P11 e P12 precisaram respectivamente de 229 e 237 tentativas para concluir o treino. P11 foi o único participante que não apresentou a leitura de palavras no Pré-Teste de nenhum dos ciclos e foi submetido em todos os ciclos às 33 tentativas de treino. P12 apesar de ter apresentado a leitura das palavras no Pré-Teste do Ciclo 6, foi o participante que apresentou o maior número de erros.

Para três dos quatro participantes (P9, P10 e P11) os erros nas tentativas de treino ocorreram exclusivamente nos Ciclos 1 e 2 , o que sugere que a precisão de respostas no treino aumentou ao longo dos ciclos. P9 e P10 apresentaram erros somente em tentativas CD e P11 apresentou erros tanto em tentativas AC quanto CD. Para P12 os erros em tentativas $\mathrm{AC}$ ocorreram em quatro ciclos diferentes, enquanto os erros nas tentativas CD ocorreram somente no ciclo 4 . 
Testes Parciais de Leitura Recombinativa: C'D' e A'C'

Os resultados dos testes parciais de leitura recombinativa são apresentados na Figura 8. Os gráficos à esquerda mostram os resultados referentes aos testes de leitura recombinativa oral (Testes C'D') e os gráficos à direta os resultados dos testes de leitura recombinativa receptiva (Testes $\left.\mathrm{A}^{\prime} \mathrm{C}^{\prime}\right)$. O eixo das ordenadas mostra a porcentagem de acertos nos testes parciais C'D' e A'C' de cada participante, e o eixo das abscissas mostra cada um dos ciclos a que o participante foi submetido. 
Testes C'D

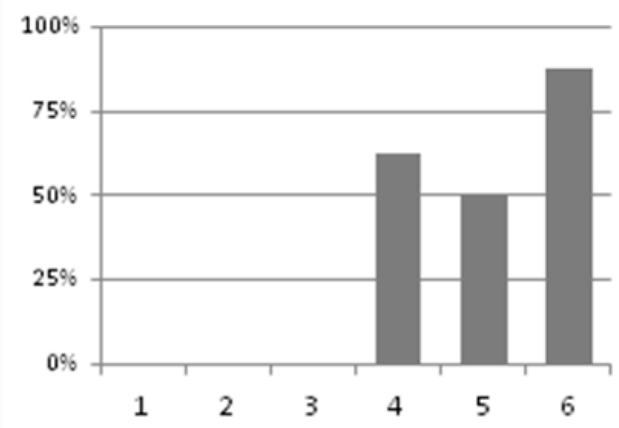

P10
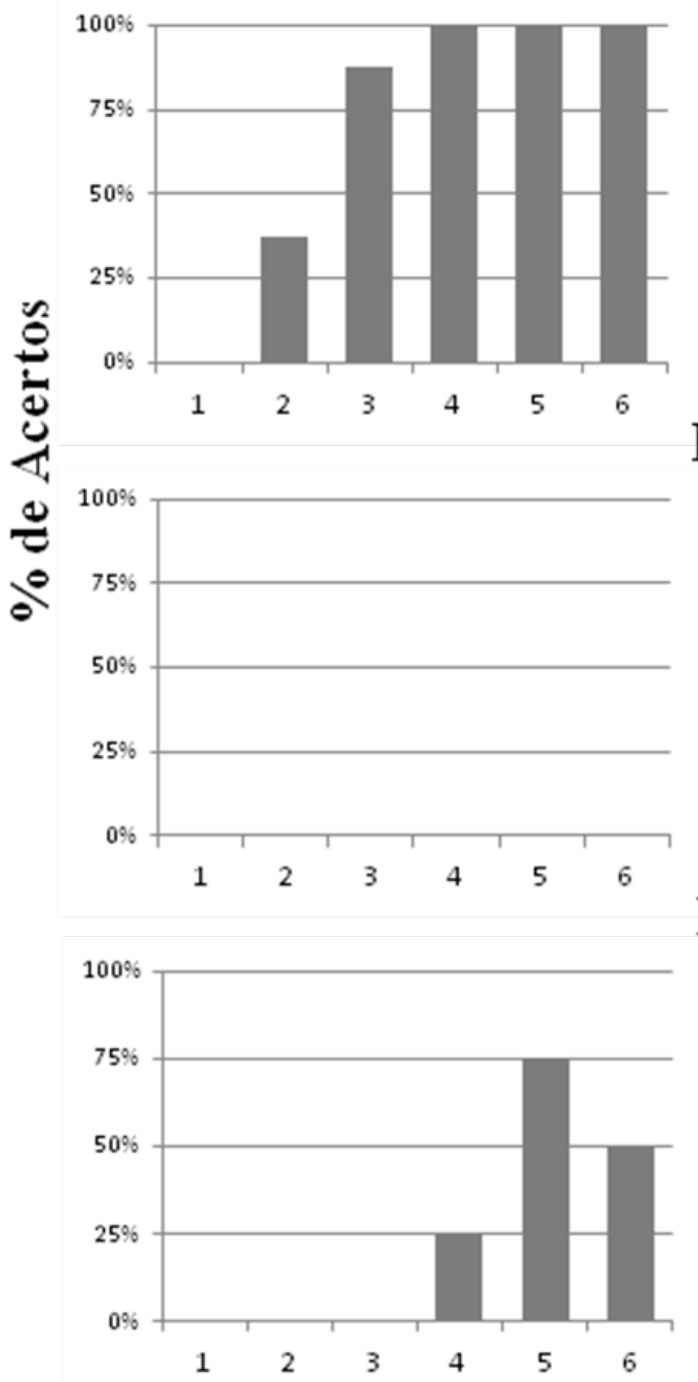

P9

Testes $\mathrm{A}^{\prime} \mathrm{C}^{\prime}$
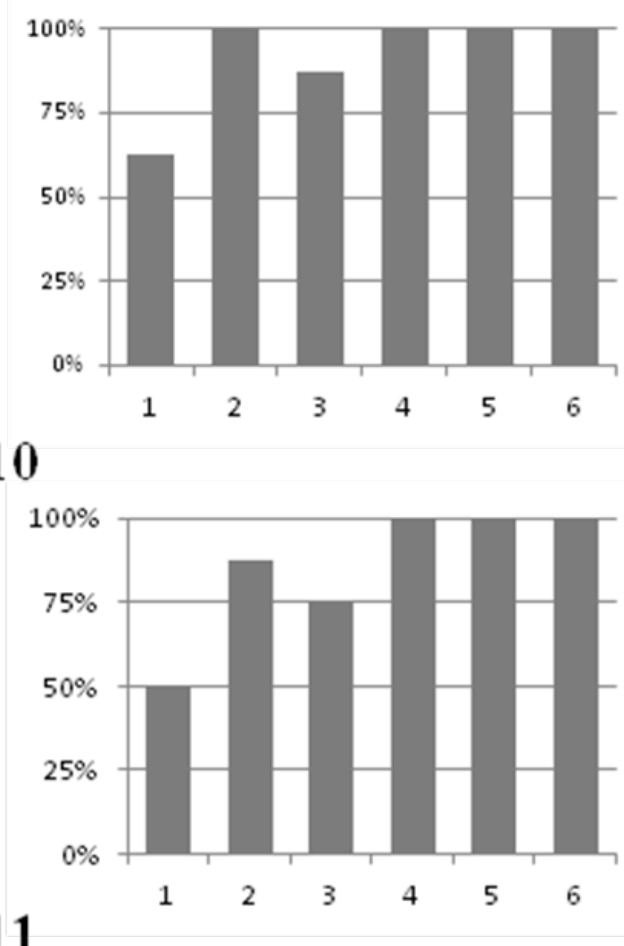

P11

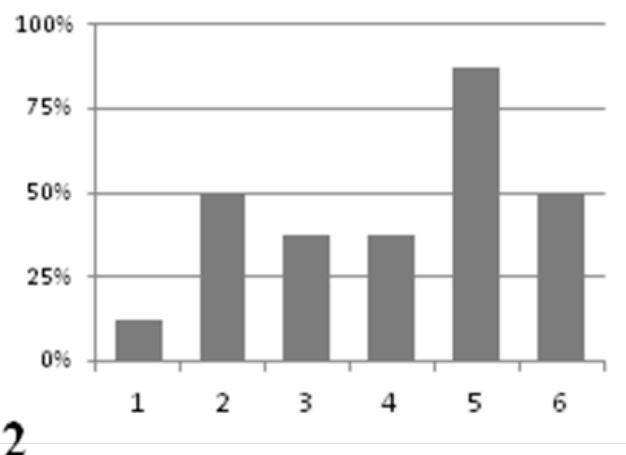

P12

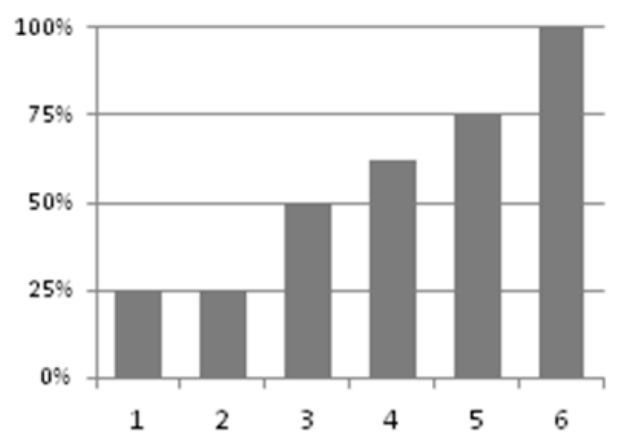

Ciclos

Figura 8. Porcentagens de acerto de cada participante nos testes parciais C'D' e A'C' de cada ciclo da Condição III. 
Nos testes parciais C'D três dos quatro participantes (P9, P11 e P12) apresentaram índice de acertos igual a $0 \%$ na leitura das palavras de teste dos Ciclos 1 a 3. Os índices de acertos dos Ciclos 4 a 6 apresentaram variabilidade entre os quatro participantes, permanecendo entre $0 \%$ e $100 \%$. P10 foi o participante que apresentou o melhor desempenho, com tendência crescente a partir do Ciclo 2 e atingindo $100 \%$ de acertos em três dos seis ciclos de testes parciais. Nos três ciclos finais, os índices de acerto permaneceram entre 50 e $87,5 \%$ para P9 e entre 25 e $75 \%$ para P12, e são indicativos de leitura recombinativa. P11 não leu corretamente nenhuma palavra nos testes C'D', o que sugere que o participante não adquiriu controle pelas unidades mínimas e leitura recombinativa oral.

Nos testes $\mathrm{A}^{\prime} \mathrm{C}^{\prime}$ dois dos quatro participantes (P9 e P10) apresentaram índices de $100 \%$ de acertos nos três ciclos finais de testes. Em relação aos três ciclos iniciais, ambos os participantes apresentaram índices de acerto iguais ou superiores a 50\% já no primeiro ciclo. $\mathrm{O}$ desempenho de $\mathrm{P} 12$ indica tendência crescente e aumento da precisão de resposta ao longo dos ciclos. Este participante apresentou índice de acertos de $25 \%$ no Ciclo 1 , e de $100 \%$ no Ciclo 6 . P11 foi o participante que apresentou o pior desempenho, com índices de acertos iguais ou inferiores a 50\% em cinco dos seis ciclos de teste.

Analisando a Figura 8, foram observados índices maiores de acertos e menor variabilidade entre os participantes nos testes parciais $\mathrm{A}^{\prime} \mathrm{C}^{\prime}$ do que nos testes parciais C'D'.

\section{Análise de erros nos testes C'D'}

A Tabela 12 apresenta os erros (trocas entre fonemas) apresentados com maior freqüência nos testes C'D' por cada participante. 
Tabela 12. Erros apresentados com maior freqüência nos testes $C^{\prime} D^{\prime}$ por cada participante da Condição III.

\begin{tabular}{lcccc}
\hline \multirow{2}{*}{$\begin{array}{c}\text { Erros } \\
\text { Troca entre Fonemas }\end{array}$} & \multicolumn{3}{c}{ Participantes } \\
& P9 & P10 & P11 & P12 \\
\hline \hline /E/ e /o/ & 9 & 8 & - & 5 \\
$/ \mathrm{a} / \mathrm{e} / \mathrm{i} /$ & 4 & 2 & - & 6 \\
$/ \mathrm{o} / \mathrm{e} / \mathrm{i} /$ & 4 & 0 & - & 0 \\
$/ \mathrm{l} / \mathrm{e} / \mathrm{b} /$ & 3 & 0 & - & 5 \\
$/ \mathrm{l} / \mathrm{i} / \mathrm{n} /$ & 3 & 1 & - & 0 \\
$/ \mathrm{a} / \mathrm{e} / \mathrm{E} /$ & 0 & 1 & - & 5 \\
$/ \mathrm{f} / \mathrm{e} / \mathrm{l} /$ & 0 & 3 & - & 0 \\
\hline
\end{tabular}

Para três dos quatro participantes (P9, P10 e P12) o maior número de erros ocorreu com trocas entres os fonemas / $/$ / e /o/ e entre os fonemas /a/ e /i/. Metade das trocas entre os fonemas $/ \varepsilon / \mathrm{e} / \mathrm{o} /$ ocorreram quando diante de uma palavra de teste $o$ participante disse o nome de uma palavra de treino. Por exemplo, diante da palavra de teste NIBE, o participante leu NIBO. Para P12 três das trocas entre os fonemas /a/ e /i/ ocorreram quando diante de uma palavra de teste P12 disse o nome de uma palavra de treino (ler BONI diante da palavra de teste BONA). Para os demais participantes, as trocas entre os fonemas /a/ e /i/ não tiveram relação com as palavras de treino. Nas trocas observadas entre os demais fonemas pelos três participantes não foi possível identificar uma padrão específico de resposta. Em algumas situações os erros apresentados consistiam na leitura incorreta de apenas um dos fonemas que compõem a palavra (ler BOLI diante de BOFI) e em outras na leitura incorreta de dois ou mais fonemas, como por exemplo, ler BONE diante da palavra de teste BENA. Os erros apresentados por P11 consistiram em dizer "não sei" diante das palavras de teste ou em nomear aleatoriamente (e.g., TEDA, BOPI) as palavras apresentadas. 


\section{2- Teste Final de Leitura Oral (C'D')}

No Teste Final, três dos quatro participantes (P9, P10 e P12) apresentaram leitura recombinativa oral. P9 e P10 apresentaram índices de acertos de 96,15\%, o que significa o erro de apenas uma palavra dentre as 26 apresentadas. P12 errou a leitura de duas palavras e apresentou índice de acertos de 92,30\%. Para os participantes P9, P10 e P12 os erros de leitura consistiram na emissão incorreta de apenas um dos quatro fonemas que compõem as palavras. As palavras lidas incorretamente por P9 e P10 foram palavras de treino. P12 leu incorretamente uma palavra de treino e uma palavra de teste. P11 apresentou índice de acertos de 7,69\% e leu corretamente somente duas das 26 palavras apresentadas, o que sugere que o participante não respondeu sob controle pelas unidades mínimas e não apresentou leitura recombinativa. As duas palavras lidas corretamente por P12 foram palavras de teste, sendo uma constante e a outra diferente a cada ciclo. 


\section{DISCUSSÃO}

O presente estudo teve como objetivo investigar o efeito de um treino de fonemas, combinado com um treino de palavras, sobre a emergência da leitura recombinativa. Verificou-se também se o momento de inserção do treino de fonemas no procedimento de ensino, se prévio (Condição I) ou sobreposto (Condição II) ao ensino de palavras, se constitui uma variável relevante para a leitura recombinativa. Para isso foram realizadas três Condições Experimentais: a) Condição I - Treino Prévio de Fonemas; b) Condição II - Treino Sobreposto de Fonemas e c) Condição III - Treino de Palavras. A Condição I permitiu verificar tanto o efeito de um treino isolado de fonemas, como o efeito de um treino prévio, seguido por um treino de palavras inteiras, na emergência da leitura recombinativa. A Condição II possibilitou uma comparação intra-participante dos resultados referentes à leitura recombinativa que ocorreram antes e após a realização dos treinos de fonemas. Finalmente, a Condição III possibilitou a realização de uma comparação dos resultados dos participantes que foram submetidos ao treino explícito dos fonemas (Condição I e II) com os resultados dos participantes expostos somente ao treino de palavras inteiras (Condição III). As principais medidas de leitura recombinativa, no presente estudo, foram o índice de acertos nos testes de leitura de novas palavras e a variabilidade no desempenho dos participantes. A velocidade com que a recombinação ocorreu foi considerada uma medida adicional do estabelecimento do controle pelas unidades menores e da leitura recombinativa. Esta medida foi observada a partir da quantidade de relações treinadas que foram necessárias para que cada participante apresentasse leitura recombinativa consistente (Hanna et al., 2008), isto é com altos índices de acertos e pouca variabilidade entre os ciclos. 
Os resultados do presente estudo foram discutidos considerando cada condição individualmente e também comparando os resultados das três Condições Experimentais. Os dados do treino foram comparados em relação à quantidade de treino necessária para aquisição do critério de aprendizagem e ao número de erros apresentados. Os resultados dos testes foram comparados em relação aos índices de acertos nos testes de leitura recombinativa, a variabilidade entre os participantes e a velocidade com que a recombinação ocorreu.

Serão discutidos separadamente os dados relativos ao treino de fonemas, ao treino de palavras e aos testes de leitura recombinativa.

\section{Treino de Fonemas}

O treino de fonemas foi composto por tentativas de emparelhamento com o modelo (AC) e de nomeação oral (CD) tanto na Condição I como na Condição II. A diferença entre as condições foi na forma e no momento de inserção do treino de fonemas no procedimento de ensino.

$\mathrm{Na}$ Condição I, o procedimento empregado consistiu em uma replicação sistemática do Experimento 2 de Hanna et al. (2010), com a diferença de que a extensão de unidade ensinada no presente estudo foi o fonema. Isso possibilitou a realização de uma comparação entre o desempenho dos participantes do presente estudo, no treino inicial de fonemas, com o desempenho dos participantes do Experimento 2 de Hanna, et al. (2010), no qual esse mesmo treino inicial foi realizado, mas para ensinar o nome, e não o som, de cada letra. No treino inicial de fonemas, realizado no presente estudo, o número de erros apresentados pelos participantes (entre 11 e 29 erros), foi maior do que o número de erros apresentados no treino inicial de letras (entre 3 e 5 erros) pelos participantes do estudo de Hanna et al. (2010). Possíveis explicações para isso tem relação tanto com as características das 
unidades ensinadas (nome da letra e fonema) quanto com o procedimento de ensino empregado.

No estudo de Hanna et al. (2010) o procedimento de treino permitiu tanto a aquisição das relações entre os nomes das letras e suas unidades impressas quanto a correta nomeação de cada letra. No presente estudo, a utilização do mesmo procedimento para o ensino dos fonemas parece não ter sido tão eficaz em estabelecer a correta emissão do som de algumas das letras do pseudoalfabeto. Isso possivelmente tem relação com o fato de que a aprendizagem dos fonemas é um fenômeno bimodal, na qual duas modalidades de informação são importantes: a auditiva, para a aprendizagem dos sons das letras, e a visual, para que o falante possa observar os diferentes pontos de articulação de cada fonema (Santos, 2009). Para serem capazes de segmentar sílabas em fonemas, por exemplo, as crianças apóiam-se em pistas tanto sonoras como articulatórias, relacionadas com os movimentos executados pela boca do falante (Valente \& Martins, 2004). Desta forma, a aprendizagem isolada de um fonema da língua portuguesa parece necessitar de dois tipos diferentes de discriminações, que precisam atuar simultaneamente. A primeira delas relaciona-se com o segmento sonoro e a segunda com os movimentos que os articuladores (lábios, língua, dentes e palato) fazem para a produção deste som. Isso pode ser verificado, por exemplo, na aprendizagem dos fonemas das letras M e N. Ambas as letras são consoantes nasais, nas quais o fonema é produzido quando o ar sai pelas fossas nasais e não pela boca (Canongia, 2006). O segmento sonoro dos fonemas $/ \mathrm{m} / \mathrm{e} / \mathrm{n} / \mathrm{e}$ bastante semelhante e, portanto, uma das formas de diferenciar os dois fonemas é por meio do ponto de articulação. Para a aprendizagem do ponto de articulação de cada fonema, a modalidade de informação visual é fundamental e refere-se à observação dos movimentos dos articuladores da boca do falante. O fonema $/ \mathrm{m} /$, por exemplo, é 
uma consoante bilabial, pronunciada com o contato dos dois lábios, enquanto o fonema /n/ é uma consoante dental, pronunciada com a língua entre os dentes (Canongia, 2006). O procedimento de ensino empregado no presente estudo favoreceu somente a aquisição das discriminações do segmento sonoro dos fonemas e não abrangeu, inicialmente, os movimentos articulatórios necessários para produção do som. Isso possivelmente dificultou a correta emissão do som dos fonemas nas tentativas de nomeação oral, produzindo um maior número de erros.

Na Condição II, por outro lado, a realização do treino de fonemas de forma sobreposta ao treino de palavras possibilitou resultados distintos dos observados na Condição I. Todos os participantes submetidos à Condição II concluíram o treino de fonemas com o número mínimo de tentativas programadas e sem a emissão de um único erro. Considerando que o procedimento de treino foi o mesmo nas duas condições e não possibilitou a discriminação do segmento articulatório dos fonemas, o desempenho acurado dos participantes da Condição II parece estar relacionado com a exposição combinada do treino de fonemas com o treino de palavras. Desta forma, a exposição anterior às palavras inteiras pareceu favorecer o estabelecimento de um responder diferencial para cada fonema individualmente, tornando a observação dos movimentos articulatórios para a correta produção do som menos relevante.

Além disso, dois outros dados foram importantes no treino de fonemas da Condição II e possibilitaram uma economia no treino quando comparado à Condição I. A realização do treino de fonemas sobreposto ao treino de palavras tornou dispensável a realização de uma subfase mista, que envolvia os oito fonemas ensinados no estudo (Subfase 5 na Condição I). Na Condição I, essa subfase foi importante pois existia uma distância temporal entre o treino dos primeiros fonemas e o início do treino de palavras, o que não ocorreu na Condição II. Finalmente, o outro 
fator que possibilitou a economia de treino na Condição II está relacionado com a utilização do desempenho dos participantes nos testes de leitura recombinativa como critério para determinar se os mesmos seriam ou não expostos ao treino de fonemas em cada ciclo (ver Figura 5). Na Condição I todos os participantes foram expostos ao ensino individual de todos os fonemas, enquanto na Condição II somente um dos participantes foi submetido ao ensino dos oito fonemas. Os demais participantes da Condição II foram expostos somente ao ensino individual de quatro fonemas, o que diminuiu ainda mais o número de tentativas de treino.

\section{Treino de Palavras}

No treino de palavras de todas as Condições Experimentais, a utilização de um procedimento que empregou o fading-in de estímulos de escolha incorretos em blocos de tentativas com o mesmo estímulo modelo, mostrou-se eficaz e possibilitou a aquisição das relações treinadas com um número reduzido de erros. Estudos que empregaram procedimentos semelhantes tanto com crianças (e.g., Albuquerque, 2001; Serejo et al., 2007; Rocha, 1996) como com participantes adultos (Hanna et al., 2008; Hanna et al., 2011; Quinteiro, 2003) também demonstraram o estabelecimento das relações ensinadas com a emissão de poucos erros. Os resultados obtidos no presente estudo sugerem ainda que duas outras variáveis podem ter influenciado a aquisição das discriminações no treino de palavras: a história de aprendizagem com o procedimento e o ensino de unidades menores do que a palavra. Nas três condições experimentais realizadas no presente estudo, pode-se observar que quanto maior a exposição ao procedimento e às unidades menores do que a palavra, menor o número de erros apresentados pelos participantes no treino de palavras. Os participantes da Condição I foram, portanto, os que apresentaram o menor número de erros. Esses 
participantes foram submetidos previamente ao treino individual de todos os fonemas empregados no estudo, por meio de um procedimento de MTS (relação AC) e nomeação oral (relação CD). Assim, apesar de os estímulos empregados no treino de palavras serem diferentes, a familiaridade com os tipos de relações treinadas, parece ter favorecido o estabelecimento de novas discriminações no treino de palavras (e.g., de Rose et al., 1996; Hanna et al., 2008; Serejo et al., 2007). Além disso, o treino prévio dos fonemas estabeleceu um responder diferencial sob controle das unidades mínimas, o que possivelmente facilitou a aquisição de discriminações de palavras formadas por estas unidades. Os participantes da Condição III, por outro lado, foram os que apresentaram o maior número de erros no treino de palavras. Esses participantes foram submetidos a um número menor de relações no treino, quando comparados aos participantes das Condições I e II, e não foram expostos ao ensino direto de unidades menores do que a palavra. A diminuição do número de erros nos treinos de palavras a partir do aumento do número de relações ensinadas já foi demonstrada em diversos estudos anteriores (e.g., de Rose et al., 1996; Gomes, 2007; Hanna et al., 2008; Hanna et al., 2011; Melchiori et al., 2000; Mesquita, 2007; Quinteiro, 2003; Serejo et al., 2007).

Outro dado relevante do procedimento de ensino empregado no presente estudo é o fato de que as palavras de treino foram apresentadas somente nos ciclos em que foram ensinadas. Isso foi possível porque um procedimento de ensino que treina diretamente unidades menores e utiliza palavras de treino de forma a garantir uma variação sistemática de suas sílabas e o estabelecimento do controle por unidades mínimas, se eficaz, torna dispensável a utilização de procedimentos adicionais para assegurar a manutenção da leitura das palavras de treino (Serejo et al., 2007). Quando o controle por unidades mínimas é estabelecido, a leitura das palavras de treino pode 
ser constantemente realizada por meio da recombinação das unidades menores (Mueller et al., 2000; Serejo et al., 2007). A não utilização de procedimentos adicionais para garantir a retenção da leitura das palavras de treino se constitui em uma vantagem, pois pode possibilitar a diminuição dos comportamentos de fuga e esquiva e quedas no desempenho dos participantes, observadas quando procedimentos longos de ensino são empregados (Hanna, Benvennuti \& Melo, 2010; Mesquita, 2007).

\section{Testes de Leitura Recombinativa}

O estabelecimento do controle por unidades mínimas e a emergência da leitura recombinativa no presente estudo foram avaliadas por meio de testes C'D' (leitura oral) e A'C' (leitura receptiva).

Na Condição I, o treino prévio de fonemas permitiu a realização de um Teste Inicial de Leitura Oral (C'D'), o qual verificou o efeito do treino isolado dos fonemas na emergência da leitura recombinativa. Os resultados deste teste demonstraram que, apesar dos participantes terem soletrado um a um os fonemas componentes das palavras, nenhum participante apresentou a correta leitura das palavras inteiras. Esses resultados confirmaram a hipótese de Jeffrey e Samuels (1967) de que o treino isolado dos fonemas não é suficiente para produzir a leitura de novas palavras. Resultados semelhantes foram obtidos na literatura em estudos que avaliaram o efeito de um treino isolado de letras tanto com participantes adultos (Hanna et al., 2010) como com crianças (Mesquita, 2007). O estudo realizado por Mesquita investigou o efeito do ensino isolado de unidades textuais de diferentes tamanhos (letras, sílabas e palavras) na emergência da leitura recombinativa. O grupo de crianças submetido ao treino do nome das letras apresentou a nomeação oral de todas as letras, mas demonstrou 
resultados nulos na leitura oral de palavras. Gomes (2007) também demonstrou que a correta nomeação de letras individuais por parte das crianças não possibilitou a leitura de palavras inteiras. Desta forma, os resultados da Condição I do presente estudo, juntamente com os obtidos por Gomes (2007), Hanna et al. (2010) e Mesquita (2007) sugerem que a exposição às palavras é fundamental para que se desenvolva o repertório de combinar letras e/ou fonemas, aprendidos previamente, na leitura de palavras inteiras.

Os testes parciais de leitura oral (C'D') e leitura receptiva (A'C'), realizados a cada ciclo, estiveram presentes em todas as Condições Experimentais. Participantes das três condições apresentaram leitura recombinativa, mas foram observadas diferenças no que se refere ao índice de acertos nos testes, a variabilidade do desempenho entre os participantes e a velocidade com que a recombinação ocorreu.

Na Condição I, o desempenho dos participantes do presente estudo replicou os resultados do Experimento 2 de Hanna et al. (2010). O treino prévio de fonemas seguido do treino de palavras foi eficaz para produzir leitura recombinativa em todos os participantes. Nos testes parciais C'D', os participantes P2, P3 e P4 apresentaram elevados índices de leitura recombinativa já a partir do Ciclo 2. Isso significa que para esses participantes o treino de oito fonemas e quatro palavras inteiras foi suficiente para a emergência da leitura recombinativa, com elevados escores de acertos e pouca variabilidade entre os ciclos. É importante ressaltar, no entanto, que as palavras de treino do presente estudo foram formadas por apenas quatro sílabas e que após o Ciclo 2 estas sílabas já haviam sido apresentadas uma vez em cada posição da palavra, isto é tanto no início como no final das palavras. Essa variação sistemática das sílabas (e.g., Hanna et al., 2008; Hanna et al., 2011; Hübner-D’Oliveira, 1993; Hübner et al., 2009; Matos et al., 2002; Matos et al., 1997; Müeller et al., 2000; 
Saunders, 2011; Saunders et al., 2003) juntamente com o treino direto dos fonemas, foi o que possivelmente favoreceu os altos índices de leitura recombinativa apresentados por P2, P3 e P4 já a partir do Ciclo 2.

Nos testes A'C' realizados ao final de cada ciclo, os quatro participantes submetidos à Condição I apresentaram pouca variabilidade entre os ciclos e entre os participantes, apresentando índices de acertos entre 75 e 100\% em todos os ciclos.

Um dado relevante dos resultados da Condição I refere-se ao fato de que o ensino isolado do fonema estabelece, para cada unidade impressa, uma topografia de resposta semelhante à exigida na presença da mesma unidade na leitura de palavras inteiras. Por exemplo, o som dos fonemas /f/ e /n/, emitidos na presenças das letras $\mathrm{F}$ e $\mathrm{N}$ isoladamente são bastantes semelhantes ao sons desses fonemas na leitura da palavra "Fino". Entretanto, quando a menor unidade ensinada é o nome da letra, isso não ocorre. Por exemplo, na palavra "FILA" a pronúncia correta do nome das consoantes seria "efe" e "ele" respectivamente. Desta forma, se o participante utilizar esta topografia de resposta na leitura da palavra FILA a resposta vocal emitida seria "efeielea" e não a resposta vocal ponto-a-ponto "Fila" (Mesquita, 2007). Considerando essas diferenças seria esperado que o procedimento empregado no presente estudo produzisse resultados superiores aos observados no Experimento 2 de Hanna et al. (2010), o que não ocorreu. Uma das possíveis explicações para os dados semelhantes obtidos em ambos os estudos é de que os resultados positivos obtidos por Hanna et al. (2010) estejam relacionados à adição de um novo estímulo (letra do pseudoalfabeto) a uma classe de equivalência previamente estabelecida que envolve tanto o nome como o som da letra. Estudantes universitários tem uma longa história prévia de estabelecimento destas relações e, portanto, o treino do nome da letra 
efetuado por Hanna et al. (2010) pode ter favorecido a emergência do som de cada letra, principalmente quando apresentadas em palavras inteiras.

$\mathrm{Na}$ Condição II, o efeito do treino de fonemas foi verificado, para cada participante, por meio dos testes parciais que ocorreram antes (pré-sobreposição) e depois (pós-sobreposição) do treino de fonemas, em cada ciclo. Para P5, P6 e P7 os índices de acertos nos testes de leitura recombinativa que ocorreram após a inserção do treino de fonemas, nos Ciclos 1 e 2, foram superiores aos índices de acertos nos testes de leitura recombinativa que ocorreram antes da exposição ao treino de fonemas. Além disso, a análise dos erros apresentados por esses participantes nos testes parciais pré e pós sobreposição do treino de fonemas, em ambos os ciclos, demonstrou que o treino de fonemas favoreceu um aumento no controle discriminativo pelas unidades mínimas e possibilitou, nos testes parciais póssobreposição, a diminuição do número de erros envolvendo os fonemas treinados. $\mathrm{O}$ estabelecimento de um responder diferencial às unidades menores, possibilitado pelo treino de fonemas, pode ainda ter permitido o reconhecimento da palavra como um estímulo composto, formado por unidades que podem ser recombinadas (e.g., Saunders, 2011; Serejo et al., 2007), o que também favorece o desenvolvimento da leitura recombinativa. Desta forma, esses dados sugerem que a inserção do treino de fonemas sobreposto ao treino de palavras foi eficaz, possibilitando o estabelecimento das relações entre grafemas e fonemas componentes das palavras e índices mais elevados de leitura recombinativa.

No entanto, além da inserção do treino de fonema, um outro aspecto do procedimento, não controlado pelo experimentador, pode ter favorecido um melhor desempenho nos testes pós-sobreposição da Condição II. Em cada ciclo, os testes parciais foram compostos por testes $\mathrm{C}^{\prime} \mathrm{D}^{\prime}$ e testes $\mathrm{A}^{\prime} \mathrm{C}^{\prime}$ que verificavam a leitura de 
quatro palavras de recombinação. Primeiramente, o participante foi submetido ao teste C'D', no qual as palavras foram apresentadas na tela do computador e o participante deveria nomeá-las. Após o término do teste C'D' o participante foi submetido ao teste $A^{\prime} C^{\prime}$, no qual as mesmas palavras testadas anteriormente foram apresentadas como estímulo modelo oral, nas tentativas de MTS. Desta forma, a apresentação das palavras como estímulo modelo oral, nos testes $\mathrm{A}^{\prime} \mathrm{C}^{\prime}$ pode ter fornecido ao participante uma dica de qual era a nomeação correta as palavras apresentadas anteriormente no testes C'D'. Os testes pós-sobreposição ocorriam após a inserção de uma subfase de treino de fonemas, o que determinava uma distância temporal entre os testes pré e pós-sobreposição. Porém, como os testes póssobreposição verificavam a leitura das mesmas quatro palavras, a ordem de apresentação dos testes pré-sobreposição (C'D' seguido de A 'C') pode ter favorecido o desempenho dos participantes nos testes pós-sobreposição.

Os resultados dos testes de leitura recombinativa da Condição II demonstraram que para três dos quatro participantes (P5, P6 e P7) o treino de fonemas sobreposto ao treino de palavras produziu leitura recombinativa com índices de $100 \%$ de acertos em todos os testes parciais C'D' e A'C' a partir do Ciclo 2. Portanto, para esses participantes o ensino individual de apenas quatro fonemas e quatro palavras inteiras foi suficiente para a emergência da leitura recombinativa consistente. É importante observar que as palavras de treino empregadas na Condição II foram as mesmas da Condição I e, após o Ciclo 2, as quatro sílabas componentes das palavras já haviam sido apresentadas tanto no início como no final das palavras. Estudos anteriores já demonstraram que a experiência com a variação sistemática dos elementos componentes dos estímulos no treino é uma variável relevante para o estabelecimento do responder diferencial sob controle das unidades menores (e.g., 
Goldstein, 1983; 1993; Hanna et al., 2008; Hanna et al., 2011; Hübner-D’Oliveira, 1993; Hübner, Gomes \& McIlvane, 2009; Mueller et al., 2000; Saunders et al., 2003; Rocha, 1996). Desta forma, a combinação do treino direto de unidades menores com a variação sistemática das palavras de treino possibilitou a emergência da leitura recombinativa com altos índices de acertos para os participantes P5, P6 e P7 da Condição II.

Os resultados apresentados por $\mathrm{P} 8$, entretanto, demonstraram que para esse participante o efeito da inserção do treino de fonemas só pode ser observado nos testes A'C'. Nos testes C'D', o desempenho de P8 se manteve o mesmo nos testes pré e pós-sobreposição do treino de fonemas. O índice de acertos de P8 nos testes C'D' foi de $25 \%$ a partir do Ciclo 3 e esse desempenho se manteve constante até o Ciclo 6 .

Finalmente, na Condição III os participantes foram submetidos somente ao treino de palavras inteiras. Os resultados replicaram os de estudos anteriores que utilizaram a palavra como unidade ensinada e demonstram que a leitura recombinativa aumentou gradativamente a depender do número de palavras empregadas no treino (e.g., de Rose et al., 1996; de Rose et al., 1989; Gomes, 2007; Hanna et al., 2008; Hanna et al., 2011; Hübner - D’Oliveira, 1990; Hübner D’Oliveira \& Matos, 1993; Hübner et al., 2009; Matos et al., 2006; Melchiori et al., 1992; 2000; Müeller et al., 2000; Quinteiro, 2003; Rocha, 1996). Diferentemente das Condições I e II, na Condição III os resultados dos testes de leitura recombinativa demonstraram variabilidade intra e inter-participantes. Essa variabilidade sugere que, assim como proposto por Skinner (1957), o controle por unidades mínimas pode ser desenvolvido quando apenas unidades maiores são reforçadas, mas que esta não é uma condição para assegurar leitura recombinativa consistente (e.g., Hanna et al., 2008; Hanna et al., 2010). Isso ocorre porque quando a palavra é a unidade ensinada 
as consequências são programadas somente para desempenhos relativos a palavras inteiras (Rocha, 1996), o que deixa ao acaso o estabelecimento das relações entre os grafemas e fonemas componentes das palavras (de Souza \& de Rose, 2006; Sidman, 1994), que é fundamental para a emergência da leitura recombinativa.

Os resultados dos testes parciais de leitura recombinativa das três condições experimentais demonstraram, para todos os participantes, maiores índices de acerto e menor variabilidade nos testes $A^{\prime} C^{\prime}$ do que nos testes $C^{\prime} D^{\prime}$. Nos testes $A^{\prime} C^{\prime}$ a resposta requerida foi uma resposta motora, de seleção, sempre com a mesma topografia: apontar. O estímulo de escolha correto nas tentativas de teste $\mathrm{A}^{\prime} \mathrm{C}^{\prime}$ apresentava diferenças críticas em relação aos estímulos de escolha incorretos, o que exigia que o participante estivesse sob controle de todas as unidades componentes da palavra para emitir a resposta correta. No entanto, como o participante deveria selecionar um entre os três estímulos textuais disponíveis a probabilidade de acerto ao acaso foi de $33 \%$, o que pode ter contribuído para índices mais elevados de acerto. Nos testes C'D' a resposta exigida foi uma resposta vocal com correspondência ponto a ponto entre estímulo e resposta, cuja topografia era diferente a cada tentativa. Neste caso, a emissão da resposta correta só foi possível se o participante apresentasse controle textual pelas unidades menores do que a palavra.

As diferenças de desempenho observadas entre os testes A'C' e C'D' replicam os resultados de diversos estudos anteriores (e.g., de Rose et al., 1996; de Souza et al., 2009b; Hanna et al., 2008; Mesquita, 2007; Serejo et al., 2007; Quinteiro, 2003; Rocha, 1996) e sugerem que o individuo aprende a reconhecer que um estímulo auditivo corresponde a um estímulo textual, ou seja leitura receptiva, antes de aprender a resposta vocal, com correspondência ponto a ponto, na presença deste texto, ou seja leitura oral (Greer \& Ross, 2007). No presente estudo, os participantes 
P8 (Condição II) e P11 (Condição III) foram os que apresentaram as diferenças mais claras entre os desempenhos nos testes A'C' e C'D'. Ambos os participantes apresentaram índices de acertos nulos ou muito baixos (25\%) nos testes C'D' de todos os ciclos. Nos testes $\mathrm{A}^{\prime} \mathrm{C}^{\prime}$ os índices de acertos para P8 variaram entre 25 e $100 \%$ e para P11 entre 12,5 e 87,5\%. As diferenças do desempenho nos testes A'C' e C'D' de um mesmo participante fornecem suporte à definição de leitura como uma rede de relações interligadas, mas que podem ser adquiridas independentemente e em momentos diferentes ao longo de um programa de ensino (e.g., de Rose, 2005; de Rose et al., 1996; Hanna et al., 2008; Matos et al., 2006; Matos et al., 2002; Matos et al., 1997; Müeller, et al., 2000; Saunders, 2011; Saunders et al., 2003; Sidman, 1971).

De maneira geral, os resultados do presente estudo demonstraram que os participantes das Condições I e II, as quais ensinaram explicitamente os fonemas, foram os que apresentaram maiores índices de acertos nos testes de leitura de palavras novas e menor variabilidade no desempenho. Isso ocorreu porque o ensino explícito das relações entre as letras e os sons possibilita o estabelecimento de um controle mais rápido e preciso por unidades menores (de Souza \& de Rose, 2006), o que favoreceu a emergência da leitura recombinativa. No entanto, apesar de os participantes das Condições I e II terem sido submetidos ao treino direto de fonemas, o momento de inserção desse treino foi diferente em cada uma delas, o que possibilitou a observação de resultados distintos entre os participantes. Estudos anteriores, que utilizaram a palavra inteira como unidade de ensino e empregaram procedimentos especiais para favorecer o desenvolvimento do controle por unidades mínimas, já demonstraram que o momento de inserção desses procedimentos é uma variável relevante na emergência da leitura recombinativa (e.g. Matos et al, 1997; Matos et al., 2002). No presente estudo, tanto os participantes submetidos à Condição 
I como os submetidos à Condição II apresentaram elevados e consistentes escores de leitura recombinativa a partir do Ciclo 2. No entanto, quando foram expostos aos testes parciais do Ciclo 2 os participantes da Condição I haviam sido submetidos ao treino de oito fonemas e quatro palavras inteiras, enquanto que na Condição II os participantes haviam sido expostos ao treino de quatro fonemas e quatro palavras inteiras. Isso sugere que a leitura recombinativa consistente emergiu para os participantes da Condição II após uma quantidade menor de treino do que para os participantes da Condição I. Esse resultado indicou que o treino de fonemas sobreposto ao treino de palavras (Condição II) possibilitou maior velocidade no estabelecimento da leitura recombinativa, quando comparado ao treino prévio de fonemas (Condição I). Além disso, os índices de acertos nos testes de leitura recombinativa a partir do Ciclo 2 foram mais altos para os participantes submetidos à Condição II, do que para os participantes da Condição I. É importante observar porém, que um dos participantes da Condição II (P8) não apresentou leitura recombinativa oral, enquanto que na Condição I todos os participantes apresentaram esse repertório. Assim, de maneira geral, os resultados sugerem que os participantes submetidos à Condição II foram os que apresentaram maior velocidade na recombinação e índices mais elevados de leitura recombinativa, enquanto os participantes submetidos à Condição I foram os que apresentaram menor variabilidade entre si.

A Condição III, constituída somente pelo treino de palavras, foi a condição do estudo na qual os participantes apresentaram menores índices de acerto nos testes de leitura recombinativa, maior variabilidade entre si e menor velocidade de recombinação. 
No Teste Final de Leitura Oral, todos os participantes submetidos à Condição I apresentaram leitura recombinativa, enquanto que nas Condições II e III, somente três dos quatro participantes apresentaram esse repertório. Esses resultados novamente sugerem que o treino prévio de fonemas (Condição I) foi o mais eficaz na diminuição da variabilidade entre os participantes. Um dado interessante do presente estudo é que não foram observadas, para nenhum participante, diferenças entre os escores finais de leitura recombinativa das palavras de treino e de teste. No presente estudo, não foram empregados procedimentos adicionais para a manutenção da leitura das palavras de treino. Assim, devido à distância temporal existente entre o treino de palavras e o Teste Final, considerou-se que o responder sob controle por unidades mínimas foi um requisito necessário para a leitura das palavras tanto de treino como de teste. Desta forma, os participantes que demonstraram um responder sob controle das unidades mínimas apresentaram a leitura correta tanto das palavras de treino como de teste, enquanto os participantes que não apresentaram este repertório (P8 e P11) não apresentaram nem mesmo a leitura das palavras de treino.

A comparação dos resultados das Condições I e II do presente estudo, com os resultados de estudos que utilizaram a palavra inteira como unidade ensinada e empregaram procedimentos adicionais para o desenvolvimento do controle por unidades mínimas (e.g. De Rose et al., 1996; Matos et al., 2002; Matos et al., 1997) sugerem que o treino direto das unidades menores do que a palavra é mais eficaz para a emergência da leitura recombinativa. No estudo realizado por de Rose et al. (1996), que utilizou o procedimento de cópia por construção de palavras, o índice de acertos dos participantes no teste de leitura recombinativa oral realizado após o ensino de 19 palavras variou entre 0 e $71,4 \%$. No teste final de leitura oral, realizado após o ensino de 51 palavras, o desempenho dos participantes variou entre 0 e $86 \%$ para palavras de 
teste. No presente estudo, todos os participantes submetidos à Condição I apresentaram índices de acertos acima de 90\% no teste final. Na Condição II três dos quatro participantes apresentaram índices semelhantes, acima de 90\% de acertos. Esses dados parecem confirmar a sugestão de de Rose et al. (1996) de que inclusão de etapas de treino, com o ensino explícito da correspondência entre unidades textuais e sons, poderia produzir resultados com índices maiores de acertos e menor variabilidade entre os participantes.

Os resultados das Condições I e II do presente estudo podem ainda ser comparados com os de estudos que empregaram o treino direto de unidades menores do que a palavra (e.g., Serejo et al., 2007; de Souza et al., 2009b). Em relação ao estudo de Serejo et al. (2007), que realizou um treino explícito de sílabas, os resultados do presente estudo também demonstraram índices superiores de acerto e menor variabilidade entre os participantes. Diferentemente do presente estudo, no estudo de Serejo et al. (2007) a menor unidade treinada diretamente (sílaba) não correspondeu à menor unidade empregada nas palavras de recombinação (letra/fonema), pois as palavras foram formadas a partir de recombinações intrasilábicas. Na Fase 1 do estudo de Serejo et al. (2007), por exemplo, as sílabas ensinadas diretamente foram FI, GO, LA e CE, enquanto algumas das palavras de testes foram GOLE e CIFA. A correta leitura da palavra CIFA, por exemplo, exigia uma recombinação das letras/fonemas que compunham as sílabas FI, LA e CE, o que exigia do participante a mudança do controle elementar da menor unidade diretamente treinada (sílaba) para a menor unidade textual empregada nas palavras de recombinação (letra/fonema). No presente estudo, a menor unidade treinada (fonema) foi também a menor unidade empregada nas palavras de recombinação o que pode ter 
favorecido a emergência da leitura recombinativa com elevados escores de acerto e pouca variabilidade entre os participantes.

O estudo de de Souza et al. (2009b), que treinou diretamente a menor unidade empregada nas palavras de recombinação (sílaba), demonstrou elevados escores de leitura recombinativa e pouca variabilidade entre os participantes. Esses resultados em conjunto com os resultados obtidos nas Condições I e II do presente estudo parecem confirmar a hipótese de que o treino direto da unidade de recombinação, ou seja, da menor unidade sonora e textual empregada na recombinação das palavras ensinadas, é uma variável relevante e favorece o desenvolvimento da leitura recombinativa.

Outra observação importante é o fato de que no presente estudo o procedimento assegurou a variação sistemática das sílabas das palavras de treino, juntamente com o ensino direto de unidades menores do que a palavra. Assim, em relação à quantidade de treino necessária para produzir leitura recombinativa com altos índices de acertos e pouca variabilidade entre os participantes, pode-se observar que o procedimento do presente estudo foi mais econômico quando comparado ao de de Souza et al. (2009b), embora os índices de acerto obtidos nos testes de ambos os estudos tenham sido semelhantes. Importante notar no entanto, que o estudo de de Souza et al. (2009b) empregou 20 letras e 51 palavras de treino, enquanto o presente estudo utilizou oito letras e 12 palavras de treino. 


\section{CONSIDERAÇÕES FINAIS}

De forma geral, os resultados apresentados pelos participantes do presente estudo, sugerem que o procedimento empregado possibilitou atingir o objetivo proposto, que foi verificar o efeito de um treino de fonemas, combinado com um treino de palavras na emergência da leitura recombinativa. A realização de três condições experimentais diferentes possibilitou uma comparação, no mesmo estudo, entre os resultados das condições que treinaram diretamente o fonema (Condições I e II) com os resultados de uma condição que ensinou somente palavras inteiras (Condição III). O treino de fonemas combinado com um treino de palavras inteiras produziu leitura recombinativa com índices mais elevados de acertos e menor variabilidade, quando comparado a um treino que empregou somente palavras inteiras. Além disso, o momento de inserção do treino de fonemas no procedimento, prévio (Condição I) ou sobreposto (Condição II) ao treino de palavras, mostrou-se uma variável relevante para a emergência da leitura recombinativa. Os resultados do presente estudo confirmaram ainda a hipótese de que o treino da menor unidade que será empregada nas palavras de recombinação, e não somente de unidades menores do que a palavra, é uma variável importante e favorece a emergência da leitura recombinativa consistente. Os resultados do presente estudo demonstraram também que a combinação de um treino direto de fonemas (seja prévio ou sobreposto) com um procedimento de treino que assegurou a variação sistemática das sílabas das palavras inteiras possibilitou a emergência da leitura recombinativa por meio de um procedimento mais econômico de treino, sem a utilização de procedimento adicionais ou blocos de tentativas extras para garantir a leitura das palavras de treino.

É interessante observar, no entanto, que é possível que resultados ainda superiores no que se refere a maiores índices de acerto e menor variabilidade entre os 
participantes tivessem sido obtidos, nas Condições I e II, caso o procedimento empregado para o treino de fonemas possibilitasse a aprendizagem do segmento articulatório dos fonemas de todas as letras do pseudoalfabeto. Como isso não ocorreu, sugere-se a realização de novos estudos que contemplem o ensino dos segmentos sonoro e articulatório dos fonemas e possibilitem verificar a extensão do efeito facilitador do treino de fonemas na emergência da leitura recombinativa.

Outra questão a ser verificada é se de fato a ordem de apresentação dos testes parciais pré-sobreposição do treino de fonemas da Condição II (C'D' seguido por $\mathrm{A}^{\prime} \mathrm{C}^{\prime}$ ) forneceu aos participantes uma dica da resposta correta, favorecendo o desempenho dos mesmos nos testes parciais pós-sobreposição. Uma das formas de se investigar isso seria a realização de um estudo no qual as palavras que exercem função de modelo nos testes $\mathrm{A}^{\prime} \mathrm{C}^{\prime}$ fossem compostas pelas quatro palavras já avaliadas nos testes C'D' e por outras quatro palavras que possuíssem diferenças críticas (somente uma letra diferente) em relação às apresentadas nos testes C'D'. Esse procedimento diminuiria a probabilidade de que as palavras apresentadas como modelo oral nos testes $\mathrm{A}^{\prime} \mathrm{C}^{\prime}$ pudessem fornecer dicas sobre as respostas corretas e favorecer o desempenho posterior dos participantes nos testes pós-sobreposição.

Sugere-se ainda a replicação do presente estudo com participantes crianças em idade pré-escolar, não alfabetizadas. $\mathrm{O}$ estudo com esta população é importante porque as crianças ainda não tem estabelecidas as classes de equivalência entre os estímulos relacionadas à leitura. No presente estudo, a utilização de participantes adultos e de um pseudoalfabeto possibilitou controlar a história dos participantes com os estímulos impressos e o efeito da instrução escolar. No entanto, como os fonemas empregados foram fonemas da língua portuguesa, as classes de estímulos já 
estabelecidas nos repertórios de adultos universitários podem ter favorecido a emergência da leitura recombinativa.

Finalmente, o presente trabalho embora se configure como pesquisa básica, tem pretensões de colaborar com procedimentos de ensino de leitura. Nesse sentido, verificou-se que os três procedimentos empregados para o ensino de leitura produziram a leitura recombinativa final. Ao fazer a escolha por um dos procedimentos, sugere-se como critério o caminho com maiores índices de acerto e maior velocidade de aquisição. Sob esse prisma, fica claro, a partir da presente pesquisa, que a sobreposição do treino de fonemas ao treino de palavras atende os critérios de maior eficácia. 


\section{REFERÊNCIAS}

Adams, M. J. (1994). Beginning to read: thinking and learning about print. Cambridge, MA: MIT Press.

Albuquerque, A. R. (2001). Controle comportamental por símbolos compostos: manipulação da similaridade entre estímulos discriminativos e do número de recombinações treinadas. Tese de doutorado, Universidade de Brasília, Brasília.

Barros, S. N. (2007). Ensino da discriminação entre sílabas e a emergência da leitura de palavras e de novas sílabas com recombinação de letras em crianças préescolares. Dissertação de mestrado não publicada, Universidade Federal do Pará, Pará.

Bishop, C. H. (1964). Transfer effects on word and letter training in reading. Journal of Verbal Learning and Verbal Behavior, 3, 215-221.

Canongia, M.B. (2006). Manual de terapia da palavra. São Paulo, SP: Revinter.

Capobianco, D., Orlando, A. F., Marques, L. B., Teixeira, C. A. C., de Souza, D. G., $\&$ de Rose, J. C. (2011). GEIC-LECH. Gerenciador de ensino individualizado por computador.(Version 4.0) [Computer manager individualized teaching]. (Software Multi-plataforma para elaboração de programas de ensino e pesquisa, aplicação online e gerenciamento de alunos, de equipe e de dados). Versao original de 2009.

Cumming, W. W., \& Berryman, R. (1965). The complex discriminated operant: studies of matching to sample and the related problems. In D. I. Moostofski (Ed.), Stimulus generalization (pp.284-330). Stanford, CA: Stanford University Press.

De Rose, J. C. (2005). Análise comportamental da aprendizagem de leitura e escrita. Revista Brasileira de Análise do Comportamento, 1, 29-50.

De Rose, J. C., de Souza, D. G., \& Hanna, E. S. (1996). Teaching reading and spelling: stimulus equivalence and generalization. Journal of Applied Behavior Analysis, 29, 451-469.

De Rose, J. C., de Souza, D. G., Rossito, A. L., \& de Rose, T. M. S. (1989). Aquisição de leitura após história de fracasso escolar: equivalência de estímulos e generalização. Psicologia: Teoria e Pesquisa, 5(3), 325-346.

De Rose, J. C., de Souza, D. G., Rossito, A. L., \& de Rose, T. M. S. (1992). Stimulus equivalence and generalization in reading after matching to sample by exclusion. In S. C. Hayes \& L. J. Hayes (Eds.), Understanding verbal relations. Reno, NV: Context Press. 
De Souza, D. G., \& de Rose, J. C. (2006). Desenvolvendo programas individualizados para o ensino de leitura. Acta Comportamentalia, 14(1), 77- 97.

De Souza, D. G., de Rose, J. C., Faleiros, T. C., Bortoloti, R., Hanna, E. S., \& McIlvane, W. J. (2009b). Teaching generative reading via recombination of minimal textual units: a legacy of verbal behavior to children in Brazil. International Journal of Psychology and Psychological Therapy, 9 (1), 19-44.

Dixon, L. S. (1977). The nature of control by spoken words over visual stimulus selection. Journal of the Experimental Analysis of Behavior, 27, 433-442.

Foss, D. J. (1968a). An analysis of learning in miniature linguistic system. Journal of Experimental Psychology, 76 (3), 450-459.

Goldstein, H. (1983). Training generative repertoires within agent-action-object miniature linguistic system with children. Journal of Speech and Hearing Research, 26, 76-89.

Goldstein, H. (1993). Structuring environmental input to facilitate generalized language learning by children with mental retardation. In A.P Kaiser \& D.B. Gray (Eds.), Enhancing children's communication: Research foundation for intervention. Vol. 2 (pp. 317-334). Baltimore: Paul H. Brookes.

Gomes, R. C. (2007). Controle por unidades minimas e leitura recombinativa: solicitação de comportamento textual durante aquisição de pré-requisitos. Dissertação de mestrado, Universidade de São Paulo, São Paulo.

Greer, R. D. \& Ross, D. (2007). Verbal behavior analysis: inducing and expanding new verbal capabilities in children with language delays. New York: Allyn \& Bacon.

Hanna, E. S., Benvenuti, M., \& Melo, R. M. (2010). Entraves no ensino de leitura e de escrita e o programa de ciência aplicada do INCT-ECCE. XIII Simpósio de Pesquisa e Intercâmbio Científico em Psicologia da ANPEPP, Fortaleza-CE.

Hanna, E. S., Karino, C. A., Araújo, V. T., \& de Souza, D. G. (2010). Leitura recombinativa de pseudopalavras impressas em pseudoalfabeto: similaridade entre palavras e extensão da unidade ensinada. Psicologia USP. 21(2), 275311.

Hanna, E. S., Kohldorf, M., Quinteiro, R. S., Fava, V. M., de Souza, D. G., \& de Rose, J. C. (2008). Diferenças individuais na aquisição de leitura com um sistema linguístico em miniatura. Psicologia: Teoria e Pesquisa, 24, 45-58.

Hanna, E. S., Kohldorf, M., Quinteiro, R. S., Melo, R. M., de Souza, D. G., de Rose, J. C., \& Mcllvane, W. J. (2011). Recombinative reading derived from a pseudoword instruction in a miniature linguistic system. Journal of the Experimental Analysis of Behavior, 95, 21-40. 
Hübner-D’Oliveira, M. M. (1990). Estudos em relações de equivalência: Uma contribuição do controle por unidades mínimas na aprendizagem de leitura com pré-escolares. Tese de doutorado. Universidade de São Paulo, São Paulo.

Hübner, M. M., Gomes, R. C., \& McIlvane, W. J. (2009). Recombinative generalization in minimal verbal unit-based reading instruction for pre-reading children. Experimental Analysis of Human Behavior Bulletin, 27, 11-17.

Hübner-D’Oliveira, M. M., \& Matos, M. A. (1993). Controle discriminativo na aquisição da leitura: efeito da repetição e variação na posição das sílabas e letras. Temas em Psicologia, 2, 99-108.

Jeffrey, W. E., \& Samuels, S. J. (1967). Effect of method of reading training on initial learning and transfer. Journal of Verbal learning and Verbal Behavior, 6, 353358.

Mackay, H. A., \& Sidman, M. (1984). Teaching new behavior via equivalence relations. In P. H. Brooks, R. Sperber, \& C. Mc Cauley (Orgs.), Learning and cognition in the mentally retarded. Hillsdale, New Jersey: Lawrence Erlbaum.

Matos, M. A., Avanzi, A. L., \& McIlvane, B. (2006). Rudimentary reading repertoires via stimulus equivalence and recombination of minimal verbal units. The Analysis of Verbal Behavior, 22, 3-19.

Matos, M. A., Hübner, M. M. C., \& Peres, W. (1999). Leitura generalizada: procedimentos e resultados? In R. A. Banaco (Org.). Sobre Comportamento e Cognição: aspectos teóricos, metodológicos e de formação em análise do comportamento e terapia cognitivista, Vol. 1. (pp. 414-429). Santo André, SP: ARBytes.

Matos, M. A., Hübner, M. M., Serra, V. R., Basaglia, A. E., \& Avanzi, A. L. (2002). Rede de relações condicionais e leitura recombinativa: pesquisando o ensinar a ler. Arquivos Brasileiros de Psicologia, 54(3), 285-303.

Matos, M. A., Peres, W., Hübner, M. M., \& Malheiros, R. H. (1997). Oralização e cópia: efeitos sobre a aquisição de leitura generalizada recombinativa. Temas em Psicologia, 1, 47-63.

Maués, A. S. (2007). A recombinação de letras no ensino e emergência da leitura generalizada recombinativa em crianças da pré-escola. Dissertação de mestrado não publicada, Universidade do Pará, Pará.

McIlvane, W. J., \& Stoddard, T. (1981). Acquisition of matching-to-sample performances in severe retardation: learning by exclusion. Journal of Mental Deficient Research, 25(1), 33-48.

Melchiori, L. E., Souza, D. G., \& de Rose, J. C. (1992). Aprendizagem da leitura por meio de um procedimento de discriminação sem erros (exclusão): uma replicação com pré-escolares. Psicologia: Teoria e Pesquisa, 8, 101-111. 
Melchiori, L. E., Souza, D. G., \& de Rose, J. C. (2000). Reading, equivalence, and recombination of units: A replication with students with different learning histories. Journal of Applied Behavior Analysis, 33, 97-100.

Mesquita, A. A. (2007). Aprendizagem de leitura de palavras: efeito do treino de diferentes unidades textuais. Dissertação de mestrado não publicada, Universidade de Brasília, Brasília.

Müeller, M. M., Olmi, D. J., \& Saunders, K. J. (2000). Recombinative generalization of within-syllable units in prereading children. Journal of Applied Behavior Analysis, 33, 515-531.

Quinteiro, R. S. (2003). Aprendizagem de leitura receptiva e de comportamento textual: efeito do número de palavras treinadas sobre o repertório recombinativo. Dissertação de mestrado. Universidade de Brasília, Brasília

Rocha, A. M. (1996). Desenvolvimento de controle de estímulos por unidades menores que as utilizadas no treino: efeito do tipo de variação nos elementos do estímulo complexo. Dissertação de mestrado, Universidade de Brasília, Brasília.

Santos, R. M. (2009). Sobre consciência fonoarticulatória. In Lamprecht, R.R., Blanco-Dutra, A.P., Scherer, A. P. R., Barreto F.M., Brisolara, L.B., Santos, R.M., Alves, U.K. Consciência dos sons da língua: subsídios Teóricos e práticos para alfabetizadores, professores de inglês e fonoaudiólogos. Porto Alegre: Edipucrs.

Saunders, K. J. (2011). Designing instructional programming for early reading skills. In Fischer, W.W., Piazza, C. C., Roane, R.S. (Eds.). Handbook of Applied Behavior Analysis. New York, NY: The Gilford Press.

Saunders, K. J., O’Donnell, J., Vaydia, M., Williams, D.C. (2003). Recombinative generalization of within-syllables units in nonreading adults with mental retardation. Journal of Applied Behavior Analysis, 36 (1), 95-99.

Serejo, P., Hanna, E. S., de Souza, D. G., de Rose, J. C. (2007). Leitura e repertório recombinativo: efeito da quantidade de treino e da composição dos estímulos. Revista Brasileira de Análise do Comportamento, 3(2), 191-215.

Sidman, M. (1971). Reading and auditory-visual equivalences. Journal of Speech and Hearing Research, 14, pp. 5-13.

Sidman, M. (1994). Equivalence relations and behavior: A research history. Boston, MA: Authors Cooperative, Inc., Publishers

Sidman, M. \& Cresson, O. (1973) Reading and cross-modal transfer of stimulus equivalence in severe retardation. American Journal of Mental Deficiency, 77, 515-523 
Sidman, M., Cresson, O. \& Willson-Morris, M. (1974). Acquisition of matching to sample via mediated transfer. Journal of the Experimental Analysis of Behavior, 22, 261-273.

Sidman, M. \& Tailby, W. (1982). Conditional discrimination vs. matching to sample. An expansion of the testing paradigm. Journal of the Experimental Analysis of Behavior, 37, 5-22

Skinner, B. F. (1957). Verbal behavior. New York: Appleton-Century-Crofts.

Souza, A. C. (2009). Efeito do ensino de palavras monossilábicas via treino de relações condicionais arbitrárias sob o controle por unidades mínimas em leitura recombinativa. Dissertação de mestrado não publicada, Universidade de São Paulo, São Paulo.

Valente, F., Martins, M. (2004). Competências metalingüísticas e aprendizagem da leitura em duas turmas do primeiro ano de escolaridade com métodos de ensino diferentes. Análise Psicológica, 1, 193-212. 
ANEXOS 
ANEXO A - Termo de Consentimento Livre e Esclarecido UNIVERSIDADE DE SÃO PAULO

INSTITUTO DE PSICOLOGIA

\section{Departamento de Psicologia Experimental}

Av. Prof. Mello Moraes, 1721- Cidade Universitária - CEP 05508-900 - São Paulo

Tel.: (011) 3091-1928 / 3091-4358

\section{Termo de Consentimento Livre e Esclarecido}

A pesquisa a ser realizada tem como objetivo investigar o comportamento simbólico. Para tanto, serão requeridas aproximadamente 8 sessões, nas quais serão realizadas tarefas em um computador. A sessões ocorrerão de duas a três vezes por semana e terão duração de aproximadamente 30 minutos.

0 procedimento da pesquisa não investigará nenhum tipo de medida sobre inteligência, aspectos afetivos ou emocionais bem como não envolverá nenhum tipo de risco ou dano à saúde dos participantes. As sessões serão gravadas em um gravador portátil e as informações armazenadas para análise posterior.

O participante da pesquisa pode, a qualquer momento, retirar seu Consentimento Livre e Esclarecido e deixar de participar das atividades da pesquisa, sem prejuízo algum. Por se tratar de uma pesquisa, os dados e resultados de cada participante são confidenciais e sua identidade não será revelada, quando da divulgação do trabalho. Assim sendo, todo trabalho realizado torna-se informação confidencial, guardada por força do sigilo profissional e a divulgação dos resultados terão finalidade apenas acadêmica. Ao final das atividades, serão fornecidas informações detalhadas sobre a pesquisa .

Este Termo de Consentimento Livre e Esclarecido é elaborado em duas vias, sendo uma para o pesquisador e outra para o participante.

$\mathrm{Eu}$,

RG:

declaro que após convenientemente esclarecido pelo pesquisador e ter entendido o que me foi explicado, consinto em participar do Projeto de pesquisa.

\section{Participante}

Nome: Sexo:

Data de nascimento: Telefone:

Endereço:

São Paulo, _/_/___

Assinatura do participante:

Assinatura do Pesquisador:

Luana Rezende Zeolla Inhauser (luana zeolla@hotmail.com)

CEPH-IPUSP: Endereço: Av. Prof. Mello Morais, 1721 - Bl. G sala 27.

Cidade Universitária - CEP: 05508-030 - São Paulo - SP -

Telefone: 3091-4182 E-mail: ceph.ip@usp.br 
ANEXO B - Estímulos de escolha incorretos (S-) utilizados com cada estímulo de escolha correto na primeira e na segunda apresentação de cada palavra nos testes parciais de leitura recombinativa receptiva ( Testes A'C').

\begin{tabular}{|c|c|c|c|c|c|c|}
\hline \multirow{2}{*}{ Ciclos } & \multicolumn{3}{|c|}{1 Sequencia de Apresentação } & \multicolumn{3}{|c|}{2 Sequencia de Apresentação } \\
\hline & St & S- & S- & St & S- & S- \\
\hline \multirow[t]{4}{*}{1} & nibe & fibe & nobe & lofi & lobi & lofa \\
\hline & falo & balo & felo & bena & befa & beno \\
\hline & lofi & bofi & lafi & nibe & niba & nife \\
\hline & bena & bana & lena & falo & fali & fano \\
\hline \multirow[t]{4}{*}{2} & bofi & lofi & bafi & nele & nalo & nabe \\
\hline & bena & bana & befa & falo & felo & fano \\
\hline & nale & bale & nole & bofi & bofe & boni \\
\hline & falo & balo & fali & bena & leba & beno \\
\hline \multirow[t]{4}{*}{3} & leba & neba & liba & bena & bana & beno \\
\hline & falo & felo & fali & nofa & nofo & noba \\
\hline & bena & lena & befa & leba & lebe & lefa \\
\hline & nofa & bofa & nefa & falo & balo & fano \\
\hline \multirow[t]{4}{*}{4} & falo & balo & felo & lefi & lefo & lebi \\
\hline & bona & fona & bena & bena & befa & beno \\
\hline & lefi & nefi & lofi & falo & fali & fano \\
\hline & bena & bana & lena & bona & boni & bofa \\
\hline \multirow[t]{4}{*}{5} & fabe & nabe & fibe & nilo & nila & nifo \\
\hline & falo & balo & fali & bena & lena & beno \\
\hline & nilo & bilo & nalo & fabe & fabo & fane \\
\hline & bena & bana & befa & falo & felo & fano \\
\hline \multirow[t]{4}{*}{6} & febi & nebi & fobi & lano & lane & labo \\
\hline & bena & bana & beno & falo & felo & fali \\
\hline & lano & bano & leno & febi & febo & feni \\
\hline & falo & balo & fano & bena & lena & befa \\
\hline
\end{tabular}


ANEXO C - Palavras apresentadas na primeira e na segunda sequência dos testes parciais de leitura recombinativa oral (Testes C'D') em cada ciclo.

\begin{tabular}{|c|c|c|}
\hline \multirow{2}{*}{ Ciclos } & 1 Sequencia de Apresentação & 2 Sequencia de Apresentação \\
\hline & Estímulo & Estímulo \\
\hline \multirow[t]{4}{*}{1} & nibe & lofi \\
\hline & falo & bena \\
\hline & lofi & nibe \\
\hline & bena & falo \\
\hline \multirow[t]{4}{*}{2} & falo & bena \\
\hline & nale & bofi \\
\hline & bena & nale \\
\hline & bofi & falo \\
\hline \multirow[t]{4}{*}{3} & leba & nofa \\
\hline & bena & falo \\
\hline & falo & leba \\
\hline & nofa & bena \\
\hline \multirow[t]{4}{*}{4} & bona & lefi \\
\hline & falo & bena \\
\hline & lefi & falo \\
\hline & bena & bona \\
\hline \multirow[t]{4}{*}{5} & fabe & falo \\
\hline & nilo & bena \\
\hline & bena & fabe \\
\hline & falo & nilo \\
\hline \multirow[t]{4}{*}{6} & febi & lano \\
\hline & bena & falo \\
\hline & lano & febi \\
\hline & falo & bena \\
\hline
\end{tabular}

